\title{
Public Health and International Drug Policy
}

Report of the Johns Hopkins - Lancet Commission on Drug Policy and Health

Joanne Csete, Adeeba Kamarulzaman, Michel Kazatchkine, Frederick Altice, Marek Balicki, Julia Buxton, Javier Cepeda, Megan Comfort, Eric Goosby, João Goulão, Carl Hart, Richard

Horton, Thomas Kerr, Alejandro Madrazo Lajous, Stephen Lewis, Natasha Martin, Daniel Mejía, David Mathiesson, Isidore Obot, Adeolu Ogunrombi, Susan Sherman, Jack Stone, Nandini Vallath, Peter Vickerman, Tomáš Zábranský, Chris Beyrer.

University of Malaya, Kuala Lumpur, Malaysia( Prof A Kamarulzaman); UN Special Envoy, HIV in Eastern Europe and Central Asia, Geneva, Switzerland (Prof. M Kazatchkine); Columbia University, New York City, USA (J. Csete PhD, Prof. C Hart); Yale University, New Haven CT, USA (Prof. F. Altice); Warsaw, Poland (M. Balicki); Central European University, Budapest, Hungary (Prof. J. Buxton); Center for Public Health and Human Rights, Johns Hopkins Bloomberg School of Public Health, Baltimore, Maryland, USA. (J. Cepeda, PhD, Prof. S. Sherman, Prof. C. Beyrer); RTI International, Washington, DC, USA (M. Comfort PhD); University of California - San Francisco, San Francisco, California, USA (Prof. E. Goosby); Ministry of Health, Lisbon, Portugal (J. Goulão); University of British Columbia, Center of Excellence in HIV/AIDS, Vancouver, BC, Canada (Prof. T. Kerr); Centro de Investigación y Docencia Económicas (CIDE), Mexico City, Mexico (Prof. A. M. Lajous); The Lancet, London, UK (R. Horton FMedSci); AIDS-Free World, Toronto, Canada (Prof. S. Lewis); University of California - San Diego, San Diego, California USA (N. Martin, DPhil); University of the Andes, Bogotá, Colombia (Prof. D. Mejía); Human Rights Watch, Yangon, Myanmar (D. Mathiesson); University of Uyo, Uyo, Nigeria (Prof. I Obot); Youth Rise-Nigeria, Lagos, Nigeria (A. Ogunrombi); Trivandrum Institute of Palliative Sciences, Trivandrum, India (N. Vallath, MBBS); University of Bristol, UK (P. Vickerman, PhD, J. Stone, MMathStat); Charles University, Prague, Czech Republic (Prof. T. Zábranský).

30,318 words, 3 tables, 27 figures, 5 text boxes, 441 References

Key Words: drug policy, prohibition, harm reduction, violence, crop eradication, HIV, viral hepatitis, mass incarceration, decriminalization, reform, public health 


\section{Executive summary}

In September 2015, the member states of the United Nations endorsed sustainable development goals (SDG) for 2030 that aspire to human rights-centered approaches to ensuring the health and well-being of all people. The SDGs embody both the UN Charter values of rights and justice for all and the responsibility of states to rely on the best scientific evidence as they seek to better humankind. In April 2016, these same states will consider control of illicit drugs, an area of social policy that has been fraught with controversy, seen as inconsistent with human rights norms, and for which scientific evidence and public health approaches have arguably played too limited a role.

The previous UN General Assembly Special Session (UNGASS) on drugs in 1998 - convened under the theme "a drug-free world, we can do it!" - endorsed drug control policies based on the goal of prohibiting all use, possession, production, and trafficking of illicit drugs. This goal is enshrined in national law in many countries. In pronouncing drugs a "grave threat to the health and well-being of all mankind," the 1998 UNGASS echoed the foundational 1961 convention of the international drug control regime, which justified eliminating the "evil" of drugs in the name of "the health and welfare of mankind." But neither of these international agreements refers to the ways in which pursuing drug prohibition itself might affect public health. The "war on drugs" and "zero-tolerance" policies that grew out of the prohibitionist consensus are now being challenged on multiple fronts, including their health, human rights, and development impact.

The Johns Hopkins - Lancet Commission on Drug Policy and Health has sought to examine the emerging scientific evidence on public health issues arising from drug control policy and to inform and encourage a central focus on public health evidence and outcomes in drug policy debates, such as the important deliberations of the 2016 UNGASS on drugs.

The Johns Hopkins-Lancet Commission is concerned that drug policies are often colored by ideas about drug use and drug dependence that are not scientifically grounded. The 1998 UNGASS declaration, for example, like the UN drug conventions and many national drug laws, does not distinguish between drug use and drug abuse. A 2015 report by the UN High 
Commissioner for Human Rights, by contrast, found it important to emphasize that "[d]rug use is neither a medical condition nor does it necessarily lead to drug dependence." The idea that all drug use is dangerous and evil has led to enforcement-heavy policies and has made it difficult to see potentially dangerous drugs in the same light as potentially dangerous foods, tobacco, alcohol for which the goal of social policy is to reduce potential harms.

\section{Health impact of drug policy based on enforcement of prohibition}

The pursuit of drug prohibition has generated a parallel economy run by criminal networks. Both these networks, which resort to violence to protect their markets, and the police and sometimes military or paramilitary forces that pursue them contribute to violence and insecurity in communities affected by drug transit and sales. In Mexico, the dramatic increase in homicides since the government decided to use military forces against drug traffickers in 2006 has been so great that it reduced life expectancy in the country.

Injection of drugs with contaminated equipment is a well-known route of HIV exposure and viral hepatitis transmission. People who inject drugs (PWID) are also at high risk of tuberculosis. The continued spread of unsafe injection-linked HIV contrasts the progress that has been seen in reducing sexual and vertical transmission of HIV in the last three decades. The Commission found that that repressive drug policing greatly contributes to the risk of HIV linked to injection. Policing may be a direct barrier to services such as needle and syringe programmes (NSP) and use of non-injected opioids to treat dependence among those who inject opioids, known as opioid substitution therapy (OST). Police seeking to boost arrest totals have been found to target facilities that provide these services to find, harass, and detain large numbers of people who use drugs. Drug paraphernalia laws that prohibit possession of injecting equipment lead PWID to fear carrying syringes and force them to share equipment or dispose of it unsafely. Policing practices undertaken in the name of the public good have demonstrably worsened public health outcomes.

Amongst the most significant impacts of pursuit of drug prohibition identified by the Commission with respect to infectious disease is the excessive use of incarceration as a drugcontrol measure. Many national laws impose lengthy custodial sentences for minor, non-violent 
drug offenses; people who use drugs (PWUD) are over-represented in prison and pretrial detention. Drug use and drug injection occur in prisons, though their occurrence is often denied by officials. HIV and hepatitis $\mathrm{C}$ virus (HCV) transmission occurs among prisoners and detainees, often complicated by co-infection with TB and in many places multidrug-resistant TB, and too few states offer prevention or treatment services in spite of international guidelines that urge comprehensive measures, including provision of injection equipment, for people in state custody.

Mathematical modelling undertaken by the Commission illustrates that incarceration and high $\mathrm{HCV}$ risk in the post-incarceration period can contribute importantly to national $\mathrm{HCV}$ incidence amongst PWID in a range of countries with varying levels of incarceration, different average prison sentences, durations of injection, and OST coverage levels in prison and following release. For example, in Thailand where PWID may spend nearly half their injection careers in prison, an estimated $63 \%$ of incident HCV infection could occur in prison. In Scotland, where prison sentences are shorter for PWUD and OST coverage is relatively high in prison, an estimated $54 \%$ of incident $\mathrm{HCV}$ infection occurs in prison, but as much as $21 \%$ may occur in the high-risk post-release period. These results underscore the importance of alternatives to prison for minor drug offences, ensuring access to OST in prison, and a seamless link from prison services to OST in the community.

The evidence also clearly demonstrates that drug law enforcement has been applied in a discriminatory way against racial and ethnic minorities in a number of countries. The US is perhaps the best documented but not the only case of racial biases in policing, arrest, and sentencing. In 2014, African American men were more than five times more likely than whites to be incarcerated in their lifetime, though there is no significant difference in rates of drug use among these populations. The impact of this bias on communities of people of color is intergenerational and socially and economically devastating.

The Commission also found significant gender biases in current drug policies. Of women in prison and pretrial detention around the world, a higher percentage are detained because of drug infractions than is the case for men. Women involved in drug markets are often on the bottom 
rungs - as couriers or drivers - and may not have information about major traffickers to trade as leverage with prosecutors. Gender and racial biases have marked overlap, making this an intersectional threat to women of color, their children, families, and communities.

In both prison and the community, HIV, HCV and TB programmes for PWUD - including testing, prevention and treatment - are gravely underfunded at the cost of preventable death and disease. In a number of middle-income countries where large numbers of PWUD live, HIV and TB programmes for PWUD that were expanded with support from the Global Fund to Fight AIDS, TB and Malaria have lost funding due to changes in the Fund's eligibility criteria. There is an unfortunate failure to emulate the example of Western European countries that have eliminated unsafe injection-linked HIV as a public health problem by sustainably scaling up prevention and care and enabling minor offenders to avert prison. Political resistance to harm reduction measures dismisses strong evidence of their effectiveness and cost-effectiveness. Mathematical modeling shows that if OST, NSP and antiretroviral therapy for HIV are all available, even if the coverage of each of them is not over $50 \%$, their synergy can lead to effective prevention in a foreseeable future. PWUD are often not seen to be worthy of costly treatments, or they are thought not to be able to adhere to treatment regimens in spite of evidence to the contrary.

Lethal drug overdose is an important public health problem, particularly in light of rising consumption of heroin and prescription opioids in some parts of the world. Yet the Commission found that the pursuit of drug prohibition can contribute to overdose risks in numerous ways. It creates unregulated illegal markets in which it is impossible to control adulterants of street drugs that add to overdose risk. Several studies also link aggressive policing to rushed injection and overdose risk. People with a history of drug use, over-represented in prison because of prohibitionist policies, are at extremely high risk of overdose when released from state custody. Lack of ready access to OST also contributes to injection of opioids, and bans on supervised injection sites cut off an intervention that has proven very effective in reducing overdose deaths. Restrictive drug policies also contribute to unnecessary controls on naloxone, a medicine that can reverse overdose very effectively. 
Though a small percentage of PWUD will ever need treatment for drug dependence, that minority faces enormous barriers to humane and affordable treatment in many countries. There are often no national standards for quality of drug dependence treatment and no regular monitoring of practices. In too many countries, beatings, forced labor, and denial of health care and adequate sanitation are offered in the name of treatment, including in compulsory detention centres that are more like prisons than treatment facilities. Where there are humane treatment options, it is often the case that those most in need of it cannot afford it. In many countries, there is no treatment designed particularly for women, though it is known that women's motivations for and physiological reactions to drug use differ from those of men.

The pursuit of the elimination of drugs has led to aggressive and harmful practices targeting people who grow crops used in the manufacture of drugs, especially coca leaf, opium poppy, and cannabis. Aerial spraying of coca fields in the Andes with the defoliant glyphosate (N(phosphonomethyl glycine) has been associated with respiratory and dermatological disorders and with miscarriages. Forced displacement of poor rural families who have no secure land tenure exacerbates their poverty and food insecurity and in some cases forces them to move their cultivation to more marginal land. Geographic isolation makes it difficult for state authorities to reach drug crop cultivators in public health and education campaigns and it cuts cultivators off from basic health services. Alternative development programmes meant to offer other livelihood opportunities have poor records and have rarely been conceived, implemented, or evaluated with respect to their impact on people's health.

Research on drugs and drug policy has suffered from the lack of a diversified funding base and assumptions about drug use and drug pathologies on the part of the dominant funder, the US government. At a time when drug policy discussions are opening up around the world, there is an urgent to bring the best of non-ideologically-driven health science, social science and policy analysis to the study of drugs and the potential for policy reform.

\section{Policy alternatives in real life}

Concrete experiences from many countries that have modified or rejected prohibitionist approaches in their response to drugs can inform discussions of drug policy reform. A number of 
countries, such as Portugal and the Czech Republic, decriminalised minor drug offenses years ago, with significant savings of money, less incarceration, significant public health benefits, and no significant increase in drug use. Decriminalisation of minor offenses along with scaling up low-threshold HIV prevention services enabled Portugal to control an explosive unsafe injectionlinked HIV epidemic and likely enabled the Czech Republic to prevent one from happening.

Where formal decriminalisation may not be an immediate possibility, scaling up health services for PWUD can demonstrate the value to society of responding with support rather than punishment to people who commit minor drug infractions. A pioneering OST program in Tanzania is encouraging communities and officials to consider non-criminal responses to heroin injection. In Switzerland and the city of Vancouver, Canada, dramatic improvements in access to comprehensive harm reduction services, including supervised injection sites and heroin-assisted treatment, transformed the health picture for PWUD. Vancouver's experience also illustrates the importance of meaningful participation of PWUD in decision-making on policies and programmes affecting their communities.

\section{Conclusions and recommendations}

Policies meant to prohibit or greatly suppress drugs present a paradox. They are portrayed and defended vigorously by many policy-makers as necessary to preserve public health and safety, and yet the evidence suggests they have contributed directly and indirectly to lethal violence, communicable disease transmission, discrimination, forced displacement, unnecessary physical pain, and the undermining of people's right to health.

Some would argue that the threat of drugs to society may justify some level of abrogation of human rights for protection of collective security, as is also foreseen by human rights law in case of emergencies. International human rights standards dictate that in such cases, societies still must choose the least harmful way to address the emergency and that emergency measures must be proportionate and designed specifically to meet transparently defined and realistic goals. The pursuit of drug prohibition meets none of these criteria. 
Standard public health and scientific approaches that should be part of policy-making on drugs have been rejected in the pursuit of prohibition. The idea of reducing the harm of many kinds of human behavior is central to public policy in the areas of traffic safety, tobacco and alcohol regulation, food safety, safety in sports and recreation, and many other areas of human life where the behavior in question is not prohibited. But explicitly seeking to reduce drug-related harms through policy and programmes and to balance prohibition with harm reduction is regularly resisted in drug control. The persistence of unsafe injection-linked HIV and HCV transmission that could be stopped with proven, cost-effective measures remains one of the great failures of the global responses to these diseases.

Drug policy that is dismissive of extensive evidence of its own negative impact and of approaches that could improve health outcomes is bad for all concerned. Countries have failed to recognise and correct the health and human rights harms that pursuit of prohibition and drug suppression have caused and in so doing neglect their legal responsibilities. They readily incarcerate people for minor offenses but then neglect their duty to provide health services in custodial settings. They recognize uncontrolled illegal markets as the consequence of their policies, but they do little to protect people from toxic, adulterated drugs that are inevitable in illegal markets or the violence of organized criminals, often made worse by policing. They waste public resources on policies that do not demonstrably impede the functioning of drug markets, and they miss opportunities to invest public resources wisely in proven health services for people often too frightened to seek services.

To move toward the balanced policy that $\mathrm{UN}$ member states have called for, we offer the following recommendations:

- Decriminalisation: Decriminalise minor, non-violent drug offenses - use, possession, and petty sale - and strengthen health and social-sector alternatives to criminal sanctions.

- Reducing violence and discrimination in policing: Reduce the violence and other harms of drug policing, including phasing out the use of military forces in drug policing, better targeting of policing on the most violent armed criminals, allowing possession of syringes, not targeting harm reduction services to boost arrest totals, and eliminating racial and ethnic discrimination in policing. 
- Reducing harms: Ensure easy access for all who need them to harm reduction services as a part of responding to drugs, recognizing the effectiveness and cost-effectiveness of scaling up and sustaining these services. OST, NSP, supervised injection sites, and access to naloxone brought to a scale adequate to meet demand - should all figure in health services and should include meaningful participation of PWUD in planning and implementation. Harm reduction services are crucial in prison and pretrial detention and should be scaled up in these settings. The 2016 UNGASS should do better than the UN Commission on Narcotic Drugs (CND) in naming harm reduction explicitly and endorsing its centrality to drug policy.

- Treatment and care for PWUD: Prioritize PWUD in treatment for HIV, HCV, TB, and ensure that services are adequate to ensure access for all who need care. Ensure availability of humane and scientifically sound treatment for drug dependence, including scaled-up OST in the community as well as in prisons, rejecting compulsory detention and abuse in the name of treatment.

- Access to controlled medicines: Ensure access to controlled medicines, establishing intersectoral national authorities to determine levels of need and giving the World Health Organization (WHO) the resources to assist the International Narcotics Control Board (INCB) in using the best science to determine the level of need for controlled medicines in all countries.

- Gender-responsive policies: Reduce the negative impact of drug policy and law on women and their families, especially minimizing custodial sentences for women who commit nonviolent offenses and developing appropriate health and social support, including genderappropriate treatment of drug dependence, for those who need it.

- Crop production: Efforts to address drug crop production must take health into account. Aerial spraying of toxic herbicides should be stopped, and alternative development programmes should be part of integrated development strategies, developed and implemented in meaningful consultation with the people affected.

- Improve research: There is a need for a more diverse donor base to fund the best new science on drug policy experiences in a non-ideological way that, among other things, interrogates and moves beyond the excessive pathologising of drug use.

- UN governance of drug control: UN governance of drug policy must be improved, including by respecting WHO's authority to determine the dangerousness of drugs. Countries 
should be urged to include high-level health officials in their delegations to CND. Improved representation of health officials in national delegations to CND would, in turn, be a likely result of giving health authorities an important day-to-day role in multi-sectoral national drug policy-making bodies.

- Better metrics: Health, development, and human rights indicators should be included in metrics to judge success of drug policy; WHO and UNDP should help formulate them. UNDP has already suggested that indicators such as access to treatment, rate of overdose deaths, and access to social welfare programmes for people who use drugs would be useful indicators. All drug policies should also be monitored and evaluated as to their impact on racial and ethnic minorities, women, children and young people, and people living in poverty.

- Scientific approach to regulated markets: Move gradually toward regulated drug markets and apply the scientific method to their evaluation. While regulated legal drug markets are not politically possible in the short term in some places, the harms of criminal markets and other consequences of prohibition catalogued in this report are likely to lead more countries (and more US states) to move gradually in that direction, a direction we endorse. As those decisions are taken, we urge governments and researchers to apply the scientific method and ensure independent, multidisciplinary and rigorous evaluation of regulated markets to draw lessons and inform improvements in regulatory practices, and to continue evaluating and improving.

We urge health professionals in all countries to inform themselves and join debates on drug policy at all levels. True to the stated goals of the international drug control regime, it is possible to have drug policy that contributes to the health and well-being of humankind, but not without bringing to bear the evidence of the health sciences and the voices of health professionals. 
"We must consider alternatives to criminalization and incarceration of people who use drugs and focus criminal justice efforts on those involved in supply. We should increase the focus on public health, prevention, treatment and care, as well as on economic, social and cultural strategies." $2015^{1}$

--Ban Ki-moon, UN Secretary-General, on World Day Against Drugs, June 26,

\section{Introduction}

In 2015, member states of the United Nations in the presence of more than 150 heads of state endorsed a set of Sustainable Development Goals (SDGs) that were formulated to embody founding principles of the $\mathrm{UN}$, including universal human rights and justice for all. ${ }^{2}$ The SDG resolution commits member states to addressing climate change and other large issues in ways that are informed by the best scientific research. The SDGs are also based on a notion of human security that is not confined to traditional public order authorities but in which health and social sectors play an important part. ${ }^{2}$

In April 2016, the same UN member states in a General Assembly Special Session (UNGASS) will take on a social policy challenge that affects millions of lives - what the UN has called the "world drug problem". As with the SDGs, addressing the use, production, and trafficking of drugs will challenge the UN to base its policies on the human rights norms that are the bedrock of the UN Charter as well as the best scientific evidence at hand. This challenge is significant because it is not only the "world drug problem" but also policy responses to drugs that can negatively affect human lives and human rights and contradict evidence-based public health approaches. As noted by former UN Secretary-General Kofi Annan, “...Drugs have destroyed many people, but wrong policies have destroyed many more." ${ }^{3}$

A 2015 report of the UN High Commissioner for Human Rights highlights some of the main ways in which drug control policies have been responsible for violations of human rights. ${ }^{4}$ The High Commissioner concluded that drug policies, law, and law enforcement have resulted in arbitrary arrest, detention and ill treatment of people who use drugs; unjust use of the death penalty for drug offenses; cruel and inhuman treatment of PWUD in the guise of "treatment"; 
racial and ethnic discrimination in drug law enforcement; denial of life-saving care and prevention interventions to people who use drugs; excessive use of incarceration as a response to minor drug infractions; denial of the cultural rights of indigenous peoples; and poor access to opioids and other controlled medicines for pain management and other clinical uses, among other human rights violations.

The last General Assembly Special Session on drugs in 1998, under the theme "a drug-free world - we can do it!", endorsed drug control policies based on the idea of elimination or prohibition of all use, possession, production, and trafficking of illicit drugs. ${ }^{5}$ This idea is embodied in national law in many countries. The 1998 UNGASS declaration pronounced drugs a "grave threat to the health and well-being of all mankind." In this pronouncement it echoed the bedrock treaty of the global drug control regime, the widely ratified 1961 Single Convention on Narcotic Drugs, which states in its preamble that drug control is motivated principally by concern for "the health and welfare of mankind. ${ }^{\prime 6}$ Neither of these international agreements, however, refers to the negative health consequences of pursuing drug prohibition. The time is long overdue for a review of the health impacts of these drug policies. The disconnect between drug control policy and health outcomes is no longer tenable or credible.

The Johns Hopkins - Lancet Commission on Drug Policy and Health has sought to examine the scientific evidence on a broad range of public health issues arising from drug control policy to inform a focus on public health as a central consideration in drug policy discussions such as the important deliberations of the 2016 UNGASS.

The JHU-Lancet Commission is motivated partly by a concern that drug policies are often founded on ideas about drug use and drug dependence that are not scientifically grounded. Like the Single Convention, the declaration from the 1998 UNGASS on drugs, for example, does not distinguish between drug use and drug abuse; all use is referred to as abuse. ${ }^{5}$ Indicating some evolution of thinking in the UN if not amongst member states, the UN High Commissioner for Human Rights in his 2015 report, by contrast, found it important to emphasize that "[d]rug use is neither a medical condition nor does it necessarily lead to drug dependence" or loss of dignity. ${ }^{4}$ The UNODC 2015 annual report concluded that of an estimated 246 million people who used an 
illicit drug in the past year, some 27 million, or $11 \%$ experienced problem drug use, defined as drug dependence or drug use disorders. ${ }^{7}$ The idea that all drug use is dangerous and evil has made it difficult to see potentially dangerous drugs in the same light as potentially dangerous foods, tobacco, alcohol, and other substances for which the goal of social policy is to reduce harms. Harm reduction, an essential element of public health policy, has too often been lost in drug policy-making amidst a dominant discourse on the overwhelming evil of drugs.

We hope that this review and analysis of evidence on the health consequences of pursuing prohibition of drugs and drug use can inform rights-based policy change. Because language is important to drug policy discussions, we include as an annex to this report a glossary of some policy-relevant terms.

\section{[open box]}

\section{Box 1: Introducing the Johns Hopkins - Lancet Commission on Drug Policy and Health}

The JHU-Lancet Commission, co-chaired by Professor Adeeba Kamarulzaman of the University of Malaya and Professor Michel Kazatchkine, the UN Special Envoy for HIV/AIDS in Eastern Europe and Central Asia, is composed of 22 experts from a wide range of disciplines and professions, and from low-, middle-, and high-income countries. We have reviewed the global evidence base on the impacts of drug policy on health outcomes and conducted novel analysis, including with mathematical modeling, to further enhance understanding of the complex and manifold interactions of dug policy with health, human rights, and wellbeing. The Centre for Public Health and Human Rights at the Johns Hopkins Bloomberg School of Public Health served as the secretariat for the Commission, and scholars and fellows from the Centre also served as commissioners and/or analysts. The Commission produced this report with the hope that it would enrich discussions at the time of the UN General Assembly Special Session on the world drug problem. We intend to continue our work after the UNGASS, especially to continue to advocate for evidence-based and health-focused drug policy reform.

\section{[close box]}

\section{Setting the scene: an evolving international debate}


The international drug control system itself has its origins in decades-old legal instruments framed by politics more than science. From the time of the 1912 Hague Opium Convention, minimizing the supply of some psychoactive drugs through policing has been the dominant strain in international drug law. ${ }^{8}$ In the decades leading up to the 1961 Single Convention, international drug control agreements largely sidestepped issues of demand and consumption. ${ }^{9}$ The eventual solution in the 1961 Single Convention to reserve some quantity of psychoactive substances for medical and scientific use did not resolve the issue of social, cultural, and recreational use that was not obviously harmful but was not "medical or scientific."9

In 1998 when the UN members states declared their commitment to a drug-free world, the UN estimated that there were an estimated 8 million people in the world who used heroin in the previous year, about 13 million who used cocaine, about 30 million who used amphetamine-type substances (ATS), and over 135 million "abusers" - that is, users - of cannabis. ${ }^{10}$ When the countries came together after 10 years to review progress toward a "drug-free world" in 2008, the UN estimated that 12 million people used heroin, 16 million used cocaine, almost 34 million used ATS, and over 165 million used cannabis in the previous year. ${ }^{11}$ The worldwide area under opium poppy cultivation was estimated at about 238,000 ha in 1998, and in 2008 was 235,700 ha, a small decline. ${ }^{11}$ Prohibition as a policy had clearly failed.

In the 2014 statement from the high-level segment of the UN Commission on Narcotic Drugs (CND, the UN's drug policy body), an important background document for the 2016 UNGASS, UN member states stressed the importance of drug policy that is consistent with human rights and acknowledged that "law enforcement measures alone" cannot achieve drug control. ${ }^{12}$

In the lead-up to the 2016 UNGASS, UN agencies were asked to make statements about how drug-control policy intersects with their mandates and affects their work. These statements signal that high-level thinking in a number of UN agencies reflects some impatience with the pursuit of prohibition. The long list of human rights violations associated with drug-control measures led the High Commissioner for Human Rights to call for member states to consider "removing obstacles to the right to health, including by decriminalizing the personal use and possession of drugs." The UN Development Programme welcomed a change away from the 
dominant "prohibitionist, law enforcement-led and abstinence-based approach." ${ }^{\text {"13 }}$ The WHO executive board called for a stronger focus on prevention of drug use and treatment and care of PWUD in drug policy as well as on reducing the harms of drugs and drug use. ${ }^{14}$

Outside the UN, debates have also evolved, including in regional bodies such as the Organization of American States (OAU) and the European Union. A 2013 OAU report raised the idea that dramatic departures from prohibition-based drug control might be the only way to reduce drugrelated violence and criminality in the Americas. ${ }^{15}$ The Global Commission on Drug Policy (GCDP) including a number of former heads of state and other prominent figures; the Latin American Commission on Drugs and Democracy, headed by former Brazilian president Ferdinand Cardoso; and the West Africa Commission on Drugs, convened by former UN Secretary-General Kofi Annan, all called for an end to strict prohibition-oriented policies and for decriminalisation of minor drug infractions, among other recommendations. ${ }^{3,16,17}$ The Global Commission on HIV and the Law, convened by UNDP, also included former heads of state and other high-level officials, called on national authorities to "decriminalise the possession of drugs for personal use, in recognition that the net impact of such sanctions is often harmful to society" and to give priority to public health considerations in drug policy. ${ }^{18} \mathrm{By}$ contrast, the Association of Southeast Asian Nations (ASEAN) agreed on an objective of a "drug-free ASEAN" by 2015, ${ }^{19}$ in spite of widespread criticism of the unrealistic nature of the goal. ${ }^{20}$

North America continues to have by far the highest rates of drug consumption and drug-related death and morbidity of any region in the world, ${ }^{7}$ and drug policy in this region tend to influence global debates heavily. Between 2002 and 2013, heroin-related overdose deaths quadrupled in the US, ${ }^{21}$ and deaths associated with prescription opioid overdose quadrupled from 1999 to $2010 .{ }^{22}$ Reactions to these trends have included calls for greater availability of naloxone, an opioid overdose antidote, for increased access to treatment for opioid dependence, ${ }^{23}$ for greater restriction on prescription of opioids. ${ }^{24}$ Opioid overdose has been found to be a major contributor to an almost unprecedented increase in mortality of middle-aged white, non-Hispanic persons in the US at a time when mortality in middle age has continued to decline in other populations. ${ }^{25}$ Many observers have commented that opioid dependence is attracting policy attention in the US for the very reason that it is affecting whites in suburban and rural environments rather than only 
inner-city African Americans. ${ }^{26}$ The policy challenge is to balance meeting the need to relieve pain and suffering with reasonable restrictions on controlled medicines, and without creating disparities - racial, economic, or otherwise - in care.

The world has also taken sharp notice of the cannabis legalisation experiences of the US states of Washington, Colorado, Oregon, Alaska and the District of Columbia in a country where opposition to drug legalisation has been deep, and of the nationwide cannabis legalisation experiment in Uruguay. ${ }^{27}$ The fiscal imperative of reducing incarceration as well as the fear of adulterants in cannabis obtained illegally have been part of the debates in the US policy changes. ${ }^{28}$ Though changes in the legal status of cannabis do not signal changes in prohibitionoriented policies with respect to other drugs in the US, concrete experiences with regulated cannabis markets at an important scale provide an opportunity for rigourous evaluations that will inform larger drug policy debates.

\section{Violence and enforcement of drug prohibition}

Since it published its first report on violence and health in $2002,{ }^{29} \mathrm{WHO}$ has highlighted numerous forms of violence as health issues. ${ }^{30}$ The Global Burden of Disease Study of 2013 found that interpersonal violence, including all types of violent assault, rose about 18.4 percent as a cause of mortality globally from 1990 to $2013 .{ }^{31}$ The region most affected was Latin America where interpersonal violence was among the top five causes of death in 15 countries. ${ }^{31}$ The 2014 WHO report on preventing violence discusses violence that is committed as a result of drug and alcohol use, but few investigators, including those at WHO, have investigated the violence resulting from drug policies. ${ }^{30}$

A great deal of drug-related violence is associated with the effort by armed criminal groups to protect their illicit markets, often against armed police or military or paramilitary forces. Some experts have suggested that heavier crackdowns by drug police can lead to major increases in violence when disruption of a given criminal network leads rival groups to intensify their efforts to capture the territory of the weakened group..$^{32}$ Mexico and Central and South America have borne an enormous burden of drug-related violence. In 2013, the OAS asserted that the transit of 
illegal drugs through the Americas leaves persistent violence in its wake - "massacres, attacks by hired assassins, and cases of people being tortured to death". ${ }^{15}$ As the OAS noted, drug trafficking is so entwined with other criminal activity that it is not always possible to say that a given episode of extra-judicial killing is purely drug-related, but criminal networks dealing in drugs are plainly behind much of this carnage. ${ }^{15}$ In its 2014 global analysis of homicides, UNODC noted that the $30 \%$ of homicides accounted for by "organized criminal groups and gangs" in the Americas, especially Central and South America, dwarf the corresponding percentages in other regions (Figure 1). ${ }^{33}$

\section{[INSERT FIGURE 1 HERE]}

From UNODC World crime trends, 2014. ${ }^{33}$

In conventional wars, sexual violence is both a consequence of war and a weapon used to terrorise the enemy, and the war on drugs is no exception. UNODC asserts that organised criminal networks dominating drug trafficking in Central America regularly use rape with impunity as they defend their territories and routes. ${ }^{34}$ Women and girls who may be hired as lowlevel couriers or smugglers experience sexual assault with no recourse. ${ }^{34}$ There are numerous well documented accounts of rape of girls and young women fleeing gang violence in Central America and the severe injuries and post-traumatic stress suffered. ${ }^{35}$ Some observers credit drugrelated violence with increases in femicide in Mexico and Central America as brutal rape and killing of women are used to terrorise communities and rival gangs. ${ }^{36,37}$

Intolerable levels of violence, insecurity, and corruption have led to mass displacement in Mexico and Central America, with displacement levels similar to those documented in war zones. ${ }^{38}$ Displaced individuals, including children, are characterised by uncertain legal status and a dearth of services. By one estimate, about $2 \%$ of the population of Mexico, some 1.65 million people, were displaced because of violence or the risk of violence between 2006 and $2011 .^{38}$ In a publication of the London School of Economics endorsed by five Nobel Prize-winning economists and other experts, Atuesta refutes the idea that this migration is largely economic and not drug-related, showing that a majority of those leaving violence-ravaged communities in Mexico generally move to lower salaries and sometimes no employment opportunities at all. ${ }^{39}$ 


\section{The case of homicide in Mexico}

The fateful decision of the Calderón government in Mexico in 2006 to use its military in civilian areas to fight drug traffickers ushered in an epidemic of violence in many parts of the country that also spilled over into Central America. ${ }^{15}$ The increase in homicides in Mexico since 2006 is virtually unprecedented in a country not formally at war. The increases in homicides in some parts of the country were so dramatic as to contribute to a reduction in the country's projected life expectancy. ${ }^{42}$ Another analysis concluded that in the period 2008-2010 in the state of Chihuahua, one of the states most heavily affected by drug violence, about 5 years of life expectancy was lost for men. ${ }^{43}$

In July 2015, the Mexican government reported that from 2007 to 2014, there were 164345 homicides in the country, with a dramatic increase after 2006. Figure 2 shows a 'join point' analysis ${ }^{44}$ conducted for this report using government data. ${ }^{45}$ The increase in homicides after 2006 is highly significant statistically and notable, especially after a long downward trend in homicides. No other country in Latin America - and few elsewhere in the world - have seen such as rapid increase in mortality in so short a time. ${ }^{46}$

\section{[FIGURE 2 HERE]}

Data from Mexican National Institute of Statistics and Geography (INEGI), 2014. ${ }^{45}$

Not all of this increase in homicides can be attributed to drug-related violence, but much of it can be. One estimate suggested that the drug war-related deaths pushed the national homicide rate up by 11 per 100000 , resulting in an overall rate over 80 per 100000 in heavily affected locations. ${ }^{47}$ Eleven per 100000 is 2.5 times the total homicide rate in the US in $2014 .{ }^{47}$ Other observers suggest that the contribution of the drug war to overall mortality is readily quantifiable because drug-gang homicides bear tangible signatures, such as the use of identifiable weapons as well as torture, beheading and other dismemberment, group executions, and mass graves. ${ }^{46}$ Though homicides have declined somewhat since 2012, by some estimates homicides perpetuated by organised crime continued to increase through $2014 .^{46}$ 
Drug-related violence in Mexico is not limited to killings and other armed incidents on the street. The Commission found that violence by state actors was also seen in the treatment of people in Mexico incarcerated for drug-related crimes. Analysis supervised by Commissioner Alejandro Madrazo used a probability sample of persons who were in prison for drug crimes $(n=479)$ in Mexico during 2002-2012 - thus before and after the military campaign against drugs - from eight federal prisons. ${ }^{48}$ About half of the detainees $(n=241)$ reported having been beaten or tortured at some time in their imprisonment. Among these 241, having experienced an act of torture or abuse was 1.31 times more likely after the 'war on drugs' than before $(\mathrm{p}<0.01)$. As shown in Figure 3, being interrogated by the military in prison was also more likely for people serving drug sentences after the military involvement $(\mathrm{p}<0.0001)$. Interrogation by the military, in turn, was significantly associated with reports of having been tortured or abused. In multivariate analysis controlling for sex, number of times interrogated, and geographical location, people who were detained after 2006 were 3.63 times more likely to have been interrogated by the military while detained $(\mathrm{p}<0.0001)$. As Madrazo has noted, a deleterious outcome of the Mexican drug war is the government's acquisition of special security powers that undermine fundamental principles of the country's constitution and human rights responsibilities. ${ }^{49}$

\section{[FIGURE 3 HERE]}

The costs, including health costs, of violence on citizens is vast and profound. Execution-style killings are clearly meant to terrorise the population. Living in fear of extreme violence is disruptive to the normal functioning of health and social services, education, and civic participation. The penetration of all aspects of society by drug trafficking organizations in Mexico, Colombia, and a number of Central American countries can corrupt everything from elections and local services to sports teams and other recreation. ${ }^{50}$

Cannabis has been estimated to account for about US \$2 billion per year of the revenue of Mexican drug cartels, almost as much as the estimated US $\$ 2.4$ billion from cocaine.$^{51}$ It is not possible to know how the legalisation of cannabis in the US, if it were to spread beyond a few states, would affect drug trafficking in Mexico and Central America. Some observers think that 
even the modest legalisation enacted so far has cut into Mexican cartels' trade and perhaps limited their capacity to disrupt security. ${ }^{52}$

Mexico is far from alone in registering high rates of homicide linked to enforcement of drug prohibition. Colombia's case is distinct from Mexico's in that anti-drug efforts were superimposed on a lethal internal war, but homicides spiked when counter-narcotics activities were most intense. ${ }^{50}$ Mejía and Restrepo estimate that about $25 \%$ of the current homicide rate in Colombia is explained by the thriving cocaine markets and the war on drugs in the country. In other words, absent the large increase in the size of cocaine markets, Colombia would have had a homicide rate in 2008 of about 27 per 100000 population instead of the observed $37 . .^{53}$

\section{[Figure 4 HERE]}

From Mejía and Restrepo, 2014. ${ }^{50}$

Mejía and Restrepo characterize these profound problems of homicide and other violence, corruption, and forced displacement as a package 'outsourced' from the major drug-consuming countries, mainly the US, to producer and transit countries. ${ }^{50}$ That is, in return for a certain amount of foreign assistance for counter-narcotics activities, the US in particular keeps the worst of the heavy burden of violence, insecurity and displacement outside its borders. (See Box 2.) But, as these authors note, this exported pillar of the drug war is beginning to be questioned in earnest by some governments in Latin America, as demonstrated by statements criticizing the status quo in drug policy by the then presidents of Mexico, Colombia, and Guatemala in the UN General Assembly in 2012 which moved the 2016 UNGASS from 2019. ${ }^{54}$

\section{[open box]}

\section{Box 2: Exporting drug-related violence: A thought experiment}

By Daniel Mejía and Pascual Restrepo ${ }^{50}$

To illustrate the exportation of violence in the current situation in Mexico and Central America, consider the following scenario: suppose that cocaine consumption in the US disappears and is displaced to Canada, but cocaine continues to pass through the US. Because of its international 
treaty obligations, the US is obliged to do everything in its power to keep cocaine from passing through its borders to Canadian cities. Canada shares some of the cost of this effort, but the result of fighting the cocaine cartels is that the homicide rate in Seattle spikes from its current level of about 5 homicides per 100,000 population to over 100 to keep cocaine from reaching Vancouver. Similar violence seizes other border cities, and a massive wave of internal displacement in the northern US challenges social services and stability of governance. Even if the Canadian government shared the costs to the tune of billions of dollars per year, how long would such a situation be tolerated?

[Close box]

\section{Drug policy and infectious diseases}

\section{HIV, HCV, harm reduction and drug policy: neglect of proven solutions}

At a time when gains in reduction of sexual transmission of HIV are evident worldwide, HIV transmission linked to injection of drugs with unsterile equipment continues to drive HIV incidence in many regions, including Eastern Europe and Central Asia (EECA) and much of Asia, in spite of the availability of proven interventions to stop it. ${ }^{55,56}$ The prevalence of HIV among PWID is many times higher than in the general population in many countries (Figure 5). ${ }^{57}$ Outside sub-Saharan Africa an estimated 30\% of HIV transmission is linked to unsafe injection. ${ }^{57}$ Drug injection is a more important determinant of HIV transmission in EECA than in any other region. ${ }^{58}$ While HIV incidence declined by 35\% globally from 2000 to 2014, new infections increased by $30 \%$ in that period in EECA, where unsafe drug injection accounts for over $65 \%$ of cumulated cases. ${ }^{58}$

\section{FIGURE 5 HERE}

From UNAIDS, Gap report, 2014. ${ }^{57}$

WHO estimates that about two thirds of PWID in the world are living with hepatitis $\mathrm{C}$ virus (HCV) infection, a much higher percentage than the estimated 13\% living with HIV. ${ }^{59}$ WHO notes that EECA, sub-Saharan Africa and East Asia are particularly affected ${ }^{59}$ though data are not regularly kept in some countries. In high-income and upper-middle-income countries 
generally a high percentage of new HCV infections are among PWID. ${ }^{59}$ A seminal study in the US found that over half of PWID were infected with HCV in their first year of injecting. ${ }^{60} \mathrm{An}$ estimated $20-30 \%$ of people living with HIV have HCV coinfection, but the coinfection rate amongst PWID is estimated at $90 \%{ }^{61}$

An extensive body of research has demonstrated that there are effective tools for preventing HIV and HCV among people who use drugs by injection and other means. Rigorous reviews of this research have informed strong recommendations by WHO, UNAIDS, and UNODC for comprehensive services for PWUD, ${ }^{62}$ which include these elements:

1. Needle and syringe programmes including other injection equipment;

2. Opioid substitution therapy and other drug dependence treatment;

3. HIV testing and counselling;

4. Antiretroviral therapy;

5. Prevention and treatment of sexually transmitted infections;

6. Condom programmes for PWUD and their sexual partners;

7. Targeted information, education and communication for PWUD and their sexual partners;

8. Vaccination, diagnosis and treatment of viral hepatitis; and

9. Prevention, diagnosis and treatment of tuberculosis.

Needle and syringe programmes (NSP): Programmes that provide PWID with sterile injection equipment - often in the form of exchange programmes in which used equipment is traded for sterile equipment - are a crucial part of prevention services and decreasing circulation time of contaminated syringes. WHO found that NSP, particularly low-threshold (easy-access) exchange programmes, were effective in reducing HIV transmission and were not associated with increased injection frequency or initiation of new injection among persons not already injecting drugs. ${ }^{63}$ A recent meta-analysis estimated that NSP reduced HIV transmission by about 58\%, though with caveats about the quality of some studies and the difficulty of disentangling the effect of NSP from that of other services. ${ }^{64}$ 
As the high HCV prevalence among PWID indicates, HCV is transmitted more efficiently than HIV through unsafe injection. Evidence from controlled trials on the effectiveness of NSP in HCV prevention is more equivocal than for HIV. ${ }^{65}$ Part of the challenge is that some people new to drug injection will be $\mathrm{HCV}$-infected even before they begin to take advantage of NSP services. NSP is most effective in HCV prevention when coverage is very high, reaching people from a time close to when they first inject. ${ }^{66}$

Opioid substitution therapy (OST): There is repeated reference in this report to the opioid agonists methadone and buprenorphine, which are the oral medicines most commonly used in medication-assisted treatment of opioid dependence, referred to as OST. OST plays a dual role as treatment for opioid dependence, which can help stabilize lives with all of the attendant benefits, and as HIV and HCV prevention because when effective, it eliminates injection. There is arguably no form of treatment of any drug dependence that has as vast a scientific evidence base or as long a successful clinical experience as OST. ${ }^{67}$ In both its treatment and harm reduction roles, OST faces drug policy impediments because the medicines used are heavily regulated in most countries. Countries do not always allocate adequate quantities of these oral opioid medicines for OST, and doctors in some countries are reluctant to prescribe them for fear of prosecution if there is diversion of these medicines to non-medical use.

A 2012 meta-analysis from Europe, North America, and Asia concluded that oral OST, methadone maintenance in particular, reduces risk of HIV transmission among people who inject opioids by about 54\%. ${ }^{67}$ A 2014 'review of reviews' concluded that the evidence is strong for OST's HIV prevention impact, particularly where doses of opioid agonists are adequate. ${ }^{65}$ Observational studies from San Francisco, the UK, Scotland, Vancouver and Sydney found that OST use was associated with dramatically reduced risk of HCV acquisition among PWID, ${ }^{66,68-70}$ with the data from Scotland, Amsterdam and the UK also concluding that combined OST with NSP further reduces the risk of HCV acquisition. ${ }^{66,71,72}$ A model analysis based on data from the UK illustrates that if enough people can get access to OST and to sufficient sterile injection equipment for virtually every injection, $\mathrm{HCV}$ transmission could decline substantially (Figure $6) .^{73}$ 


\section{[FIGURE 6 here]}

From Vickerman et al., 2012. ${ }^{73}$

In spite of the very large body of evidence of the effectiveness and cost-effectiveness of opioid agonist therapy, some countries insist that generating new research in their settings is necessary before scaling up OST. For these and other reasons, OST has remained in a "perpetual pilot" mode in a number of countries. ${ }^{74}$

Access to OST in Western Europe is a positive contrast to most other regions, with a number of Western European countries virtually eliminating HIV from unsafe injection as a public health concern by scaling up NSP and OST as well as treatment for HIV. ${ }^{75}$ Unlike their counterparts in Western Europe, EECA countries generally have inadequate coverage, quality, and accessibility of NSP and limited or no access to OST. ${ }^{76,77}$

Gains have been made in harm reduction policy and practice in some of the Asian countries with large populations of PWUD. In China, Malaysia, and Vietnam, zero tolerance of harm reduction has given way to government-supported OST and sometimes NSP. ${ }^{56}$ China was estimated in 2015 have been serving about 200000 OST patients,${ }^{58}$ but this still represented a small percentage of people who might benefit, and the problems of high drop-out rates and low dosages remained challenging. ${ }^{56}$ By a 2015 estimate, Vietnam was reaching 32000 OST patients in 44 provinces in a country with an estimated 130000 PWID. $^{78}$ Though coverage may be relatively low, the existence and continued growth of these programmes are important achievements.

While it is advantageous with respect to HIV prevention that coverage levels of these measures be as high as possible, an important body of research demonstrates that if OST, NSP, and HIV treatment are all present their synergistic effect can compensate for partial coverage. Figure 7 illustrates this point using data from Dushanbe, Tajikistan. In this case, if needle exchange and ART alone are available, a 50\% decrease in HIV incidence over a 10 -year period requires that the coverage of both programmes be about $30 \% .{ }^{79}$ But if ART, NSP, and OST are all available, a $50 \%$ decline in HIV incidence over this period can be achieved with $20 \%$ coverage of these interventions. ${ }^{79}$ Similar results have been found in other settings. ${ }^{55,80}$ Therefore partial coverage of 
OST, NSP, and ART may provide effective prevention if it is not possible to attain very high ART coverage, which may be especially challenging where people who use drugs are criminalised.

\section{FIGURE 7 here}

From Vickerman et al., 2014. ${ }^{79}$

HIV and HCV treatment: HIV testing with a link to treatment is important for all people. For PWUD as for other populations, ART can suppress viraemia and lower transmission risks. ART coverage for PWUD is high in Western Europe, North America and Australasia, but it was not always so. In the early years of ART availability, HIV-positive people who used drugs had to battle scientifically unfounded ideas that excluded them from treatment programmes. One was that the lives of people who use drugs are too chaotic to allow them to adhere to daily multi-pill treatment regimens, ${ }^{81}$ although research had shown that PWUD can adhere to ART and achieve viral suppression. ${ }^{82}$ It took more research in several settings and the experience of successfully expanded treatment programmes for PWUD to dispel these ideas. ${ }^{83}$

Studies from a number of settings have reported that agonist treatment for opioid dependence improves ART adherence among PWUD ${ }^{83}$ In Vancouver, Canada, several longitudinal studies showed not only that OST continuation improved ART adherence over time, ${ }^{84}$ but also the converse - that OST discontinuation significantly increased the risk of ART non-adherence ${ }^{85}-$ and that OST patients with higher opioid agonist doses had the strongest adherence to ART. ${ }^{86}$ In China, the understanding of the importance of the OST-ART link led to an effort to integrate ART services in methadone clinics. ${ }^{87}$ While a number of practical challenges were encountered, the effort showed an appreciation for the value of integrating these areas of care. In Ukraine, patients having access to integrated and co-located ART and OST services had greater access to ART than those receiving OST in non-integrated facilities. ${ }^{88}$

In places where there is significant HIV transmission linked to unsafe injection, denying treatment to HIV-positive PWUD both ensures that they and their injection and sex partners will be at risk of HIV and violates the rights of all concerned. Nonetheless, PWUD seem to be systematically excluded from ART in many parts of the world. A 2014 review of HIV services in 
the countries with the largest number of people who inject drugs estimated that in both China and Malaysia, less than 5\% of PWUD living with HIV had access to treatment, and in the Russian Federation about $1 \%{ }^{56}$ There is relatively poor access to HIV testing and ART in EECA, due at least in some places to fear of police harassment or arrest, as well as to systematic exclusion of PWUD from treatment programmes. ${ }^{89}$ UNAIDS' 2014 report on gaps in the global HIV response summarises the crisis of inaccessibility of ART for PWID, also noting that less than $1 \%$ of HIVpositive PWID in Africa receives ART (Figure 8). ${ }^{57}$

\section{[FIGURE 8 HERE]}

From UNAIDS, Gap report 2014. ${ }^{57}$

People who use drugs in many parts of the world have no access to HCV screening and treatment. Unlike HIV, HCV infection can be cured and cleared from the body. Interferon-based therapies as the treatment of choice are giving way to direct-acting antivirals (DAA) marketed since 2013. The cost of the DAAs, however, is orders of magnitude greater than interferon-based therapy. ${ }^{90}$ There is an urgent need for measures to reduce the price of the new generation of hepatitis $\mathrm{C}$ medicines and to ensure that PWUD can benefit from these treatments. In this regard, there may be many applicable lessons from the well documented efforts that succeeded in bringing down the prices of HIV medicines. ${ }^{91}$

For PWUD, cost is far from the only barrier to being able to benefit from DAA therapies (see Figure 9). Policy-making on HCV treatment is replaying a number of misinformed tropes from the HIV past, including the idea that PWUD - or even those with any history of drug use - do not adhere well to treatment and are not worthy of expensive care. ${ }^{92}$ This non-adherence myth was disproven with respect to HIV treatment, which usually requires a lifetime regimen of several medicines, and it has been researched and equally disproven with respect to HCV therapies, which are much shorter in duration. ${ }^{92}$ Requiring abstinence from drugs or alcohol before initiating HCV treatment, a condition already established in many US states, is also not scientifically justified and excludes underserved and needy persons from care. ${ }^{92}$ It has also been suggested that active drug users are poor candidates for HCV treatment because they are likely to be reinfected, but several studies disprove this assertion. ${ }^{92,93}$ None of these claims should stand in 
the way of comprehensive HCV prevention and treatment for PWID. WHO along with many professional liver and infectious disease associations urge HCV screening and treatment of PWUD as a public health priority. ${ }^{92,93}$ Modeling analyses have indicated that HCV treatment for PWID could be an effective and cost-effective means of HCV prevention, ${ }^{94,95}$ and that combination prevention strategies incorporating OST, NSP and HCV treatment could dramatically reduce $\mathrm{HCV}$ incidence and prevalence among PWID in a range of settings. ${ }^{96}$

\section{FIGURE 9 HERE}

From Wolfe et al., 2015. ${ }^{97}$

Condom programmes: Unsafe injection-linked transmission of HIV sometimes overshadows sexual transmission in programme priorities for PWUD, but both are essential. UN reports and research in many settings have for years highlighted the importance of condom programmes for all men who have sex with men (MSM), and particularly those who use drugs either to enhance sexual pleasure, to lower sexual inhibitions, to escape or cope with situations of discrimination, persecution, or uncertainty about sexuality, or for other reasons. ${ }^{98,99}$ Many studies have demonstrated a link between drug use at the time of sexual activity ('sexualized drug use') and lower condom use, resulting in a higher prevalence of HIV and other sexually transmitted diseases and lower incidence of condom use. ${ }^{99-101}$ But more work is needed in many settings to understand the complex motivations for sexual decision-making that would inform effective condom promotion programmes. ${ }^{102}$

The UN recommendations do not include a number of interventions for which an evidence base exists to justify their contribution to an HIV or HCV response. Supervised injection sites are an example. In a number of European countries, Australia and Canada, there are legally sanctioned indoor locations where people can inject (and sometimes smoke and inhale) illegal drugs under medical supervision, obtain clean equipment, be referred to OST and learn HIV and overdose prevention education. The harm reduction intended by these facilities is not only with respect to HIV transmission but also to prevent mortality and other adverse outcomes of overdose, as well as to reduce unsafe disposal of syringes. ${ }^{75}$ A recent meta-analysis reported a $69 \%$ reduction in syringe sharing resulting from use of supervised injection sites. ${ }^{103}$ In the case of Insite, the 
supervised injection facility in Vancouver, Canada, a conservative estimate indicates that on the sole grounds of HIV cases averted, Insite more than pays for itself, and savings are even greater if one takes into account behavioral change leading to use of sterile syringes outside Insite. ${ }^{104}$

As noted by Coffin and colleagues, research on pre-exposure prophylaxis (PreP) using tenofovir, an important newer HIV prevention measure, has often excluded PWUD. ${ }^{105}$ Nonetheless, an important PreP trial reported in the Lancet amongst PWID in Bangkok demonstrated an HIV prevention effect for both men and women who inject drugs. ${ }^{106}$

\section{The cost in HIV and HCV transmission of neglecting harm reduction and prevention measures}

Preventable outbreaks of HIV in recent years have constituted graphic real-life demonstration of the value of ready access to harm reduction services and the cost of impeding access to them. EECA bear a heavy burden from the neglect of harm reduction measures. Harsh anti-drug policies and moral judgments against PWUD contribute to making health services for this population a low political priority. ${ }^{89}$ In the first decade of its work, financial support from the Global Fund helped to overcome these difficult political environments and supported the expansion of harm reduction services, especially NSP and OST, in a number of EECA countries as well as in East and Southeast Asia. ${ }^{107}$ However, with changes in Global Fund policy that have eliminated or reduced funding for middle-income countries, some of these services have been cut (see Box 3 below). ${ }^{108}$

\section{[open box]}

\section{Box 3: Funding crisis for HIV-related harm reduction}

In pure fiscal terms, preventing HIV through harm reduction measures should be an easy sell. Cost-effectiveness is high, and start-up costs for these services are low. But harm reduction continues to be resisted as a funding priority in too many countries. Support by the Global Fund in its first decade, however, inspired some countries that had not previously scaled up NSP and OST to do so, particularly in EECA. ${ }^{107}$ The Global Fund encouraged the inclusion of HIV prevention services for PWID and other "key populations" in country proposals. ${ }^{108}$ 
In the first ten funding rounds of the Global Fund plus a special transitional funding period, some \$620 million in grant support went to programmes for PWIUD in 55 countries, an unprecedented wave of life-saving support for a politically unpopular population. ${ }^{108}$ When the official country proposal to the Global Fund in Thailand, for example, excluded programmes for PWUD in spite of high HIV prevalence in that population, the Global Fund made a special grant to NGOs that were able to bring services directly to the community. ${ }^{109}$

In 2013, the Global Fund unveiled a "new funding model" that, unlike its previous processes, assigned ceiling amounts to countries and significantly limited funding to most middle-income countries, even those with severe injection-linked epidemics where it was unlikely that governments would pick up the costs of the newly scaled-up programmes. ${ }^{110}$ Romania lost funding at a key moment (see main text); Serbia's harm reduction programmes are operating on a shoestring; ${ }^{111}$ programmes in Ukraine - a country with over 350000 PWID - are gravely threatened; ${ }^{110}$ and Vietnam may suffer a similar fate. ${ }^{108}$ Thailand is no longer eligible for support.

Civil society advocacy continues for governments to provide the funding no longer available from the Global Fund, ${ }^{112}$ but it is clear that when it comes to politics harm reduction will remain a hard sell in many places.

\section{[close box]}

In 2010-2012, of the 27 European Union member states plus Norway, Iceland and Turkey, it was estimated that Romania and Greece accounted for one third of all the HIV incidence among PWID, the two countries together having seen a 20-fold increase in new HIV diagnoses linked to drug injection. ${ }^{113}$ In Romania the reduction in external support for harm reduction services coincided with the availability of relatively inexpensive amphetamine-type "legal highs" - new psychoactive substances (NPS) not yet under legal control. Some people who previously injected heroin shifted their consumption to these new stimulants. But heroin is injected two or three times a day, and the stimulants six to ten times. ${ }^{113}$ NPS use was found to be associated with syringe sharing and high-risk sexual practices to a greater degree than heroin use. The number of persons injecting drugs is estimated to have risen from about 17000 in 2008 to about 20000 in 2011 - and with riskier and more frequent injection ${ }^{114}$ - and harm reduction services were largely 
curtailed in 2010. NGOs ran effective NSP and OST services that kept HIV low until then, but funding from the Global Fund was lost when Romania joined the EU. ${ }^{108}$ The dramatic rise in HIV cases through 2013 is shown in Figure 10, representing cases at a major hospital in Bucharest, which practitioners judged to mirror the national situation. Among the newly infected PWID, about $20 \%$ were estimated to be injecting heroin, $20 \%$ NPS, and $20 \%$ a combination of the two. ${ }^{115}$ As UNAIDS has noted, HIV outbreaks among PWID tend to be dramatically fastgrowing. ${ }^{56}$

\section{[FIGURE 10 HERE]}

From Dr Christina Oprea, Victor Babes Hospital, Bucharest, 2015. ${ }^{115}$

In Greece, even before the severe economic recession of 2008-09, harm reduction services for PWUD were provided at a relatively low level of coverage. ${ }^{116}$ The recession was associated with impoverishment and dramatic increases in homelessness among PWID, which separated some people even more from existing services and funding to existing NSP services was cut significantly. ${ }^{117}$ After years of fewer than 20 new cases of HIV transmission among PWID in the country, in 2011 the number of new cases of HIV linked to injection was 260 and in 2012 it jumped to $522 .{ }^{116}$ With assistance from the European Union, Greece scaled up low-threshold harm reduction services, including in cities that had not had them previously, and existing services got support to distribute low-dead-space syringes, which reduce HIV transmission risk. ${ }^{118}$

For most of the period since the emergence of HIV as a public health problem, the US government banned the use of federal funds for NSP, though some states and municipalities supported them. ${ }^{119}$ In January 2016, the US Congress lifted that ban for all NSP program costs other than needles and syringes, a move seen by many as a response to an increasingly visible opioid injection problem even outside major urban areas. ${ }^{120}$ In 2015, a rural county in the US state of Indiana experienced a dramatic increase in $\mathrm{HCV}$ infection followed by a linked outbreak of HIV cases linked to injection of oxymorphone, a synthetic opioid. ${ }^{121}$ Some 135 persons were infected with HIV in a short time in a district that previously had reported very few HIV cases. Almost half the new infections were among women, and they spanned a wide age range as it was 
found that injection took place in multi-generational groups. ${ }^{121}$ Indiana did not permit needle and syringe programmes before the outbreak--non-medical use of syringes was a felony punishable by up to three years in prison. ${ }^{119}$ The governor of Indiana changed the state's policy to allow NSP services for a year on the basis of a public health emergency. ${ }^{119}$ Similar outbreaks of HCV among PWID have been reported across this region, including in Kentucky, and West Virginia, all states with limited or no NSP, and with limited access to OST. ${ }^{119}$

For policy-makers interested in hard numbers on the value of comprehensive HIV and HCV prevention, the cost savings associated with these services are considerable. The government of Australia, for example, which has invested significantly in harm reduction from the early years of HIV, estimated that for every dollar spent on NSP, more than \$4 was gained in short-term (10year) savings on health care costs, and over a longer period where coverage has been maintained, as much as \$27 is gained. ${ }^{122}$ A World Bank study in Malaysia, where about two thirds of HIV transmission is related to unsafe injection, concluded that over the long term NSP in that country even at a relatively low rate of coverage would give a more than threefold return on investment. ${ }^{123}$ Other studies have shown that needle and syringe programmes can also help refer people to treatment for HIV and drug dependence and other services. ${ }^{124,}{ }^{125}$ A 2015 review suggests that the low cost of these programmes and the high cost of the HIV suffering and treatment that NSP can avert means that NSP are "one of the most cost-effective interventions ever funded." 124

Commenting on the cost-effectiveness of OST, WHO, UNODC and UNAIDS UN asserted both the effectiveness and the cost-effectiveness of OST with respect to HIV, noting that for every dollar spent on it, a return of $\$ 4-7$ could be expected due to crime reduction alone and a return of about $\$ 12$ if health-care savings are included. ${ }^{126}$ Although OST is more expensive per person than NSP, Wilson and colleagues assert in their review that OST is highly cost-effective not only in HIV prevention terms but because of health savings linked to less relapse, reduced incarceration, and a wide range of quality of life improvements. ${ }^{124}$

\section{The impact of law and law enforcement on HIV and HCV services}


Evidence from a number of countries indicates that drug law, policy, and law enforcement practices can be barriers to provision and use of harm reduction and other HIV prevention services. These barriers take many forms, a few related to the letter of the law in force in a country - the "law on the books" -- but many more related to the way in which law is enforced in practice, or what Burris calls the "law on the street". ${ }^{127}$ Some of these are the following:

\section{"Law on the books"}

Banning OST and NSP: In some cases, there are legal prohibitions against or poor legal grounding for harm reduction services for PWID. The case of the Russian Federation is extreme: OST is prohibited by law though opioid injection is widespread, and NSP have been allowed only sporadically and are generally not supported by the state. ${ }^{128}$ The official estimate of Russians living with HIV rose to 907000 by end 2014, up almost 7\% from 2013 figures and up from 500000 in $2010 .{ }^{129}$ Over $57 \%$ of new cases were attributed to unsafe drug injection. NSPs are banned by law or effectively blocked by policy, including zoning restrictions, in many jurisdictions. $^{76}$

Laws and law enforcement practices limiting OST and NSP: While OST may not be banned outright or explicitly, in some countries methadone and buprenorphine, the medicines used most in OST, may not be registered or authorized for this use. ${ }^{76}$ This problem persists in spite of the inclusion of methadone and buprenorphine on the WHO Model List of Essential Medicines and strong support from WHO for OST. There are many other ways in which drug-control laws or regulations limit the use or usefulness of OST, including arbitrary restrictions on numbers of patients; arbitrary limitation of dosages and the duration of treatment; prohibition of take-home doses; periods of drug or alcohol abstinence or having to try other kinds of treatment as a prerequisite to starting OST; limiting the neighborhoods or geographical zones where OST services can be offered; lack of integration with accessible community health services so that people have to make special trips for OST; and lack of access to OST in prison and pretrial detention. ${ }^{76,130}$ In a number of countries there is relatively good access to OST in the community but none offered to people in prison or other detention. ${ }^{76}$ 
As with OST, NSP not banned outright can be undermined by various laws and policies. According to a 2014 estimate by Harm Reduction International, significant drug injection is reported in 158 countries, but only 90 have functioning NSP, most of which have very low coverage. ${ }^{76}$ Laws, policies or local ordinances may limit NSP to remote or unpleasant neighborhoods; limit the hours of operation or permitted geographic coverage; limit the number of needles or syringes that can be exchanged or require one-to-one exchange in every transaction (that is, getting clean syringes requires producing the same number of used syringes); limit the age of NSP participants; and limit or forbid provision of clean injection equipment in prison and pretrial detention. ${ }^{76}$ In the US, the 50 states have a dizzying array of laws and regulations regarding needle exchange. In some jurisdictions, local health authorities have to declare emergencies periodically to continue to justify NSP; some states simply ban these services. ${ }^{76}$

In many countries, drug paraphernalia laws undermine NSP, often prohibiting the possession of syringes. In the Global Fund-supported project known as CHAMPION (2008-2013), which was meant to help address the high prevalence of HIV among PWID in Thailand, evaluators reported that an important impediment to scaling up NSP was that PWID feared carrying syringes. ${ }^{131}$ They reported that being caught with syringes could lead to arrest, detention, forced drug treatment, and obligatory urine testing.

In some countries health workers are required or strongly encouraged to register PWUD, and registries are turned over to the police (see web appendix I).

\section{"Law on the street"}

Possession of injection equipment: In some places, there is no legal prohibition of possession of drug paraphernalia, but police nonetheless use possession of injection equipment as grounds for stop-and-search, arrest, and detention. For example, among nearly 600 Russians living with HIV surveyed in 2014, over 50\% reported having been arrested for possessing a syringe (or having a syringe planted on them by the police), though it is not against the law in the Russian Federation to possess a syringe. ${ }^{128}$ Those reporting such arrests were more likely to have shared needles with others and to have suffered an overdose than those not arrested. ${ }^{128}$ This quantitative study corroborates qualitative accounts suggesting that repressive policing in the Russian 
Federation in many ways raises HIV risk and discourages seeking out and using the few HIV prevention services that may exist. ${ }^{132}$ In a number of countries, even if syringe possession is legal, police routinely seize injection equipment that they find, further undermining protection of health. ${ }^{75}$ Police presence was associated with unsafe rushed injection among PWID in Bangkok in a multivariate analysis, ${ }^{133}$ and a small sample of PWID in Hai Phong, Vietnam, reported greater likelihood of needle sharing and other risky practices when police were present or their presence was feared. ${ }^{134}$

Police targeting harm reduction services: The performance of drug police in many countries is judged by the number of arrests they make, and PWUD are likely to be easier to find to help bolster arrest totals than major drug traffickers. It is perhaps for this reason that police may target facilities providing health and harm reduction services to PWUD. ${ }^{135}$ A 2015 study involving over 500 methadone patients conducted by NGO service providers in New York City found that $38 \%$ of the patients reported being stopped and searched by police outside the clinics where they received methadone, and 70\% reported witnessing someone else being searched in these locations. ${ }^{136}$ In some countries, extortion of bribes from PWUD may be an important source of income for poorly paid police. ${ }^{137}$

Crackdowns and other intensive policing: Crackdowns and other intensive policing, often targeting low-income, minority, or marginalized persons, can undermine harm reduction and add to drug-related risk. During a crackdown on drug use known as "Operation 24/7" in Vancouver, Canada in 2003, researchers documented a significant decline in access to sterile injection equipment as police actions drove PWID away from the only NSP open at night. ${ }^{138}$ During police crackdowns in Australia, PWUD reportedly switched from inhalation or smoking of substances to injection, which is much riskier, partly because during crackdowns drugs became scarcer and injection could be accomplished with lower quantities of drugs as well as more quickly and less visibly than smoking. ${ }^{139}$ Other studies have shown that crackdowns lead to rushed injections, more vascular accidents, and the likelihood that steps such as disinfecting the injection site will be skipped. ${ }^{140}$ In Malaysia, rushing an injection because of police presence was found to be linked to risk of overdose. ${ }^{141}$ 


\section{Tuberculosis, drug use and drug policy}

According to WHO, tuberculosis is the single most important cause of death among people living with HIV, responsible for one in four deaths. ${ }^{142}$ People living with HIV have a 30 -fold higher risk of TB infection than HIV-negative persons. ${ }^{142}$ But WHO emphasizes that PWUD are at very high risk of both infection with Mycobacterium tuberculosis and TB disease even if they do not live with HIV; the risk of TB linked independently to drug injection - and even to non-injection drug use - was well established before HIV was in the picture. ${ }^{143}$

WHO estimates that people who both live with HIV and inject drugs are two to six times more likely than HIV-positive people who do not inject drugs to contract TB. ${ }^{144}$ But the role of drug use in the epidemiology of TB is complex and, as noted by Deiss and colleagues, the existing literature does not always distinguish drug injection from other drug use. ${ }^{145}$ Many elements of the risk environment of at least some people who use drugs - homelessness or sub-standard housing, heavy alcohol and tobacco use, and incarceration, for example - are risk factors for TB. Some studies suggest that people who use drugs present later than other persons to seek TB testing or care. ${ }^{145}$ Deiss and colleagues also raise the possibility that use of opioids may inhibit the cough reflex and thus mask symptoms of TB that might otherwise lead to seeking care. ${ }^{145}$

Multi-drug-resistant TB (MDR-TB) has threatened to undermine progress in TB control in many parts of the world. ${ }^{146}$ The region with the highest documented proportion of MDR-TB among TB cases is EECA, also home to major unsafe injection-linked HIV and HCV epidemics. ${ }^{142}$ Remarkably, though HIV-HCV coinfection is high in the region, HIV-TB coinfection is reportedly low, but experts warn that with the combination of sparse harm reduction services, low ART coverage among people who use drugs, high rates of incarceration of people who use drugs, non-integrated vertical health services, and substandard housing and social support, a perfect storm of HIV-MDR-TB coinfection may be brewing. ${ }^{147}$

WHO recommends that PWUD be included systematically in anti-TB efforts and especially that HIV, HCV and TB services be integrated and low-threshold for people who use drugs. ${ }^{144}$ The reality, however, is that recommended services remain out of reach for many people who use drugs worldwide. Diagnosis of TB with microscopy identifying acid-fast TB bacilli and 
molecular DNA detection using geneXpert systems is recommended, ${ }^{144}$ but in Central Asia, for example, TB diagnosis is still made mostly using chest radiography ${ }^{147}$ though $\mathrm{x}$-ray results are compromised by the presence of HIV. ${ }^{144}$

WHO has compiled detailed guidance for integrated treatment of TB and HIV as well as TB and $\mathrm{HCV}$, including ensuring sustained access to ART for all who need it. ${ }^{148}$ The exclusion of PWUD from ART, which persists in many parts of the world, undermines the effectiveness of TB treatment as well as HCV treatment.

The importance of integrated and sustained care cannot be overstated. Deiss and colleagues report cases in which TB treatment was integrated with treatment for drug dependence but was lost after people left drug treatment. ${ }^{145}$ The NGO Partners in Health addressed the challenge of keeping people who use drugs in sustained care for MDR-TB in a programme called Sputnik in Tomsk, Russian Federation, through a strategy of intensive accompaniment of patients. ${ }^{149}$ Trained teams of nurses, drivers, and others worked with patients to ensure delivery of treatment in places and circumstances that the patient could maintain to minimize missed appointments. Family, friends, and neighbors were helped to understand the importance of treatment and to provide support to patients. ${ }^{149}$ Over $70 \%$ of high-risk patients completed treatment. The cost compared to hospitalization was small. A study in Malaysia demonstrated that TB screening and care in drug rehabilitation centres and facilities offering OST was a very effective targeting strategy. ${ }^{150}$

TB and drug use experts at WHO, writing in 2013 in the WHO Bulletin, asserted that it was urgent to address the undermining role of "punitive drug policies and laws in fueling the tuberculosis epidemic among people who use drugs". ${ }^{151}$ Not only do punitive laws drive PWUDs away from health services, they may also contribute to stigmatising or disrespectful treatment in health services. ${ }^{151}$ For these reasons, in its 2014 guidance on HIV services for "key populations" including PWUD, WHO recommended decriminalisation of drug use as well as training and protections for health workers to reduce fear of treating PWID. ${ }^{152}$

\section{Drug-related incarceration and health}




\section{Use of incarceration in drug control}

In 2014, UNODC estimated that persons convicted of drug crimes make up about $21 \%$ of incarcerated persons worldwide. Possession defined, by UNODC as possession of drugs for individual use, was the most frequently reported crime globally (Figure 11). ${ }^{32}$ Based on data from 2011 annual country reports, UNODC estimated that drug possession offenses constituted 83\% of drug offenses reported worldwide. ${ }^{32}$ While not all of the crimes reported by the police result in incarceration, mandatory prison sentences are attached to possession of even a small amount of drugs in many countries. In some countries that have decriminalised drug use, possession for individual use remains an offense, or the amount defined for non-criminalised individual use is so low that possession is effectively a crime. ${ }^{153}$

UNAIDS estimates that in places where drug use and small-scale drug possession are criminal offenses, the majority of people who use drugs may wind up in the custody of the state at some time in their lives. ${ }^{57}$ In Central Asia, one estimate suggests that more than 50\% of PWID have been arrested at least one time. ${ }^{77}$ Though there have been some reform efforts, many countries have drug laws that impose extended custodial sentences on people convicted of non-violent offenses including drug use alone, possession of amounts of drugs intended only for individual use, and sale of very small amounts of drugs. ${ }^{76}$ The over-representation of PWUD in prison and the lack of essential care and support for them while in state custody are amongst the most devastating health legacies of pursuing drug prohibition. There is, moreover, no evidence that incarceration is an effective deterrent for drug use either in prison or afterward. ${ }^{154}$ Indeed, the Vancouver Injection Drug User Study (VIDUS), a long-running cohort study, found that recent incarceration was negatively associated with cessation of injection. ${ }^{155}$

Several studies conclude that criminal prosecution of minor use and possession infractions does not have the deterrent effect with respect to drug use, possession, or minor crimes that supporters of these sanctions claim. A classic study comparing cannabis use in San Francisco and Amsterdam - cities with very different approaches to cannabis regulation - found that the partial decriminalisation of cannabis in Amsterdam was not associated with increased use or possession, 
and the rigorous criminalisation in San Francisco was not associated with reductions in use or possession. ${ }^{156}$

\section{[FIGURE 11 HERE]}

From UNODC, World crime trends, $2014 .^{33}$

The OAS in its landmark 2013 report on drugs and drug policy in the Americas lamented the dramatic rise in prison populations especially linked to prosecution of minor offenses because they are less likely than major traffickers to be able to afford legal assistance in attaining "access to justice". ${ }^{15}$ This increase, at least in some Latin American countries, is a detrimental outcome of steady increases in legislated penalties for drug offenses since the 1950s (Figure 12). ${ }^{157}$ (See also web appendix II.)

\section{[FIGURE 12 HERE]}

From Uprimny et al., 2013. ${ }^{157}$

Table 1 shows the most recent information for selected countries on the proportion of people incarcerated for drug offenses among all incarcerated persons. UNODC's data on the prominence of possession offenses and the data informing Table 1 do not distinguish the proportion of drugrelated offenders who are incarcerated for minor, non-violent offenses. But, as noted by Penal Reform International in a 2015 report, mandatory prison sentences are attached to possession of even a small amount of drugs in many countries. ${ }^{160}$

\section{[Table 1 here]}

From Penal Reform International; ${ }^{158}$ Giacomello, 2014; ${ }^{159}$ OAS-CIM report, 2014; ${ }^{160}$ US Bureau of Justice Statistics, 2015; ${ }^{161}$ Perez Correa and Azeola, $2012^{48}$

\section{[open box]}

\section{Box 4: The death penalty for drug offenses}

June 26 is designated by the UN as the International Day Against Drug Abuse and Illicit Trafficking. The day has been "celebrated" in some countries by holding public executions of drug offenders. ${ }^{162}$ Some 32 countries have laws on the books that impose capital penalties for 
drug offenses. ${ }^{163}$ But most drug-related use of the death penalty is by a smaller number of countries including China, Iran, Singapore, Saudi Arabia, Indonesia, and Thailand. ${ }^{163}$

Advocacy for the abolition of the death penalty has succeeded globally in general as many countries have removed it from their books in the last 50 years. But in the same period a number of countries included definition of capital crimes in their drug laws. ${ }^{163}$ The Single Convention of 1961 may have influenced some countries; the commentary accompanying it suggests that capital punishment for drug offenses is an appropriate sanction. ${ }^{164}$ The $1988 \mathrm{UN}$ drug convention with its strong emphasis on criminal penalties for drug trafficking may also be an influence. ${ }^{165}$ But in recent years, UN human rights experts and UNODC have denounced the use of the capital punishment for drug offenses as a violation of international human rights norms. ${ }^{166}$

Some countries have applied the death penalty very publicly to foreign nationals in an attempt to discourage international trafficking, as in Indonesia's execution of Australian, Nigerian, and Brazilian nationals for drug offenses in July $2015 .{ }^{167}$ But there is no evidence that drug-related executions have a deterrent effect on drug trafficking or other offenses. ${ }^{163}$ In Iran, where in 2011 over $70 \%$ of state-sponsored executions were for drug offenses, the then head of the Iranian High Council for Human Rights observed that the executions did not seem to make a dent in the level of trafficking in the country. ${ }^{168}$

[close box]

\section{Racial discrimination in drug-related mass incarceration}

The US has the highest rate of incarceration in the world at about 707 persons per 100000 population, about 50\% higher than in the Russian Federation and more than five times higher than in China. ${ }^{169}$ As Table 1 shows, drug-related offenses account for a significant percentage of this incarceration. Aggressive prosecution of drug offenses along with mandatory minimum sentences for certain infractions helped to make drug-related mass incarceration a major engine for growth in US state and federal prison populations beginning in the 1980s (Figure 13). ${ }^{170}$

\section{[FIGURE 13 HERE]}

From Snyder and Mulako-Wangota, 2014. ${ }^{170}$ 
The racially disparate application of drug-related incarceration in the US is a prominent feature of mass incarceration. Persons of color, particularly African Americans, have been disproportionately affected by drug-related mass incarceration. In 2011, amongst men aged 3034, 1 in 13 African Americans were in prison, 1 in 36 Hispanic Americans, and 1 in 90 whites, though prevalence of drug use in these populations was similar. ${ }^{171}$ The Sentencing Project, an NGO focused on criminal justice, calculated in 2014 that African American men had a 32\% probability of being in prison or other state custody at some time in their lives, compared to $17 \%$ for Hispanic men and $6 \%$ for whites. ${ }^{172}$ Figure 14 shows the racial disparity in drug-related incarceration at the federal and state level in $2013 .{ }^{173}$

\section{[FIGURE 14 HERE]}

From Carson (Bureau of Justice Statistics), $2014^{173}$

This pattern reflects documented racial disparities at all stages of US law enforcement, from "stop and search" and arrest to sentencing and incarceration. Beginning in the late 1990s, New York City undertook to clamp down on cannabis infractions, resulting eventually in nearly a half million arrests through 2013 - of young people for the most part - for minor cannabis infractions. ${ }^{174}$ There was consistent evidence that marijuana use was higher among whites than among African Americans or Hispanic Americans. In the decade beginning in 2004, African Americans comprised $25 \%$ of the population of the City but accounted for $54 \%$ of cannabis arrests; Hispanics made up $27 \%$ of the population but accounted for $33 \%$ of arrests. ${ }^{174}$ Arrests for drug-related infractions amongst teenagers across the US from 1980 to 2012, the large majority for cannabis, show a similar racial disparity (Figure 15). ${ }^{177}$

The striking racial disparity in arrest and incarceration in the US parallels racially disparate patterns of HIV, and some investigators conclude that the two phenomena are closely related. Though African Americans comprise 14\% of the US population, about $40 \%$ of new HIV cases and about half of AIDS cases in the US occur in this population. ${ }^{176}$ A number of studies show that a history of incarceration is associated with HIV incidence and prevalence among African American men and women. ${ }^{176-178}$ 


\section{[FIGURE 15 HERE]}

From Snyder, 2012. ${ }^{175}$

Racial and ethnic minorities are over-represented in prison and in arrest figures in countries other than the US, including aboriginal people in Canada and Australia and people of African origin in Brazil, but the contribution of drug-related arrests and convictions to these patterns is not clear. ${ }^{179}$ In Canada, aboriginal persons accounted for $3 \%$ of the adult population but $20 \%$ of adults sentenced to prison in 2013-14. ${ }^{180}$ Afro-Brazilians reportedly receive longer sentences for all categories of crime than Brazilians of non-African origin, and they are disproportionately targeted in drug policing and crackdowns. ${ }^{181}$

In October 2015, the US government announced that it would release 6,000 federal prisoners incarcerated for minor drug offenses, meant to be the first tranche in a release of a possible 46 000 federal prisoners of the 100000 convicted of federal drug offenses. ${ }^{182}$ This unprecedented release is occasioned by a decision by the executive branch to reduce federal mandatory minimum sentences for minor drug offenses and make the reduction retroactive. ${ }^{182}$ The great majority of people serving prison sentences for drug offenses are in state - not federal - prisons, which are not affected by this change. ${ }^{173}$

\section{Drug-related incarceration of women}

Table 1 illustrates a striking gender disparity in drug-related imprisonment. While in any given drug market there are likely to be many more men than women involved in use, possession, and sale of drugs, a higher percentage of women than men are imprisoned because of drug-related convictions in virtually all countries where data exist on this point. ${ }^{158}$ The unanimously endorsed UN Bangkok Rules urge governments to find alternatives to incarceration for women convicted of non-violent offenses - the vast majority of incarcerated women - and to ensure protections from violence and other human rights abuses for those who are in state custody. ${ }^{183}$ But these rules seem to be commonly honoured in the breach. 
Giacomello asserts that a large proportion of women convicted for small-scale sale and other non-violent offenses in Latin America are uneducated women living in poverty who had limited opportunities to earn licit income. ${ }^{159}$ A report by the OAS and the Inter-American Commission (IAC) on women echoes this view, estimating that most women imprisoned for drug-related offenses in the Americas are engaged in 'micro-trafficking' though they may be sentenced for long periods under harsh anti-trafficking statutes. ${ }^{160}$ The OAS-IAC report also notes that in many countries in the Americas, many women are convicted for bringing drugs into a prison or pretrial detention facility for a spouse or family member and that women's low level in the drug market power chain means they have little leverage in plea bargaining or sentence reduction. ${ }^{160}$ In Mexico, CIDE researchers found that virtually all of the women imprisoned for drug-related crimes in 2012 were first-time offenders, and $92 \%$ were convicted of non-violent offenses. ${ }^{48}$ Of women accused of drug infractions in Argentina in 2013, almost 30\% had been detained without trial for one to two years and about $12 \%$ for more than two years. ${ }^{160}$

Overall in Europe and Central Asia, about one quarter of women in state custody are convicted drug offenders. ${ }^{184}$ In the US, there was a doubling of drug-related arrests of women, mostly for drug possession, from about 400 per 100000 population in 1990 to a peak of about 800 per 100 000 in 2006, after which the rate declined somewhat. ${ }^{175}$

Women who use drugs in prison are also at risk of HIV from sexual violence or unprotected coercive sex as well as from drug use. ${ }^{185}$ As much as HIV services, including access to condoms, and drug dependence services are inadequate in men's prisons, they are even more so in women's prisons. ${ }^{185}$ While incarceration of women has increased in many countries in the last 20 years, women are still a small percentage of the prison population in most countries, and developing specialised HIV, HCV or TB programmes for them is rarely a political, public health, or budgetary priority. ${ }^{185}$

Detention of children and young people and the effect on children of parents' incarceration are too little studied (web appendix III). Pretrial detention of children and adults for drug offenses also poses health risks (web appendix IV). 


\section{Impact on families and communities}

The over-reliance on incarceration as a response to drug use may have a profound effect on the well-being of relatives and partners of people imprisoned for drug offenses. Many studies document that incarceration of a family member imposes unique forms of financial strain, psychological distress, and logistical hardship on the family and is associated with deleterious health outcomes. ${ }^{186-196}$

Caring for a family member who uses drugs has its own challenges, ${ }^{197}$ but incarceration may generate further difficulties by increasing geographical distance between PWUD and their families, erecting barriers to communication, and subjecting family members to correctional surveillance and regulations when they maintain contact with their incarcerated loved one. ${ }^{198-200}$ Parole and probation conditions may sometimes be incompatible with resources family members have to offer (e.g., housing outside of a district of parole, or in government-subsidised housing). ${ }^{201}$ In the US the impact of all of these factors falls disproportionately on people of color. (See web appendix V.)

A 2014 survey of people visiting family members in Mexican prisons indicated similar kinds of challenges in that setting. Of those visiting relatives, mostly women, over 50\% said that because of the imprisonment of a spouse or family member they had had to get a job or an additional job; $41 \%$ on the other hand said they lost a job; over $18 \%$ said they had to move house; and almost $40 \%$ said the imprisonment impeded their ability to care for their children or grandchildren. ${ }^{48}$ Spouses of incarcerated persons in this study also reported suffering disproportionately from a range of health problems, including high blood pressure and depression. ${ }^{48}$

\section{Infectious disease and drug-related incarceration}

Prisons and pretrial detention facilities worldwide are high-risk environments for infectious disease transmission. UN agencies estimate that prevalence of HIV, other sexually transmitted diseases, hepatitis $\mathrm{C}$ and hepatitis B infection, and TB is from 2 to 10 times higher in prisons than in the community. ${ }^{57}$ Coinfections among these infectious diseases are also likely in prison. In Argentina, for example, people living with TB who had a history of incarceration were 6 times more likely to be HIV-positive and 18 times more likely to have HCV infection than the general 
population. ${ }^{76}$ Since most people in prison and pretrial detention return to the community, what happens behind prison walls in addressing infectious disease has ramifications for the whole population.

As UNAIDS notes, excessive criminalization of drug-related offenses is one factor that contributes both to prison overcrowding and to the over-representation in prisons of people who are likely to have been exposed to HIV and, in the case of PWID, HCV and TB. ${ }^{57}$ PWUD are likely to be over-represented in prison particularly in countries where laws allow for lengthy custodial sentences for minor drug use, possession, and sale, and many may be imprisoned repeatedly. ${ }^{202}$ These factors figure in the 2014 recommendation of WHO to decriminalise drug use - and thus reduce incarceration of PWUD - as a critical step to enabling optimal HIV prevention, treatment, and care. ${ }^{152}$

Drug injection does take place in prison, even where very restrictive measures are in place. Over 90\% of men surveyed in a 2015 study in Indonesia said they shared injection equipment while injecting drugs in prison, and 78\% said they shared equipment with ten or more other prisoners. ${ }^{203}$ UNODC in 2015 summarized reports from 43 UN member states that had estimated or surveyed lifetime, annual, and past-month drug use while in prison among people in custody (Figure 16). ${ }^{7}$ A study of drug use in prison in the European Union, found that reported rates of ever having injected drugs in prisons among the countries providing data were in the range of 15$30 \% .{ }^{204}$ While some PWUD before serving a prison sentence will discontinue or reduce their use in prison or change their method of use, some people will seek to maintain drug use, including drug injection, or will begin using drugs while in prison. ${ }^{205}$ In addition to drug-related risk, PWUD in prison face HIV risks associated with unprotected sex, sexual violence, and unsafe tattooing. As noted above, risk of sexual transmission of HIV may persist after prison if incarceration destabilises existing sexual relationships. ${ }^{176}$

\section{[FIGURE 16 HERE]}

From UNODC, World Drug Report, 2015. ${ }^{7}$ 
Numerous studies have documented HIV and HCV transmission in prison linked to drug injection, and others have demonstrated high prevalence of HIV and HCV among formerly incarcerated persons compared to other populations. ${ }^{202}$ One study estimated that about $10 \%$ of adults in the penitentiary system of the Russian Federation inject drugs with two thirds of those sharing syringes. ${ }^{202}$

HIV in prison: There is not a recent comprehensive accounting of HIV prevalence in prison worldwide. In its 2014 report on gaps in the global HIV response, UNAIDS noted results for selected countries: HIV prevalence among adult prisoners is 15 times higher than in the general adult population in Ukraine, 10 times higher in Argentina, and 2.4 times higher in both South Africa and the US. ${ }^{57}$ In 2007, 11 sub-Saharan African countries reported HIV prevalence in prisons at least twice that in the general population. ${ }^{206}$ Data on HIV transmission in prison are rarer. An evaluation of attributable risks among PWID in a long-term study in Vancouver concluded that $21 \%$ of the HIV infections in this population were likely acquired in prison. ${ }^{207}$

Prevalence and transmission of HCV in prison: People living with $\mathrm{HCV}$ infection are also over-represented in prison in many countries. Based on data from 39 countries, a 2013 review found an average prevalence of $26 \%$ positivity to $\mathrm{HCV}$ antibody among people in prison and about $65 \%$ among prisoners with a history of drug injection. ${ }^{208}$ Overall prevalence among women in this analysis was $32 \%$ compared to $24 \%$ for men. ${ }^{208} \mathrm{~A}$ number of the reviewed studies presented evidence of $\mathrm{HCV}$ transmission in prisons. $\mathrm{HCV}$ prevalence in prisons may be high even where harm reduction services are available in the community. In Australia, for example, the prevalence of $\mathrm{HCV}$ infection among people entering prison in 2010 was $22 \%$ and among those with a history of drug injection 51\% ${ }^{209}$ Phylogenetic and spatial analysis in Australia located a number of clusters of in-prison HCV transmission and suggested high transmission risk when people move from between prisons or from prison to the community. ${ }^{210}$

The Commission sought to investigate through mathematical modelling the contribution of incarceration to HCV transmission among PWID in several countries. Given the high incarceration rate amongst PWID ${ }^{211-214}$ and association between $\mathrm{HCV}$ infection or high risk 
behavior and a history of incarceration, ${ }^{213,215-224}$ it is unsurprising that incarceration could play an important role in driving HCV transmission among PWID.

According to our results, interventions that aim to reduce transmission risk in prison (such as OST and possibly HCV treatment) ${ }^{225,226}$ or post-release could substantially reduce HCV incidence among PWID. Figures 17 and 18 illustrate this point, using modelling undertaken by Commissioner Peter Vickerman and colleagues Jack Stone and Natasha Martin to consider the role of incarceration on HCV transmission among PWID in four illustrative scenarios (similar to Scotland, Australia, Ukraine and Thailand), chosen to mimic important PWID incarceration characteristics of varied global settings. Using a model calibrated to a Scotland-like scenario, where moderate levels of incarceration (61\% of PWID ever incarcerated, $12.7 \%$ in the last 6 months), and short sentence lengths for PWID (average 7 months) ${ }^{71,220,227}$ means that PWID spend $16 \%$ of their injecting career being incarcerated (1.1 years). Despite lower HCV incidence amongst incarcerated PWID than amongst PWID in the community in Scotland ${ }^{227}$ (likely due to high levels of prison OST-- 57\% -- among incarcerated PWID), ${ }^{71,227}$ modelling suggests incarceration still has a negative impact on the overall HCV epidemic due to the elevated risk of HCV acquisition among recently released PWID (threefold greater in first 6 months following release). ${ }^{220}$ Indeed, prison contributes only $5 \%$ of incident infections, whereas $24 \%$ of all incident infections occur in the period of elevated risk post-release. Because of the heightened HCV incidence post release, the HCV incidence amongst PWID in our Scotland-like scenario could be $47 \%$ lower if this risk was not present with OST maintained (Figure 18), but only 20\% lower if incarceration had no effect on HCV transmission during or after prison.

\section{[Figures 17 and 18 here]}

Although Australia has similar incarceration rates and durations to those of Scotland, a lower level of prison OST (19\% PWID receiving OST in prison) ${ }^{228}$ correlates with higher HCV incidence among incarcerated PWID, ${ }^{70,229}$ such that $22 \%$ of incident infections may occur in prison. In a setting such as Australia, modelling indicates HCV incidence amongst PWID could possibly be $49 \%$ lower if incarceration had no effect on HCV transmission and $66 \%$ lower with high coverage of prison OST and no elevated risk following release (Figure 18). By comparison, 
in a setting with similar incarceration dynamics to those of Ukraine, where PWID receive longer sentences on average (14 months) compared to Scotland or Australia and inject for much longer (25 years on average compared to 7 years in Scotland), the lower proportion of PWID recently or ever incarcerated (52\% of PWID ever incarcerated, $9.7 \%$ in last 6 months) results in a similar proportion of their injecting career in prison (18\% of injecting career or 4.4 years) as in Scotland and Australia. Here, possibly due to longer durations of injecting, the overall contribution of prison to the epidemic amongst PWID could be far less than the other two settings if the pattern of transmission risk in and out of prison were similar; the model projects that HCV incidence amongst PWID could only be $14 \%$ lower if incarceration had no effect on HCV transmission and $26 \%$ lower if there was higher coverage of prison OST and no elevated risk following release.

By contrast, in a setting with similar incarceration patterns to those of Thailand, the combination of high incarceration rates (80\% of PWID ever incarcerated, 17\% in the last 3 months) and long prison sentences for PWID (12 months on average) $)^{230,231}$ means PWID are likely to be incarcerated for a substantial proportion of their injecting career (estimated at $46 \%$ ), and to experience numerous periods of elevated HCV transmission post-release. For this Thailand-like scenario, the model estimates $53 \%$ of incident infections could occur in prison; HCV incidence could be $60 \%$ lower if incarceration had no effect on HCV transmission, and $94 \%$ lower with high coverage of prison OST and no increased risk following release (Figure 18). This analysis, although illustrative, highlights that incarceration could contribute substantially to HCV transmission among PWID and supports a growing body of evidence that interventions to reduce HCV risk among PWID in prison and post-release (such as OST and possibly HCV treatment) ${ }^{226}$ could result in substantial benefits to the community and reduction in HCV transmission.

TB and MDR-TB in prison: TB in prison and other closed settings has long been a public health concern, but TB risks increase in the presence of drug injection in closed settings. Overcrowding, poor sanitation, inadequate ventilation, the relatively high prevalence of HIV, and the insufficiency of basic services all contribute to TB transmission in prison. ${ }^{232}$ The significant representation in prisons in many countries of people with HIV, PWUD, people living in poverty, and formerly incarcerated people means that many people in custodial settings have been exposed to TB before they are incarcerated. ${ }^{144}$ Biadglegne and colleagues in 2015 indicated sub- 
Saharan Africa and Eastern Europe and Central Asia as the regions of greatest concern for TB transmission in prison, though data from Africa are sparse. ${ }^{232}$ Central Asia has the highest estimated prevalence of TB and MDR-TB of any region. ${ }^{147}$ A widely cited study by Stückler and colleagues estimated that in Eastern Europe and Central Asia from 1991 to 2002, increases in the rate of incarceration accounted for about $60 \%$ of the increase in TB in the general population. ${ }^{233}$ In the WHO-Europe region, which includes Eastern Europe, it was estimated in 2010 that the relative risk for TB in prison was 145 times higher than in the community. ${ }^{234} \mathrm{WHO}$ cites the estimate that worldwide about 1 in 11 cases of TB transmission in high-income countries occurs in prison, and about 1 in 16 in low- and middle-income countries. ${ }^{144}$

Containing MDR-TB is crucial to national TB responses. Both MDR-TB and XDR-TB extensively drug-resistant TB - have been reported in prisons at high levels in some cases. ${ }^{146} \mathrm{~A}$ 2015 review of MDR-TB in prison found, for example, about 19\% of all TB patients in Thai prisons were classified as MDR-TB, 13-55\% in the Russian Federation, 52\% in Azerbaijan, and almost $10 \%$ in Zambia. ${ }^{232}$ One study in the Russian Federation found XDR-TB cases to be $11 \%$ of TB patients tested in the prison. ${ }^{232}$

Infectious disease in prisons is a heavy burden in EECA. Central Asia is estimated to have the highest rate of $\mathrm{HCV}$ prevalence among prisoners of any region. ${ }^{235}$ Ukraine, with the next-highest prison population in Eastern Europe after the Russian Federation, reported an HIV prevalence among prisoners of $14.5 \%$ in 2008 and $13.6 \%$ in $2011,{ }^{235}$ as against HIV prevalence in the general population in that period of $1.2 \% .{ }^{236}$ The Russian Federation has prison population of about 800000 annually - the second highest in the world after the US - of which about $20 \%$ is estimated to have been convicted of drug offenses. ${ }^{237}$ It has not participated in reporting on HIV in prisons in the Dublin Declaration process, but it has experienced HIV outbreaks in prison in recent years. ${ }^{202}$ In 2002 it was estimated that the 36000 HIV-positive persons in Russian prisons at the time accounted for about $20 \%$ of all HIV cases in the fast-growing epidemic in the country. ${ }^{205}$

\section{Prison services related to $\mathrm{HIV}, \mathrm{HCV}$ and TB and drug dependence}


It is an international norm that people in prison and other custodial settings have a right to health services at the level of those offered in the community in their jurisdictions. ${ }^{238}$ When it comes to $\mathrm{HIV}, \mathrm{HCV}$, and TB services, that norm is far from being respected. UNODC and WHO recommend a comprehensive package of measures for HIV prevention, care, and support for incarcerated persons, including NSP and OST (web appendix VI). ${ }^{239}$ These measures are also important for HCV prevention and care. Making these measures a reality, however, is proving challenging.

\section{Access to HIV and HCV prevention and care in prison}

OST has been shown in many countries to be very effective in custodial settings where people can be directly observed in taking medicine and can be followed if they have problems with dosage. ${ }^{205}$ But, according to a 2014 estimate by Harm Reduction International, of the 80 countries where OST is available in the community, only 43 provide the services in at least one prison. ${ }^{76}$ In all of East and Southeast Asia, only Malaysia and Indonesia provide OST in prison. ${ }^{76}$ Even in the European Union, which has high OST coverage in the community, OST in prison lags behind OST in the general population (Figure 19), though it is offered in prison in the majority of EU countries. ${ }^{240}$ Eight countries in Western, Central and Eastern Europe allow a people in prison to benefit from OST only if they were already OST patients before incarceration. ${ }^{235}$ In Central Asia where the need for HIV and HCV prevention services is so great, only Kyrgyzstan has OST and NSP in prison. ${ }^{76}$ OST is generally absent from US prisons but is available in most Canadian prisons. ${ }^{76}$ Resistance to OST in prisons is motivated partly by the belief, also found outside corrections systems, that any drug treatment in prison should be abstinence-based. As was noted by authorities in Scotland in the 1990s, however, it is as unrealistic to aspire to a drug-free prison as it is to aspire to a drug-free society. ${ }^{205}$

\section{[FIGURE 19 HERE]}

From EMCDDA, Prisons and drugs in Europe, 2012. ${ }^{240}$

As noted by Kopak, the failure to provide effective treatment and care to people with problem drug use in the enormous US prison population perpetuates crime when people are released and returned to their previous circumstances. ${ }^{241}$ In the European Union, EMCDDA judged that in 
2013 the availability of drug treatment programmes tailored especially to people in prison was "extensive." ${ }^{.75}$ Most EU countries report a variety of treatment options for drug dependence in prison, including "low-intensity" counseling, therapeutic community-type interventions, detoxification using various methods, abstinence-based Narcotics Anonymous, and group sessions, in addition to OST. ${ }^{240}$

Provision of sterile injection equipment in prison is even rarer than OST, having been established and sustained in prisons in only eight countries, mostly in Western Europe. ${ }^{240}$ Several countries in Eastern Europe had prison NSP but were unable to sustain the programmes, which are always politically challenging. ${ }^{76}$ In a few countries, prison staff have resisted these programmes, and advocates for the programmes have faced the argument that providing injecting equipment encourages drug use. But in the case of Germany, when closure of NSP in prisons was proposed, prison workers protested, knowing that the programme protected them from injuries with contaminated needles as well as protecting the prison population. ${ }^{205}$

$\mathrm{HCV}$ diagnosis and treatment services are limited in prisons in many countries. Diagnosing HCV is not a good investment if treatment cannot be provided, and the cost of HCV medicines as well as the need to ensure treatment over a long period are likely to have impeded treatment as a priority in prisons, especially in Western Europe where some drug sentences are relatively short. ${ }^{240}$ In the US from 2000 to 2012, only 12 of 50 state prison systems did any systematic $\mathrm{HCV}$ antibody testing. ${ }^{241}$ The much shorter duration of DAA therapies may make them more attractive in prisons, and a recent UK-based cost-effectiveness analysis indicates that HCV testing and treatment with short-course DAA therapy is cost-effective. ${ }^{226}$ One middle-income country that has made a breakthrough is Georgia, which struck a deal with Gilead Sciences for concessionary pricing on its DAA sofosbuvir and decided to include free treatment for people in prison who need it. ${ }^{244}$

$\mathrm{HIV}$ and HCV services other than these harm reduction measures are equally important and frequently lacking in prisons and pretrial detention settings. Availability of voluntary HIV testing at any time during incarceration is recommended by WHO and UNODC, ${ }^{239}$ and some jurisdictions routinely offer HIV tests to people entering prisons. ${ }^{76}$ Nonetheless, UNAIDS reports 
have consistently concluded that people in prison have poor access to HIV testing and treatment. ${ }^{57}$ While research from North America has shown that optimal outcomes from ART can be achieved in prisons, ${ }^{245}$ a large body of work from a range of settings shows that among PWID, incarceration is often strongly associated with poor access and adherence to ART, premature discontinuation of ART, and low rates of viral suppression. ${ }^{246-249}$ It appears that problems ensuring access to ART and related care within North America occurs throughout the incarceration process (e.g., in detention, during transfers, at discharge), and low access and adherence is shaped by high rates of HIV-related stigma and concerns about breaches of privacy within prison systems. ${ }^{246,250}$ (see web appendix VII).

WHO's 2007 global review of prison HIV services found virtually no ART in prison in countries with significant populations of PWID outside the Global North. ${ }^{251}$ Reviews in 2010 and 2014 of ART availability in prisons in the five countries outside the US with the largest number of PWID - the Russian Federation, China, Malaysia, Vietnam and Ukraine - indicated very limited ART overall for PWID in the community and virtually none at scale in prisons. ${ }^{56,83}$ Indonesia, a country with significant representation of PWID in prison, has provided ART to prisoners incarcerated for drug offenses. A 2015 study of randomly sampled prisoners found that HIVpositive prisoners with a history of drug use were more likely to be receiving ART partly because they had been incarcerated for longer periods than other prisoners. ${ }^{252}$ Work from a range of settings, including Zambia, ${ }^{253}$ Namibia, ${ }^{254}$ India, ${ }^{255}$ Argentina, ${ }^{256}$ Brazil, ${ }^{257}$ and Thailand ${ }^{258}$ reveals low rates of engagement in HIV care, which often reflect structural and social barriers, including suboptimal health systems, privacy concerns, and violence. Whether for PWUD or others, WHO has recommended that ART in prison be given in a way that ensures confidentiality of the prisoner's HIV status and that treatment efforts take care to ensure continuity of treatment for prisoners who are transferred or released. ${ }^{152}$

\section{Access to TB prevention and care in prison}

Prisons are an extremely high-risk environment for tuberculosis, but prison TB services remain inadequate in many countries, making TB a risk of incarceration. The significant representation in prisons in many countries of people with HIV, people who use drugs, people living in poverty, 
and formerly incarcerated people means that many people in custodial settings have been exposed to TB before they even face the TB risks of prisons. ${ }^{144}$

WHO and UNODC recommend a range of measures to control TB in prison, including:

- "active case finding" including systematic offer of TB tests to all people in custody as well as monitoring of respiratory symptoms;

- case reporting to a central health authority;

- isoniazid preventive therapy for people living with HIV in prison, even in the absence of a positive TB test;

- treatment of TB and reliable linking to care in the community if the course of treatment is of longer duration than the custodial sentence;

- improvements in ventilation and sanitation;

- provision of TB information to people in custody; and

- offer of HIV testing for people testing positive for TB. ${ }^{239,259}$

TB testing does not take place systematically in many prisons. ${ }^{144}$ Among the many barriers to TB services is the fact that prison health services are often not managed by health ministries, which may compromise the quality and coverage of care in prisons and may impede ensuring continuity of care between prison and the community. ${ }^{234}$ Loss to follow-up of people receiving TB treatment in prison is also a major challenge. An estimated $60-70 \%$ of prisoners testing positive for TB in Eastern Europe are not referred to any care in the community upon release. ${ }^{260}$ Dara and colleagues also note that prisons in many countries have not invested in laboratory capacity to use the GeneXpert assay that WHO recommends for diagnosis but rather rely on less accurate tools. ${ }^{260}$ Collaboration between TB and HIV authorities and integration of interventions in the two areas is crucial for TB control in prisons but lacking in many places. ${ }^{259}$

Capacity to address HIV, HCV and TB in prisons, using the best medicines and diagnostic tools available in the community, is obviously dependent on financial resources. The Global Fund has been an important source of funding for HIV and TB interventions in prison, enabling previously unavailable services to be expanded in prisons, especially in EECA and sub-Saharan Africa. ${ }^{261}$ But many EECA countries have already become or soon will be ineligible for Global Fund 
support, ${ }^{108}$ and it remains to be seen whether governments or other donors will fund these services.

Even where services are available to people in state custody, delivering them in a patient-centred way is a particular challenge given the coercive nature of incarceration. Another central challenge is ensuring continuity of care upon release. Previously unpublished work in northern California by Commissioner Megan Comfort and colleagues illustrates that a lack of discharge planning and coordination of services virtually ensures the disruption of care. Among the 60 persons living with HIV in an in-depth qualitative study, many described being released from county jail around midnight. Although it was standard practice to provide a 30-day supply of medications at release, if people were discharged when the jail pharmacy was closed, they left with no medications at all. Furthermore, participants characterised leaving jail in the middle of the night as generally destabilising for them, especially when public transportation was not running. The feeling of being sent back out onto the streets without even the most basic means of "reentering" the community encouraged people to immediately seek comfort in familiar activities, such as drug use, rather than wait for daylight to take the uncomfortable steps of seeking services on their own.

The importance of continuity of care is illustrated quantitatively using data from the US and Canada reported by Iroh and colleagues (Figure 20). ${ }^{262}$ These authors conclude that testing and treatment can be achieved for people in prison, even at higher rates than in the general population, but that without attention to links to care after release, treatment interruptions are likely and may have serious health consequences. ${ }^{262}$ A PAHO report on HIV services in the Caribbean also concludes that for the large prison populations in that region, ensuring HIV services in prison is less challenging than making reliable links to care in the community for those leaving prison. ${ }^{263}$

\section{[FIGURE 20 HERE]}

From Iroh et al., 2015. ${ }^{262}$

\section{Drug policy and death from overdose}


Drug overdose should be an urgent priority in drug policy and harm reduction efforts. Overdose can be immediately lethal and can also leave people with debilitating morbidity and injury, including from cerebral hypoxia. A 2013 systematic global review concluded that overdose was a leading cause of mortality of PWID in all regions. ${ }^{264}$ In 2014, WHO estimated that about 69000 people worldwide died annually from opioid overdose, ${ }^{265}$ but that estimate may not have captured the dramatic increase in opioid overdose deaths especially in North America since 2010. In the European Union, drug overdose accounts for $3 \cdot 4 \%$ of deaths among people aged 15 to 39 years. $^{75}$

Data on overdose are not systematically reported in many countries, but survey data in a number of countries indicate that nonfatal overdoses are not rare events among PWID. For example, 75\% of a sample of about 600 PWID in Saint Petersburg, Russian Federation, indicated that they had experienced at least one overdose. ${ }^{128}$ Amongst about 900 men who injected drugs in Vietnam who were followed for two years, overdose was the second-highest cause of death after AIDS. ${ }^{266}$ In Bangkok, amongst over $2400 \mathrm{HIV}$-negative people who injected drugs who were followed for an average of four years, overdose was the leading cause of death, far above traffic accidents. ${ }^{267}$

In 2014, WHO issued its first guidance on community management of opioid overdose, underscoring evidence accumulated over four decades of the effectiveness of naloxone in averting death from opioid overdose. ${ }^{265}$ Naloxone (n-allylnoroxymorphone) is an opioid antagonist that can reverse the clinical manifestations of overdose essentially by displacing other opioids from the brain's opioid receptors. ${ }^{265}$ Naloxone can be administered without highly specialized training, and it has no record of being diverted to non-medical use. Naloxone administration by police or emergency medical teams as well as by organizations providing services to people who use drugs has been documented to avert many thousands of deaths. ${ }^{265}$

The literature suggests there are a number of ways in which pursuit of drug prohibition can exacerbate overdose and the risk of death from overdose. These include:

- barriers to access to OST and other treatment for opioid dependence; - lack of control over strength, toxicity, and adulterants of street drugs; 
- policing that increases overdose risk;

- overdose vulnerability linked to incarceration and/or abstinence-based detoxification;

- bans on supervised injection sites;

- lack of use of anti-tampering packaging and other measures for controlled medicines;

- barriers to access to availability and use of naloxone.

Treatment for opioid addiction and overdose: Overdose risk has been linked to lack of access to treatment for dependence on opioids, including for people using prescription opioids. ${ }^{265}$ Van Amsterdam and van den Brink conclude that the lower use of prescription opioids in the Netherlands - and thus the lower risk of overdose associated with that use - is because over $75 \%$ of those who need it have easy access to OST, compared to about 30\% in the US. ${ }^{268}$ It is undoubtedly also the case that over-prescription of opioids in the US figures in the bleak overdose picture, a problem that must be addressed without curtailing access to opioid medicines for legitimate use. ${ }^{21}$ The long history in France of OST dominated by buprenorphine and more recent experience in New York suggest that buprenorphine may be particularly useful for overdose prevention in some populations. ${ }^{269,270} \mathrm{~A}$ well documented experience in Glasgow in the early 1990s suggested that treatment for opioid dependence dominated by buprenorphine kept overdose rates low. ${ }^{271}$

Vulnerability to overdose is very high when people are released from abstinence-based detoxification and residential programmes or if they are abruptly dropped from medicationassisted maintenance therapies. ${ }^{265}$ In this regard, the practice of institutions such as some drug treatment courts to force people to abandon OST after an arbitrary period without reference to medical need may contribute to overdose risk. ${ }^{272}$

Adulterants and toxicity of street drugs: In recent years, heroin sold on the street in North America and Europe has been found to contain anthrax, fentanyl, and benzodiazepenes in addition to more benign additives such as caffeine and sugar. ${ }^{273}$ Fentanyl marketed as heroin has also been associated with lethal overdoses in some countries. ${ }^{274}$ Part of the advantage of prescribed and medically administered heroin as treatment for opioid dependence in Switzerland, Germany, and several other countries, for example, is the health authority's ability to control and 
know the dosage and purity of the heroin prescribed. Countries that pursue the goal of drug prohibition may object to heroin-assisted therapy as feeding rather than eliminating an addiction. $^{275}$

Policing and overdose risk: Policing and police crackdowns can add to the risk of overdose. When police pressure leads to injecting hurriedly without testing the strength of drugs, overdose risk increases. ${ }^{140}$ Crackdowns that cause people to inject in remote locations far from emergency services may also increase overdose risk. In countries where drug use itself is criminalised, people experiencing overdose may not seek emergency help if it comes in the form of police with authority to arrest them. A study in New York City found a strong correlation between police activity and overdose deaths, which the authors suggested was due to the reluctance of people who injected drugs to seek help for fear of arrest. ${ }^{276}$ Lunze and colleagues similarly found in Saint Petersburg that rate of drug arrests as a proxy for intensity of policing was associated with experiencing non-fatal overdose amongst PWID. ${ }^{128}$

Incarceration and overdose: Multiple studies confirm that the period soon after release from prison is a time of very high overdose risk. ${ }^{265}$ Men in the first two weeks after their release from prison were 29 times more likely to die than men of the same age in the general population, and women in the first two weeks after release were 69 times more likely to die than their counterparts in the general population. ${ }^{277}$ Tackling this problem requires concerted effort to ensure that people are linked to services, including access to naloxone and OST, as soon as they are released. ${ }^{265}$

Overdose and supervised injection sites: The EU drug monitoring agency (EMCDDA) notes that supervised injection sites (SIS) in eight European countries have been important in reducing overdose deaths. ${ }^{278}$ SIS enable people to inject in the presence of health professionals who can provide assistance in the case of overdose. Between 2004 and 2010, for example, the SIS in Vancouver, Canada, witnessed 778 overdoses among people using the site, but there were no deaths. ${ }^{279}$ A 2011 study published in the Lancet found that overdose deaths declined by $35 \%$ in the area around Vancouver's SIS within just two years. ${ }^{280}$ In addition to their health benefits, 
there is no evidence from research on SIS that they are linked to initiation of new drug use, more frequent injection, or a rise in crime. ${ }^{278,281-283}$

Anti-tampering measures for prescription opioids: Pharmaceutical technology has made possible a range of formulations and packaging of prescription medicines, especially opioids, that are designed to reduce the possibility of non-medical use of these medicines and overdose. These include formulations that are resistant to crushing, chewing, smoking, dissolving and injectability; extended-release formulations; addition of naloxone or other aversive ingredients to the formulation; and formulations that chemically isolate the active form of the opioid. ${ }^{284,285} \mathrm{In}$ the US state of Florida, a policy change requiring the use of a tamper-resistant formulation of the widely used opioid oxycodone was associated with a significant decline in oxycodone overdose. ${ }^{286}$ Some other studies had more equivocal results, and some experts caution that tamper-resistant formulations may create a false sense of security and contribution to overpresciption of opioids. $^{287,288}$

Factors impeding access to and use of naloxone: Advocates for improved health services for PWUD have long asserted that naloxone should be widely available, even without a prescription. But naloxone remains out of reach in many places because of tight legal and regulatory restrictions. Part of the challenge in some jurisdictions is that physicians fear legal liability in prescribing naloxone, just as people who may witness an overdose and be in a position to assist may fear legal liability in administering naloxone if something goes wrong. ${ }^{289}$ Bystanders who have used drugs may also be reluctant to contact the police or medical emergency personnel for fear of being arrested themselves. ${ }^{290}$

In many countries, PWID fear health services but may frequent pharmacies for injection equipment and other supplies. For this reason, Hammett and colleagues investigated possibilities for naloxone provision in pharmacies in the Russian Federation, Viet Nam, China, Canada, Mexico, and the US. They found a variety of legal barriers and practices. Even where naloxone can be prescribed by any physician, it was unlikely to be stocked in pharmacies but rather supplied directly to emergency personnel under so-called standing orders. ${ }^{291}$ In the Russian Federation, where the need is great, naloxone could be supplied to and administered only in health facilities at the time of this study. Similarly, in China only health facilities could receive 
and use naloxone. ${ }^{291}$ Media reports indicate that a programme of the province of Ontario, Canada to improve availability of naloxone, including the purchase of 1800 doses, was stopped in 2013 because of unspecified regulatory problems. ${ }^{292}$

Since the study by Hammett and others, there have been some positive changes in the US. As of July 2015, facing increasingly visible overdose problems, 31 of the 50 states plus the District of Columbia had passed 'Good Samaritan' laws to enable people to provide assistance in the case of overdose, including using naloxone, without legal liability for the outcomes. ${ }^{289}$ Some 40 states have made it easier for physicians to prescribe naloxone for use in responding to overdoses without legal repercussions. In addition, as of 2015, 14 US states have authorized over-thecounter - that is, non-prescription - sale of naloxone in some pharmacies to some first responders or family members. ${ }^{293}$ In 2015 a bill was introduced in the US Congress that would enable federal support for greatly expanded access to naloxone. ${ }^{294}$

\section{Treatment for drug dependence: the need for standards}

\section{Compulsory detention for 'treatment'}

A small minority of people who use drugs develop drug dependence. But in many parts of the world, many PWUD are assumed to have problematic use or to be criminals, and compelling them to undergo drug treatment is a widespread practice.

In addition to the vast use of incarceration through criminal justice systems in the pursuit of drug prohibition, in some countries there is large-scale extrajudicial detention of drug offenders in the name of "treatment" or "rehabilitation". In China, Cambodia, Viet Nam, Lao PDR, Malaysia, Thailand, and Indonesia, compulsory "treatment" centres hold thousands of people who are detained generally without due process, for the most part without valid assessments of whether they are drug-dependent, without access to scientifically sound treatment of any kind, and offering 'treatment' that sometimes consists of forced labour and cruel and demeaning punishment. ${ }^{295,296}$ In March 2012, 12 UN bodies denounced these centres on public health and human rights grounds and called for their closure, ${ }^{297}$ but most continue to operate. Human Rights Watch did ground-breaking from 2008 to 2013, documenting heinous human rights abuses in 
these centres - including many forms of forced labour, torture, beating, humiliation and degradation, and denial of basic health care and adequate sanitation and food. ${ }^{295}$ (See web appendix VIII for a longer description.)

Compulsory drug detention centres are extreme in the scale and nature of abuses committed in the name of treatment, but there are many other examples of abusive and scientifically unsound practices brought to bear to address drug dependence. In many countries, treatment of drug dependence is one of the most unregulated and unmonitored of all health services, left often to private actors not required to adhere to standards of quality and clinical soundness. ${ }^{298}$ There is no systematic monitoring of drug treatment practices by $\mathrm{UN}$ or regional multilateral bodies. Though there are general recommended standards and position papers from the $\mathrm{UN},{ }^{299}$ there are no agreed quality-control standards approved by UN member states.

A few researchers have documented cruel and inhuman practices in private-sector drug "treatment" operations in countries in Asia, Eastern Europe, Latin America and North America. ${ }^{298}$ Some examples of abusive practices include the following:

- Coercion to enter treatment, with or without the help of local police. In the Russian Federation, there are cases of family members colluding with treatment facilities effectively to abduct people and deliver them to treatment centres. In Guatemala, church-affiliated centres organize "hunting parties" sometimes made up of current patients, to take people who are inebriated into treatment without informed consent. ${ }^{300} \mathrm{O}$ 'Neill's in-depth studies of centres in Guatemala document cases of people living in squalid conditions, being mocked, derided, beaten, tied up, and left to scream for help, sometimes not even understanding how they arrived at the facility. ${ }^{300}$

- Some private treatment facilities lock people up and even chain them to beds or trees without offering them any means of challenging or appealing involuntary commitment. The danger of chaining of people to their beds in drug 'rehabilitation' facilities was graphically illustrated in Moscow in 2006 and twice in Lima, Peru in 2012 when fires struck the facilities, and patients were killed because they could not flee. ${ }^{301}$ Both HRW ${ }^{302}$ and the UN Special Rapporteur on torture $^{303}$ documented horrific conditions in 'prayer camps' in Ghana in which people were 
chained to beds and trees, held sometimes for over a year, and required to fast and to undergo exorcisms.

In Nigeria, young people report abusive behavior by the police, in some cases when they are taken to facilities that are meant to offer health services. (See web appendix IX.)

\section{Access to drug dependence treatment and drug policy}

Lack of or curtailed availability of OST using methadone, buprenorphine or other opioids, discussed above, is a public health concern not only for reduction of injection and thus of HIV risk but also because of OST's effectiveness and cost-effectiveness for treating opioid dependence. ${ }^{126}$ It is backed by more than 50 years of extensive practice and an enormous body of research including several meta-analyses and large reviews in many settings. ${ }^{304,305}$

Decades of research on OST have helped to inform consensus on treatment standards and good practice. In the European Union, for example, nearly all countries have OST minimum standard and quality-of-care guidelines, though they often do not have such guidance for treating nonopioid dependence. ${ }^{306}$ National guidelines cover elements of care such as dosage levels, criteria for judging whether take-home doses can be given and for how long, use of urinalysis as part of treatment, certification of health professionals as OST specialists, the need to give priority in care to pregnant women, and in some countries elements of integrating OST in general practice and primary care facilities. With regard to dosage, there are many controlled studies and research reviews indicating that higher doses of methadone in OST programmes are associated with better retention in and outcomes of treatment as well as lower likelihood of use of illicit drugs. ${ }^{307-311}$ Nonetheless, based on its monitoring of national policies and practices, WHO has found it necessary to remind national authorities that adequate doses in OST are essential practice in spite of drug control concerns and that lowering doses of methadone as a punishment for drug use or breaking programme rules is not acceptable, even in prison. ${ }^{126,312}$ Switzerland's remarkable experience with one of the historically most rapid expansions of OST in history (discussed further below) exemplifies how reforming drug policy to be more centered on health outcomes and less centered on policing can facilitate the establishment of best practices in OST. $^{313}$ 
In a number of European countries and Canada, OST is complemented by heroin-assisted therapy (HAT) usually for the limited number of people with long-time use for whom other medication-assisted therapies have not had the desired results. ${ }^{275}$ HAT programmes are well received in Germany and Switzerland, for example, where it is recognized that, like methadone therapy, they enable people to stabilise their cravings without having to rely on street drugs of unknown quality and toxicity from illicit dealers. ${ }^{314}$ The HAT trial in Montreal and Vancouver, Canada, in spite of excellent results, was discontinued by the Conservative-led government in 2013 with the pronouncement that HAT was “in direct opposition to the government's anti-drug policy." 315 A 2014 court decision, however, allowed patients already receiving HAT to continue doing so. ${ }^{316}$

A substantial body of research, mostly from the Global North, includes several meta-analyses and large evaluations of drug dependence treatment investigating these factors. ${ }^{317}$ There are many methodological challenges in this work, including that measurement of the costs associated with drug-related crime and productivity losses is not always straightforward, accounting for relapse is tricky, and there are not good data on some of these elements in many countries. ${ }^{317}$ Nonetheless a number of studies indicate that the costs of crime reduction alone more than offset the costs of treatment, in some cases several times over. ${ }^{318,319}$ Two studies from China calculated high returns from OST based largely on the economic benefit from averting HIV transmission. 320,321

Options for treatment of dependence on many types of psychoactive drugs are very limited and remain a challenge for addiction science. Research on new treatments for dependence on stimulants, including amphetamine-type stimulants and cocaine, has been called for by health professionals for some time, particularly medication-assisted treatments that would be the analogue of OST for opioids. ${ }^{322}$ Some studies suggest that drug dependence treatment is most effective when combined with support for stable housing, food assistance, employment assistance, and other social services. ${ }^{317}$ The poor track record of some forms of treatment without attention to these social services suggests that public funding priorities should include social services linked to treatment. ${ }^{323}$ 
There remain many gaps in access to and affordability of care for those who need it. The annual report of UNODC regularly documents drug seizures and drug crop production but only for the first time in 2015 reported information from UN member states on availability of treatment for drug dependence. The information from countries reflects only the existence of services and a rough estimate of the level of coverage (low, medium, high) and says nothing about quality. ${ }^{7}$ Even so, as shown for psychosocial treatment methods in Figure 21, the data reveal wide regional disparity in availability of services. Cognitive-behavioral therapy, for example, is frequently recommended to treat dependence on stimulants for which there is not currently a consensus recommendation for medication-assisted therapies. But it is virtually unavailable in Africa and much less available in Asia and the Americas than in Europe. A 2013 estimate concluded that $80 \%$ of the people needing treatment for substance abuse live in lower-income and middle-income countries, but the proportion of those receiving care in those countries is more like $20 \%{ }^{324}$

\section{[FIGURE 21 HERE]}

From UNODC, World Drug Report, 2015. ${ }^{7}$

Drug dependence can be impoverishing, and treatment of it can be expensive. Subsidized treatment slots may be scarce and waiting lists long, even in countries with well-developed health systems, as in Western Europe and Canada. ${ }^{315,325}$ In the US, realizing the promise of the Affordable Care Act (ACA) to expand health insurance coverage for drug dependence-related services for millions unable to afford them before ACA has been hampered by lack of human resources to expand care and lack of integration of these services with other federally qualified health services. ${ }^{326}$

\section{Women and drug dependence treatment}

In many countries, women are particularly disadvantaged by the lack of access to good-quality, affordable treatment for drug dependence that is tailored to their situations and needs. Policy discussions about women's access to treatment for drug dependence surface most readily in some places with respect to pregnant women and concerns about the well-being of newborns - the 
"innocent victims". But it is women's own concern about retaining custody of their children that may stand in the way of seeking treatment. In EECA, for example, women in some countries would be justified in fearing that just the act of seeking treatment would brand them as users in official drug registries, which could trigger loss of child custody in some circumstances. ${ }^{327}$ In other countries, even where there are not formal drug registries, drug use may figure prominently in child custody decisions by state authorities as women who use drugs are likely to be seen as unfit parents. ${ }^{328,329}$ A 2004 UNODC report noted that there were still some places where by law women who are found to use drugs could be incarcerated for their entire pregnancy and sometimes longer. ${ }^{330}$ Any such factors, including stigma on the part of health service providers, can inhibit women's seeking of treatment services.

Pregnant women who use drugs are often confronted with concerns about their newborns that are not scientifically sound. An example is the demonisation, assisted by mass media, of women who used crack in the United States in the 1980s and 1990s who were accused of producing a generation of mentally deficient 'crack babies'. ${ }^{3}{ }^{31}$ Long-term longitudinal studies demonstrated that exposure to crack during pregnancy did not significantly affect cognitive outcomes of children in later life and that other factors associated with poverty were probably more important determinants. ${ }^{332}$ Myths and exaggerations have also persisted about opioid dependence among neonates, including about infants born to women who are OST patients, in spite of research showing that neonatal abstinence syndrome related to opioids can be cured and does not have long-term effects on children. ${ }^{333}$ In protesting widespread media reports in 2013 about "opiateaddicted babies" born to OST patients, 40 prominent physicians and scientists from Europe and the US asserted that "demonizing pregnant women creates an environment where punishment rather than support is the predominant response, and will inevitably serve to discourage women from seeking care. ${ }^{334}$

Health experts lament the lack of drug treatment services tailored to women's needs. ${ }^{187,327}$ Drug treatment services are rarely integrated with reproductive health, pediatric and other services that women may seek. ${ }^{335}$ Child care may not be available in drug clinics, or children may simply not be allowed on the premises. A global review by a UN-convened group of experts in 2010 concluded that treatment programmes for women rarely account for the differences between men 
and women in the speed with which they may develop drug dependence, their responses to varied forms of treatment, and the psychological co-morbidities with which they present. ${ }^{335}$ These experts concluded that women in drug treatment are more likely to be suffering from anxiety, depression, suicidal thoughts, and deep guilt than their male counterparts, and much more likely to be the main caregivers of dependent children. ${ }^{335}$

Numerous countries have established special drug treatment courts, which are generally meant to offer court-supervised drug treatment to as an alternative to incarceration for some categories of drug offenses. Emerging evidence raises concerns about some of these models. (See web appendix X.) Many drug courts as well as other treatment providers use drug testing, not always in rights-based ways. (See web appendix XI.)

\section{Drug control policy and access to controlled medicines}

The Single Convention on Narcotic Drugs of 1961 has the dual purpose of (1) ensuring that controlled substances, including opioids, are available for medical and scientific purposes and (2) preventing their misuse and diversion. However, after more than 50 years under this regime, some $75 \%$ of the world's population or about 5.5 billion people do not have safe and adequate access to controlled medicines for the management of pain, including post-operative pain and the severe pain associated with cancer, burns, fractures, and other causes. ${ }^{336}$ For example, $92 \%$ of morphine use is in countries that account for $17 \%$ of the world's population, mostly in the Global North. ${ }^{336}$ Inequity of access to controlled medicines for pain management and other clinical uses is now a public health and human rights crisis.

WHO explicitly highlights the role of drug control policy as a barrier to access to licit controlled medicines:

...[T] he drug control conventions that established the dual obligation of ensuring adequate availability of controlled medications and of preventing their misuse have existed for almost 50 years. Yet the obligation to prevent abuse of controlled substances has received far more attention than the obligation to ensure their adequate availability for medical and scientific purposes, and this has resulted in countries adopting laws and regulations that consistently and severely impede accessibility of controlled medicines. ${ }^{337}$ 
WHO notes that national drug legislation often "includes provisions stricter than the international drug control conventions require." 337 The health agency urges countries to "examine their drug control legislation and policies for the presence of overly restrictive provisions that affect delivery of appropriate medical care involving controlled medicines" and make needed reforms. ${ }^{387} \mathrm{WHO}$ also enjoins countries to ensure that drug-related decisions that are "medical in nature should be taken by health professionals". 337

There are numerous ways in which drug control policy and regulations exceed the measures recommended in the $\mathrm{UN}$ drug conventions and contribute to impeding access to and utilisation of controlled medicines ${ }^{337,338}$ (Table 2).

Inappropriate regulatory language, emphasizing "abuse" or "misuse" to describe long-term use of controlled medicines, can affect attitudes and stigmatise these medicines and their use. ${ }^{337}$ Certain national drug laws and regulations refer to controlled medicines as "poisons" or "dangerous drugs." ${ }^{339}$ WHO warns against laws that suggest incorrectly that "a patient requiring increasing doses of an opioid for pain relief because of pharmacological tolerance due to prolonged treatment" is drug-dependent. ${ }^{337}$ Poor knowledge of addiction medicine in the medical community can lead to propagation of such misunderstandings. In India, for example, the law includes a definition of an "opioid addict" but does not include distinct definitions for a patient receiving prescribed opioid medicines of a drug-dependent person who is undergoing treatment, leading to stigmatising characterisations of these persons. ${ }^{340}$

Striking a balance in national policy between maintaining adequate access to and availability of controlled medicines and retaining strong measures to prevent diversion or misuse is an important goal. Among the measures that countries should take to strike this balance, international bodies, including $\mathrm{WHO}^{337}$ and the Global Commission on Drug Policy, ${ }^{341}$ recommend the following:

- Establishing a national authority for controlled medicines that enables health-care and law enforcement interests to be represented equally in policy-making and procedures; 
- Ensuring that laws and regulations recognize that controlled medicines are essential for a wide range of medical conditions and guarantee people's right to have access to them;

- Ensuring competence of health professionals on the latest science of use of controlled medicines; and

- Monitoring to recognize and define points of high risk for misuse and diversion within the distribution system, and refining policies to address these specific points without undermining access to and availability of controlled medicines.

Balanced policy on controlled medicines has been difficult to achieve in many countries in all regions of the world. India, for example, is a major producer and exporter of opium destined for medical and scientific use. ${ }^{342}$ Ironically, $97 \%$ of patients in pain in the country do not have access to opioid analgesics. ${ }^{343}$ The chief barrier was the Narcotic Drugs and Psychotropic Substances (NDPS) Act of 1985, which required hospitals and pharmacies to procure and maintain five or six time-bound licenses from distinct state-level bureaucratic agencies. ${ }^{344}$ Punitive consequences were very severe for even minor clerical errors. This led most institutions to refrain from stocking and dispensing opioids to avoid the legal complexities and punitive consequences. ${ }^{344}$ For decades health-care professionals went through their training programmes without gaining skills in using opioids as medications; opioids were not stocked or used even in medical schools. Opioid consumption fell by $97 \%$ in the first decade of enactment of the law. ${ }^{344}$

But changes are under way in India. A civil society alliance, driven by the health and humanitarian need, helped to spearhead a 2014 amendment to the NDPS Act, which reoriented the law, incorporating simplified procedures for improving access and availability of opioid medications in the country. ${ }^{342}$ The reformed policy also incorporates processes supporting opioid substitution therapy as medication-assisted treatment for managing drug dependence, expanding possibilities beyond abstinence-based treatment. ${ }^{342}$ Such reforms along with country-wide efforts on training of health-care professionals on use of opioids based on the WHO guidelines, is expected to counteract historical demonization of opioids and opioid users in several countries. Nonetheless, practices cannot change overnight. Sustained advocacy and reorientation of training and research is called for. ${ }^{342}$ 


\section{Assessing the public health risk and clinical value of controlled substances}

The challenge of ensuring adequate access to controlled medicines is related closely to the way in which international and national authorities assess the degree of danger or potential harm associated with specific substances. For the international regime, the Single Convention (article 3) explicitly confers on WHO the responsibility to judge whether substances are dangerous and in need of strict control. ${ }^{6}$ The 1971 convention emphasizes in its article 2 that the CND should regard WHO's assessments on drugs to be "determinative as to medical and scientific matters." 345

Like many national laws, the international drug treaties establish a "scheduling" or ranking of substances by their degree of risk. Schedule IV substances in the 1961 Single Convention are judged to be the most risky, defined as substances deemed by the World Health Organization to be "particularly liable to abuse and to produce ill effects...not offset by substantial therapeutic advantages" (article 3(5)). ${ }^{6}$ Cannabis and cannabis resin, for example, are in Schedule IV. (The numbering of the schedule classifications in the 1961 convention is somewhat counter-intuitive. Schedule I also classifies substances as "liable to abuse" and without off-setting therapeutic value, but Schedule IV emphasizes for some Schedule I substances that they are "particularly" dangerous. Schedule III includes substances judged to be less "liable to abuse". The scheduling system of the 1971 drug convention on synthetic psychotropic substances is more straightforward, with Schedule I being the most restrictive and Schedule IV the least.)

Widely cited articles in the Lancet in 2007 and 2010 report on exercises in which drug dependence specialists in the UK ranked drugs by their potential to cause physical harm to the user, their potential to induce dependence, and their harms to families and communities. ${ }^{346,347}$ The authors compared the ranking of these experts with the scheduling of medicines in the drug conventions. For example, the experts deemed cannabis, LSD, and GHB to be less harmful than many substances though they are classified as "most dangerous" in the conventions. Alcohol, which was deemed more dangerous than many controlled substances, is obviously not scheduled in the conventions. A later assessment by addiction experts from across the European Union made a similar ranking. ${ }^{348}$ 
In the international drug conventions, $\mathrm{WHO}$ is mandated to oversee the application of the latest scientific evidence to the classification of the potential harms of psychoactive substances, but its conclusions are not always the last word on these issues. (See web appendix XII .)

\section{Research challenges in drug policy}

A large body of research has helped to advance many aspects of the drug policy debate. Opioid agonist therapy, for example, has benefited from decades of clinical research in numerous settings to the point where good practises are well documented and can be adopted and adapted readily. The benefits and cost-effectiveness of NSP and programmes to address opioid overdose are also supported by a strong research base that should inspire scaling up these programmes to reduce the needless morbidity and mortality suffered by millions because of the absence of these services.

The same is not true of empirical research on larger drug policy decision-making, including social science research on alternatives to traditional prohibition-oriented policy. In view of the rapid pace of cannabis legalization in Uruguay and the US, it would arguably have been useful to have the chance to test measures such as restriction of various forms of advertising, pricing and taxation strategies, and 'cannabis club' approaches vs. general population-based legalization. ${ }^{27}$ More social science research would also be useful to follow experiments in less harmful policing of drugs. ${ }^{137}$

Hall notes that funding research that would draw lessons on drug market regulation from alcohol and tobacco regulation, for example, has not been a priority of major research funders, especially compared to more abundant funding for neurological and clinical harms of drug use. ${ }^{349}$ The effectiveness of treating drug dependence depends on correct diagnosis of dependence and other disorders, which remains a matter of controversy in many respects and a subject of considerable research. Academic debates abound on the physiological and psychological basis for assessing drug-use disorders. A central debate, highlighted in a 2015 exchange in Lancet Psychiatry, is around the "brain disease" model of drug dependence ${ }^{349}$ Commissioner Carl Hart, who is a 
member of the Advisory Council of the US National Institute on Drug Abuse (NIDA), discusses this idea in an online appendix (section XIII)..

With cannabis having been the centre of drug policy reform discussions in North and South America and Western Europe, medical uses of cannabis are of great interest to researchers. Cannabinoids have been approved for medical use in numerous jurisdictions and have been the object of enough research to warrant systematic reviews and meta-analysis. ${ }^{350,351}$ The 2015 review by Whiting, et al, supports the use of some cannabinoids to address neuropathic pain and spasms. ${ }^{350}$ At this writing, the evidence is somewhat less plentiful on medical uses of the cannabis plant. Both a 2015 review by Deshpande ${ }^{351}$ and an analysis by Madras undertaken for the WHO Expert Committee on Drug Dependence ${ }^{352}$ concluded that while there are many reports of benefits from medical cannabis users, there is a need for more controlled studies. The Expert Committee itself undertook to collect more evidence on medical use of cannabis and cannabis resin for a future comprehensive review. ${ }^{353}$

There is also a need for research on the health impact of different patterns recreational use of cannabis - research that should be greatly facilitated by the availability of legal cannabis in more and more locations. ${ }^{354}$ At least in the US, however, there remain obstacles to expanding this research. ${ }^{355}$ Restrictions impede research both on the health effects of medical and recreational cannabis use and also on the important drug policy question of whether cannabis availability influences the use of other legal and illegal substances. At a time of enormous policy-level concern about dependence on prescription opioids, for example, there are a few ecological studies that suggest the possibility that greater access to cannabis might reduce use of opioids for pain relief. ${ }^{356,357}$ This is a question that richly merits controlled studies with human subjects.

In 2002, the United Nations established a Reference Group on HIV and Injecting Drug Use that both advised the UN system on programmes and policies related to HIV amongst PWID and also was involved in generating independent research on HIV and drug use. ${ }^{358}$ Some of the work cited in this report came from this group, ${ }^{335}$ as well as other thematic works on methamphetamine use and HIV and prescription opioid use and HIV 359,3610 and global reports on patterns of HIV transmission and prevalence amongst PWID and HIV services for PWID. ${ }^{361-363}$ In our view, the 
Reference Group served an important research function, particularly in helping to keep independent, high-quality research on drug use and health in the public sphere. The Reference Group no longer meets as an independent body. We believe its job is not done, and it, or something like it, would be very valuable to reconstitute.

In some countries, there is a dearth of data on fundamental elements such as the extent and nature of drug consumption. Nigeria is undertaking one of the continent's first population-based surveys of drug use with support from the European Development Fund. ${ }^{364}$ The survey is meant, among other things, to serve as a baseline for measuring progress of the improved services for people who use drugs that are also planned.

Respected scholars who have endeavoured to bring the best new research to drug policy decision-making have sometimes been attacked for their efforts. For an example from Vancouver, Canada, see the web appendix XIV.

\section{Drug crops, drug policy and health}

People may become involved in drug markets for many reasons, but poverty and exclusion from mainstream economic opportunities are important factors in many cases. Nonetheless, it is rare that drug policies are evaluated by the way that they affect people living in poverty or human development more broadly. ${ }^{13}$ In this report, we highlight the situation of people whose livelihood depends on growing crops used to make psychoactive drugs as an example of neglected health and human security issues at the intersection between drug control and development (see web appendix XV).

\section{Drug crop production flourishes in spite of risks}

Enforcing prohibition-oriented drug policy means not only policing use, possession, and sale but also terminating the supply of these drugs at the sources. Historically the obligations of obligations of international drug control have rested heavily on states in South America and Southeast and Southwest Asia to curb supply of coca leaf, opium poppy, and cannabis, rather than consumer countries of the North to reduce demand. ${ }^{365}$ The Single Convention of 1961 prohibits the cultivation of coca leaf, opium poppy and cannabis for anything other than 
scientific or medical purposes. ${ }^{6}$ The focus on eradicating these crops, including through the militarised means implied in the term 'drug war', persists despite the strong growth of synthetic drug manufacture and use, which now dominates drug supply and consumption. ${ }^{365}$

In spite of aggressive prohibition, these crops nonetheless are widely grown. Cultivator communities are typically located in regions or countries where basic state services are deficient and where there is an absence of health services and infrastructure. In 1998 UNODC estimated that some 4 million persons were in households deriving income from cultivation of coca leaf and opium poppy (without attempting an estimate for cannabis), ${ }^{8}$ and there is little reason to suppose that the figures today are smaller. Decades of investment in initiatives to eradicate these crops have failed to make a sustained dent in global production. Figure 22 shows estimated production of opium poppy destined for non-medical use from the countries that account for the great majority of production. ${ }^{366}$ In Afghanistan, the principal producer, opium poppy production in 2012-2013 was two and a half times the level of 2000. ${ }^{367}$

Motivations for relying on drug crops for household income may differ, but the decision to grow drug crops is generally highly rational. Opium and coca are non-perishable, robust crops, well suited to the poor agricultural conditions in which farmers in coca, poppy and cannabis-growing areas often find themselves. ${ }^{368,369}$ Extensive cannabis cultivation in the Rif region of northern Morocco, for example, provides the livelihood for hundreds of thousands of people where the mountainous and arid terrain would permit few other crops to thrive and transporting perishable goods would be difficult. ${ }^{370}$ Drug crops have high value for the amount of labor they require, and the market for these crops is, in spite of illegality, relatively reliable. ${ }^{368}$

\section{[FIGURE 22 HERE]}

From UNODC, Southeast Asia opium survey, 2014. ${ }^{366}$

Another important factor that may influence the decision to grow drug crops is insecurity of land tenure or lack of access to land. Coca bush, for example, produces four to six crops per year after only six to eight months of growth of new bushes ${ }^{371}$ whereas coffee and some fruits, for example, require a longer growth period before there is revenue.. Opium poppy yields returns 
after a short growing period and requires few inputs. In Afghanistan, according to Mansfield and Pain, poppy growing has at times enabled poor farmers to arrange land tenancy or sharecropping that would be impossible without the effective credit-worthiness that comes with poppygrowing. ${ }^{372}$

In the Andes, rural households have persisted in coca production in spite of herculean efforts to cut them off from this source of livelihood. Forcible eradication of coca - through burning, use of chemical herbicides or manual deracination - has been part of drug supply reduction strategies for decades. ${ }^{50}$ It has been encouraged by massive infusions of US funds particularly to support aerial spraying of enormous areas of the Andes with herbicides. Under Plan Colombia (20002012), an average of 128,000 hectares per year in Colombia alone were subjected to aerial spraying of glyphosate - a product also known under the Monsanto brand name of Round-Up. ${ }^{373}$ Despite enormous investments in the aerial spraying program in Colombia, impact evaluations show that this is a very ineffective and costly strategy in reducing coca cultivation. Mejía and coauthors show that in order to eliminate 1 hectare of coca crops, 30 hectares need to be sprayed, at a cost of about $\$ 80000$ per hectare eliminated (the market value of coca leaf in one hectare is about $\$ 400) .{ }^{369}$

Coca production patterns since the 1990s illustrate the so-called 'balloon effect', as shown in Figure 23. That is, as eradication efforts intensified in one place, cultivation moved elsewhere. For example, under the US-supported program Plan Colombia, over US \$1.2 billion per year in the period 2006-2011 - more than 1\% of the GDP of Colombia - was spent on aggressive eradication of coca in Colombia. ${ }^{50}$ As coca production declined in Colombia after 2006, it increased in Peru and Bolivia as producers moved (and in some cases moved back) to those locations, and cocaine processing facilities also moved to neighboring countries. ${ }^{50}$ In its 2014 survey of coca production, UNODC noted that in addition to simply moving, coca producers have found various means of combating aerial spraying, including interspersing and rotating their coca bushes with other crops to avoid detection, planting in remote areas less likely to be detected, washing the leaves, putting molasses or other substances on the leaves to counter the herbicide, and isolating the leafy part of the plant from the herbicide. ${ }^{366,374}$ 


\section{[FIGURE 23 HERE]}

From UNODC and Plurinational State of Bolivia, 2015; $;^{375}$ UNODC and Government of Colombia; ${ }^{376}$ UNODC and DEVIDA (National Drug Commission of Peru), 2015 $5^{377}$

Growing drug crops, then, may be rural households' strategy to confront many forms of marginalisation - lack of secure land tenure, lack of access to credit, poor transportation infrastructure, hostile agronomic conditions, and lack of other opportunities in the mainstream economy. The mentality of drug prohibition, however, is to dismiss this complexity of people's decision-making and see drug crop producers simply as profit-motivated criminals.

\section{Health impact of crop eradication}

The health impacts of crop eradication have been relatively little studied. While the US provided high levels of assistance for the mobilization of the needed aircraft, contractors, and herbicide supplies, rigorous and independent evaluation of the health and social impact of aerial spraying were not a priority of Plan Colombia. In 2005, the drug policy arm of OAS, known as CICAD (Comisión Ineramericana para el Control del Abuso de Drogas, or Inter-American Drug Abuse Control Commission), undertook an investigation of the health and environmental effects of glyphosate spraying in Colombia. The study concluded that there were no significant risks to human health from the aerial spraying and that spraying was much safer than the alternatives of burning coca in farm fields or manual deracination of the plants. ${ }^{378}$ The study was widely criticised by civil society groups, which noted that by this time the government of Colombia had received thousands of complaints of health problems associated with spraying, which were not taken into account by the CICAD researchers. ${ }^{379}$

Numerous complaints of health problems associated with aerial spraying were made to human rights bodies and other authorities over the years. ${ }^{380}$ In 2008, Ecuador filed a case with the International Court of Justice alleging that Ecuadorians living near the border with Colombia were suffering ill effects of glyphosate spraying, including "burning, itching eyes, skin sores, intestinal bleeding and even death," with children especially affected. ${ }^{381}$ Ecuador requested that Colombia limit its spraying to at least 10 kilometers away from the border. The case was settled in 2013 before the International Court was to hold final hearings on the matter. Colombia 
reportedly provided compensation for damages to people and livestock and agreed to a buffer zone of no spraying near the border. ${ }^{382}$

In 2015, the International Agency for Research on Cancer (IARC) of WHO undertook a review of animal and human studies and classified glyphosate as "probably carcinogenic to humans." 383 This classification is used by IARC "when there is limited evidence of carcinogenity in humans and sufficient evidence of carcinogenity in experimental animals" (emphasis in original). ${ }^{384}$

Investigators at the Universidad de los Andes undertook research using a large data set capturing millions of individual records of medical consultations among people affected by unannounced incidents of spraying in the heart of the period of intensive spraying from 2003 to $2007 .{ }^{373}$ These data included multiple observations for given individuals, providing something of a control over individual characteristics such as baseline health. The authors also had daily data on the level of spraying in all the municipalities in Colombia.

Exposure to aerial spraying was significantly associated in this large sample with increased incidence of dermatological and respiratory symptoms in the 15 days following exposure to the herbicide. ${ }^{373}$ It was also highly significantly related to incidence of miscarriage, as shown in Table 3 with an estimated one standard deviation increase in aerial spraying associated with a 10$15 \%$ increase in miscarriages amongst women exposed to the herbicide during pregnancy. The relationship between spraying and miscarriages was somewhat stronger in low-income communities but also highly significant in higher-income municipalities. ${ }^{373}$ The effects of aerial spraying on miscarriages are greater in municipalities with positive levels of spraying between 2003 and 2007, and for the non-migrant sample of women exposed to aerial spraying.

\section{[Table 3 HERE]}

Signaling an end to over 20 years of the practice, in May 2015 the government of Colombia decided to stop using aerial fumigation of coca fields. ${ }^{387}$ The decision came on the heels of the IARC report on glyphosate and also followed a recommendation to cease glyphosate spraying by the Colombian minister of health. 
With respect to coca eradication and other forcible crop eradication programmes, the effects of exposure to herbicides are far from the only health concern. Farm households in the Andes have complained that aerial spraying and some other eradication activities have affected food crops or food from animal husbandry on which they are also dependent for income or direct consumption. ${ }^{382}$ Contamination of water sources has also been a complaint.

Crop eradication activities have forced poor rural households to be displaced, often to more marginal and hostile environments and at times with deadly consequences. In her extensive review of the history of forced eradication programmes, Buxton notes the following: ${ }^{365}$

- About 260,000 households or over 1 million people were forcibly displaced and faced starvation and lethal epidemics of infectious disease during opium eradication campaigns in Myanmar in the mid-2000s.

- Some 65,000 people were forcibly displaced in Lao PDR as part of "zero opium" campaigns in 2003-2004, resulting in mass poverty with men exploited as laborers in neighboring Thailand and many young women turning to the sex trade for survival.

- In Bolivia, crop eradication programmes in the early 2000s threw 50,000 households into dire poverty and malnutrition with only about $25 \%$ receiving any form of assistance.

Displacement compounds socio-economic and cultural differences in diet, nutrition, health habits, and housing, and it can exacerbate or cause psychological problems associated with vulnerability and forced re-location such as post-traumatic stress disorder. ${ }^{365}$

In addition to large-scale displacement and the disruption and poverty it brings, people who grow crops linked to drug production often face violence as a fact of life. Drug traffickers purchasing coca for the manufacture of cocaine or opium for heroin production for illicit markets may enforce the obligations of crop producers through violence. As Mejía notes, since contracts in illegal markets are not enforced with the help of the courts or the rule of law, traffickers take it upon themselves to use their own violent means. ${ }^{374}$ While in some cases in the Andes drug trafficking organizations provide infrastructure, even schools and health centres, to communities 
relying on drug crop cultivation for survival, sometimes the interaction with drug traffickers is in the form of death threats and lethal gun battles. ${ }^{386}$

UN Women in its pre-drugs UNGASS reflection concluded that crop eradication in the Andes destroys food crops that are the domain of women and enable them to have some economic autonomy in the household. ${ }^{387}$ The German bilateral development organization GIZ (Gesellschaft für Internationale Zusammenarbeit) noted that women's roles in ensuring food security in households involved with drug crops is not taken into account either in eradication programmes or when alternative livelihoods are offered to households, generally targeting men. ${ }^{388}$

In Africa, rural households depend on cannabis as a cash crop in numerous countries. Cannabis is often interplanted with food crops, and cannabis eradication campaigns that burn farm fields indiscriminately have threatened food security of farmers in some of the world's poorest nations. ${ }^{390}$ Klantschnig characterizes cannabis eradication in Nigeria as the most violent and repressive part of government drug-control operations, with the violence linked especially to invasion of rural communities and destruction of farmland. ${ }^{390}$

\section{[open box]}

\section{Box 5: Environmental damage and drug prohibition}

The pursuit of eradication of drugs and drug crops causes environmental damage with health consequences. Salisbury and Fagan documented displacement of coca farming due to eradication activities into areas protected for flora and fauna conservation in Peru near the border with Brazil. ${ }^{386}$ These authors conclude that before intensive eradication activities, coca cultivation in Peru was environmentally sound and associated with relatively little deforestation and a clustering of coca bushes that in some cases helped anchor the soil. With coca eradicationmostly manual eradication in the area they studied - farmers have been displaced to more remote areas with devastating consequences for biodiversity in the Peruvian Amazon. ${ }^{386}$ They also note the involvement of drug traffickers in logging and other potentially ecologically damaging activities. 
From 2000 to 2014, Honduras and Guatemala witnessed some of the most rapid and extensive deforestation in the world. McSweeney and colleagues attribute this phenomenon in part to the clearing of forest land by drug trafficking organizations for roads and landing strips as well as for large ranches owned by traffickers. ${ }^{390}$ In addition, people enjoying the profits of illicit drug markets have invested in forest-clearing activities such as cattle ranching, palm oil production, often at the expense of the forest-based activities of indigenous peoples. ${ }^{390}$ Deforestation in Central America since 2000 has closely tracked the movement of cocaine through Honduras, for example (Figure 24).

\section{[Figure 24 HERE]}

From McSweeney, 2014. ${ }^{390}$

\section{[close box]}

In the Andes, one of the most important health consequences of crop eradication may in fact be the horrific violence being experienced in Mexico and Central America. As Mejía and Restrepo note, in the face of intensive coca eradication activities in Colombia, major drug trafficking organizations moved their bases of operation from Colombia to Mexico and Central America, where they have been part of the deadly violence in that region. ${ }^{50}$

Some forced eradication programmes are judged by experts to be highly cost-ineffective, even without accounting for their impact on health. Mejía estimates that eliminating the marginal cost of eliminating the amount of coca needed to produce $1 \mathrm{~kg}$ of cocaine is about US $\$ 240000 .{ }^{374} \mathrm{In}$ announcing the end to US support to poppy eradication in Afghanistan, then US envoy Richard Holbrooke cited an estimate that destroying a hectare of poppies cost US $\$ 44000 .{ }^{391}$ Holbrooke noted:

The United States [and its allies] are not going to go around assisting or participating in the destruction of poppy fields anymore. The United States has wasted hundreds of millions of dollars doing this.... All we did was alienate poppy farmers who were poor farmers, who were growing the best cash crop they could grow in a market where they 
couldn't get other things to market, and we were driving people into the hands of the Taliban. ${ }^{391}$

\section{A better way for drug policy? Learning from selected experiences}

The public health harms of the pursuit of drug prohibition have led some cities and countries to rethink approaches to drug control. Their experiences with respect to many of the health problems described in previous sections are largely replicable and show the path to drug policies that support health and development and do not undermine human rights.

\section{Rejecting criminalisation of minor offenses and scaling up health services}

Portugal's transition from decades of isolating authoritarian rule to democratic governance in the mid-1970s brought enormous social change. Opening its doors to the world brought Portugal a new place in international relations but also a flow of illicit drugs for which it was ill-prepared. By the 1980s, the Portuguese people considered drugs to be their most pressing social problem. ${ }^{392}$ HIV linked to injection drug use was exploding, drug dependence was an important public health problem, and more aggressive policing did not seem to deter drug use.

In 1998, a multi-sectoral expert committee was convened by the national government to address the drug problem. Its proposed solution, eventually written into a 2000 law that came into force in 2001, was to remove criminal sanctions from individual-level use and possession of all drugs. ${ }^{393}$ Individual-level use was defined liberally as the quantity needed for 10 days' use. Individual-level drug infractions were still illegal but only under administrative law; they could not be punished by a prison sentence and were not attached to a criminal record. Larger-scale offenses such as trafficking and sale of large amounts of drugs retained penal sanctions. ${ }^{392}$

People found to be engaging in minor infractions are invited - not required - to meet with what are called 'dissuasion committees', groups of health and social sector practitioners who offer people the chance to be referred to services voluntarily and try to determine if there is problematic drug use to be addressed. HIV prevention services, including OST for people using 
opioids and NSP, were scaled up dramatically, as were services offering treatment for drug dependence other than OST. ${ }^{392}$

The results of this experience may be judged by numerous outcomes, but for one of the main harms being addressed, unsafe injection-linked HIV transmission, the experience can be said to have succeeded. As shown in Figure 25, new HIV transmission among people who inject drugs declined from almost 800 cases in 2003 to less than 100 in $2012 .{ }^{394}$ Injection as a mode of drug use has also declined since 2001, as has other problem drug use. ${ }^{395}$ Independent researchers studying the Portuguese experience note with respect to the health benefits such as these that it is difficult to disentangle the impact of the actual decriminalisation from the impact of the dramatic scale-up of health and social services. ${ }^{394}$

\section{[Figure 25 HERE]}

From J. Goulão, Government of Portugal. ${ }^{394}$

Critics of the Portuguese policy decision feared that drug use in Portugal would increase overall. As of the 2011 compilation of figures by the EU's monitoring body, this was not the case for cannabis use in the last year (Figure 26), where Portugal's totals are on the low side for the EU, and the ranking of Portugal with respect to amphetamine use in the last year is similar. ${ }^{396}$

\section{[Figure 26 HERE]}

From EMCDDA, Statistical bulletin, 2011. ${ }^{396}$

Faced with an extensive open scene of heroin injection and a rapidly growing drug-related HIV epidemic in the late 1980s, the Swiss public regarded drugs as a major social scourge. In Switzerland, the police attempted geographical confinement of people who injected drugs, most notably corralling them into a public park in Zurich that became known as the "needle park.' 397 Needle exchange was not permitted in Switzerland at the time, and methadone was heavily regulated with each case requiring special clearance by the health authorities. ${ }^{397}$ The benefits of lowering the threshold of services for people who injected drugs - especially needle and syringe programmes and OST - were soon made clear to policy-makers, and Switzerland accomplished one of the most effective scale-ups of HIV prevention services in history. ${ }^{398}$ The country went on 
to pioneer supervised injection sites in its largest cities, which were quickly seen to help reduce both overdose deaths and public injecting, and medical administration of heroin or heroinassisted therapy (HAT) for those relatively few opioid-dependent people for whom other treatments did not produce the desired result. Like Portugal, Switzerland witnessed a precipitous decline in HIV incidence linked to drug injection and sustained that decline for a long period. ${ }^{399}$ The HAT program in Switzerland was established over the objections of the INCB and with openness by the Swiss authorities to evaluations by independent researchers. ${ }^{398,400}$ Evaluations of the Swiss HAT experience have consistently shown good results in reduction of illicit drug use, crime and mortality linked to the program, ${ }^{401,402}$ findings later replicated in other settings. ${ }^{403}$

In referendums the Swiss public endorsed OST, NSP and HAT as part of a major harm reduction pillar in national drug policy, all the while rejecting decriminalisation of drugs. ${ }^{398}$ In 2013, Switzerland decriminalised minor cannabis offenses, making them administrative infractions. ${ }^{404}$

The Czech Republic in the late 1980s emerged from a long period of Soviet occupation at a time when HIV and drug injection were on the rise across Europe. The Czech experience is especially notable as visionary health professionals helped lead the country to invest in low-threshold HIV prevention services before an injection-linked HIV could take hold, thus sustainably averting the run-away epidemics seen elsewhere in Europe. ${ }^{405}$ In the early post-Soviet period, the Czech (then Czechoslovak) authorities sought a legal regime that would keep minor drug infractions out of the penal code. The drug law of the newly independent country established possession of drugs for individual use as and administrative - not criminal - infraction. ${ }^{406}$

Drug use became a major political issue in the cities in the 1990s. In 1998, the Czech Republic changed its approach and criminalized penalties for all drug offenses involving a certain quantity of drugs that was not clearly specified. Remarkably, the government commissioned academic researchers to study the impact of the new law. Led by Tomáš Zábranský (a JHU-Lancet Commissioner), the study team found that the new criminal penalties did not reduce problematic drug use or the availability of drugs, as their supporters had claimed they would do, and that the policing and incarceration needed to enforce the law was very costly. ${ }^{406}$ Following long debate, the 1998 law was replaced in 2010 by a law that decriminalised use and possession below clearly 
defined cut-off amounts for all drugs. The Czech experience is also remarkable in that the national drug policy coordinators in the post-Soviet period have all been persons with frontline health or social service experience with people who use drugs. ${ }^{407}$

Decriminalisation of or at least removal of custodial penalties for minor drug offenses is more the rule than the exception in Western Europe. A 2015 review noted that EU countries have instituted a range of practices at the time of arrest or with respect to prosecution and sentencing that have effectively reduced criminal sanctions for minor drug offenses. ${ }^{408}$ Most countries have recognized that a large part of non-violent drug-related crime is committed by a very small number of persons with problematic use who should be identified and directed to help with the health and social problems at the root of their infractions, and most countries have explicit procedures to remove these persons from criminal proceedings. ${ }^{408}$ In addition, EU countries have the highest coverage of OST and needle exchange of any region, and most countries have high coverage of ART for people who inject drugs. These factors have together led to a situation in which HIV transmission by means of injection with contaminated equipment, while not eliminated, is no longer a significant contributor to HIV epidemics at a population level (Figure 27)..$^{75}$

[Figure 27 HERE]

From EMCDDA, European drug report, 2015. ${ }^{75}$

The Netherlands' drug policy experience has unique harm reduction aspects, as described in web appendix XVI.

\section{Expanding public health action against HIV in North America: Vancouver, Canada}

In the mid-1990s, Vancouver, Canada, was home to an epidemic of HIV infection among PWID living in the city's Downtown Eastside (DTES) area. With an annual incidence of 18.6 per 100 person-years in 1996-97, ${ }^{409}$ the epidemic was characterised as the most rapid spread of HIV infection seen outside of sub-Saharan Africa. ${ }^{410}$ Drug-use patterns had shifted with the increased availability of powder cocaine, which was often injected 10 or more times daily by local PWID. ${ }^{411}$ Although a local NSP was in operation, it was constrained by restrictive rules and 
limited hours of operation. ${ }^{410}$ Further, efforts to deinstitutionalise people living with mental illness resulted in large numbers of vulnerable individuals arriving in the DTES with little support. ${ }^{410}$ Lastly, the dense network of single-room occupancy hotels fostered the creation of risky indoor injecting environments. ${ }^{409}$ 
Faced with dual epidemics of HIV infection and overdose, in 1997 the local health board declared a public health emergency in the DTES. ${ }^{410}$ Over the next 15 years, various interventions were implemented to address the HIV epidemic. First, responsibility for the delivery of methadone shifted from the federal to the provincial government, resulting in a large increase in the number of individuals receiving methadone in the DTES. ${ }^{412}$ Second, given a growing body of research revealing the limitations of the local NSP, ${ }^{413}$ the local health authority revised its policies and instituted a decentralised NSP, removed limits on the number of syringes that could be obtained, as well as the one-for-one exchange rule, and expanded hours of operation. ${ }^{413}$ All local health clinics soon implemented NSP and, importantly, PWID increasingly became involved in the delivery of NSP services. These peer-run NSP, including fixed and outreach services, were found to effectively reach those PWID at highest risk of acquiring HIV ${ }^{414}$ An evaluation of these changes to NSP policies revealed large declines in syringe borrowing and lending over time, as well as HIV incidence. ${ }^{413}$

An important third development was the widespread delivery of ART and related support for local PWID. Although many jurisdictions have excluded PWID from ART programmes or limited access to former PWID, all HIV-positive PWID in Vancouver, regardless of whether they were actively using drugs or not, were offered ART. Recent analyses have revealed large increases in access to ART among PWID over time, as well as large declines in the median HIV RNA viral load within this population. ${ }^{415}$ A landmark study in 2009 revealed that these reductions in "community viral load" were strongly associated with declining HIV incidence among local PWID. ${ }^{415}$ 
A fourth important development was the implementation of two supervised injection sites in Vancouver where PWID can inject pre-obtained illicit drugs under the supervision of nurses. The sites include a large stand-alone facility that accommodates an average of 800 injections per day, and a smaller program within a large integrated day program and residence for people living with HIV. The larger program, named Insite, has been shown to have reduced syringe sharing among PWID, ${ }^{416}$ and modelling studies suggest that the site is reducing HIV incidence. ${ }^{417}$ The programme has remained controversial, however, in 2011 the Supreme Court justices of Canada ruled 9-0 in favour of the continued operation of Insite, noting that the site had been proven to save lives without any negative impacts on the government's public health and safety objectives. ${ }^{418}$

Although the response to the HIV epidemic among PWID in Vancouver evolved slowly, the impact has been impressive. The HIV epidemic was successfully reversed through a comprehensive combination prevention approach involving harm reduction and addiction and HIV treatment. In addition to dramatic declines in syringe borrowing and lending, the annual HIV incidence rate declined from 18.6 per 100 person-years in 1996-97 to below 0.38 per 100 person-years since 2008. ${ }^{412}$ The case of the Vancouver epidemic should serve as a reminder that HIV epidemics among PWID can be reversed through comprehensive combination prevention approaches, provided the necessary political will exists.

\section{Reducing drug-related harm in sub-Saharan Africa}

Even without fundamental change in their drug laws and in the face of political and economic constraints, some countries have found ways to strengthen health sector approaches that are a departure from policing-centred drug policy. An estimated 500000 people use opioids in East Africa, and in Tanzania alone an estimated 30000 people inject opioids. ${ }^{310} \mathrm{HIV}$ prevalence among people who inject drugs in Tanzania is estimated to be in the range of $42-50 \%$ and is plainly an important challenge for the national HIV response. ${ }^{419}$ In 2011, Tanzania undertook the first relatively large-scale OST programme using methadone, beginning with a site at Muhimbili National Hospital in Dar es Salaam, now with four sites and an enrollment of about 2500. 
The methadone programme has had good success in retaining people in treatment, with lessons learned along the way about the importance of keeping methadone doses adequately high. ${ }^{310}$ The programme has also had excellent results in linking methadone patients living with HIV to sustained ART. ${ }^{419}$ Active TB case finding was also conducted among methadone patients with links to care. ${ }^{420}$ As noted by Guise and others, the fact that Tanzania did not require people to be registered as drug users with the police, was a great advantage; police in general have not interfered with this program. ${ }^{74}$

The Tanzania experience bodes well for other experiences in sub-Saharan Africa. In late 2014, Senegal announced the first government-support methadone programme in West Africa, a region where opioid use is not as well documented as in East Africa but certainly is significant. ${ }^{421}$ The Senegal programme promises an integrated approach to drug-related and HIV treatment, care and support.

\section{Reducing harms in prison}

Combined harm reduction and HIV treatment measures in prison have proven very effective in a variety of settings. Spain's experience illustrates the synergistic impact of combined interventions. The frank recognition in Spain of extensive drug use within prison walls led to the establishment of both OST and needle and syringe programmes in the prison service. ${ }^{422}$ ART in prison was provided. The dramatic decline in HIV incidence in Spanish prisons from about 7 per 1000 in 2000 to virtually 0 per 1000 in 2012 attests to the effectiveness of this combination of interventions. ${ }^{422}$

Moldova, unusually for its region, began offering sterile injection equipment in prisons in 1999. The Moldova prison NSP model relies for distribution of equipment on trained focal points, thus enabling their peers to get syringes and other equipment without having to ask prison authorities. ${ }^{423}$ ART is also provided. In 2014, Moldova began providing naloxone in prison. HIV prevalence in Moldovan prisons where these services are available declined from 4.2\% in 2007 to $1.9 \%$ in 2012 , and $\mathrm{HCV}$ prevalence from $21 \%$ to $8.6 \%$ in the same period. ${ }^{424}$

\section{Reducing the harm of overdose}


Low- and middle-income countries and countries with harsh drug laws can also make progress on eliminating overdose deaths. In the Russian Federation, Tajikistan, and Kazakhstan, for example, hundreds of overdoses were reversed in part by people who use drugs themselves who were trained in the use of naloxone. ${ }^{425}$ Using data from the Russian Federation, one modeling exercise found that if even $20 \%$ of people who experience overdose could be reached with naloxone, overdose deaths would decline by over 13\% in five years at a cost of US \$94 per quality-adjusted life year (QALY) gained. ${ }^{426}$

In Western Europe, overdose programmes are beginning to target the high-risk population of people leaving prison and entering the community. Scotland is the first country to have a nationwide programme that distributes naloxone to people at the end of a prison sentence. ${ }^{427}$ Programmes run by people who use drugs themselves had shown the feasibility of this intervention for years before the Medicines Act of 2005 opened the doors to removing legal penalties against anyone who uses naloxone to save a life. ${ }^{428}$ The government's 2014 evaluation of the first three years of the program estimated that over 500 overdose deaths had been averted and $90 \%$ of those who participated, including people who use drugs, said that the program helped them better understand the causes of overdose. ${ }^{428}$ An innovative experience with naloxone for recently released prisoners in the politically challenging environment of a US state is described in web appendix XVII.

Harm reduction can also take the form of discouraging the most dangerous modes of consuming drugs. An innovative programme in Germany aimed to persuade people injecting opioids to switch to inhaling them. ${ }^{429}$ In this case, participants were provided with good-quality foil for inhalation; people using some of Germany's 24 supervised injection sites were the target population because drug smoking and inhalation are also allowed in the sites. ${ }^{429}$ While the follow-up was not of very long duration, this pilot effort found that more than half of those approached reported having used the foil provided to smoke rather than inject between visits to the site, with older people reporting higher inhalation, some noting that they needed to give their veins a rest. ${ }^{429}$ There are 400000 dispensing points for sterile injecting equipment in Germany. The researchers involved with the smoking promotion recommended that smoking equipment be made available along with injection equipment. ${ }^{429}$ 


\section{Eliminating the harms of compulsory treatment}

Some countries may be moving away from detention of people who use drugs in squalid facilities using brutal punishment and forced labour in the name of treatment. Beginning in 2011, Malaysia began implementing a plan to convert 18 of its 28 compulsory treatment centres into 'cure and care' clinics offering voluntary in-patient and out-patient treatment for drug dependence, including OST. ${ }^{430}$ These clinics use existing health infrastructure, and the drug law has not changed. As of early 2015, some 36000 people who use drugs had used these new services ${ }^{430}$ Early results indicate that among people who used both methamphetamine and opioids, use declined after the treatment received in 'cure and care' facilities. ${ }^{429}$ A qualitative study indicated that patients appreciated the range of activities offered in the new services, including the stabilizing effect of OST, psychosocial support from staff and peers, and links to other health services. ${ }^{431}$

In Vietnam, compulsory rehabilitation centres existed for both people who use drugs and sex workers, but in 2012 it was decided to discontinue detention of sex workers in these centres. ${ }^{431}$ The centres for drug users still exist, but a law was passed that in theory enables people in these centres the right to appeal their situation and bring complaints to court with legal representation; it remains to be seen how this provision will be used. ${ }^{432}$ In late 2012, UNAIDS announced that pledges had been secured from nine countries in East and Southeast Asia to reduce populations in compulsory treatment centres and decrease the number of centres. ${ }^{433}$

\section{Reducing harms in drug crop production}

In 2006, Bolivia elected Evo Morales, a former coca farmer, as president of the country. The Morales government led Bolivia to reclaim its commitment to protecting traditional uses of coca leaf. Coca leaf has a long history of traditional and cultural use in the Andes as a mild stimulant, chewed and also used in tea. It is said by rural households to relieve hunger, as well as some stomach ailments and dizziness. ${ }^{434}$ The 1961 Single Convention (art. 49) explicitly states that governments that are ratifying parties to the convention "may at the time of signature, ratification or accession reserve the right to permit temporarily in ... its territories...coca leaf chewing" 
subject to a number of restrictions that are specified in the article, but otherwise coca leaf is scheduled as a dangerous narcotic. ${ }^{6}$

Under Morales, Bolivia, which ratified in the 1961 Convention under a previous military government, did not want temporary leave to allow coca chewing but rather sought to make a permanent reservation to the Single Convention for traditional uses of coca leaf as a mild stimulant. In a nearly unprecedented move, Bolivia withdrew its ratification of the convention and sought permission to re-accede with a formal reservation for traditional uses of coca leaf. ${ }^{435}$ Under the terms of the Single Convention, Bolivia's re-accession would have been blocked if 61 ratifying parties to the Convention objected. In the event, only 15 countries objected, ${ }^{435}$ and Bolivia made its point - coca and cocaine are not the same.

Licit uses of coca leaf also led Bolivia to establish an innovative kind of alternative livelihood for coca growers. With firm recognition of the need for a legal market for coca leaf, the government established a scheme by which some coca farmers are permitted to grow coca for licit use over a fixed area of land - one cato or $1600 \mathrm{~m}^{2}{ }^{436}$ Coca grown above that limit could be subject to eradication. As noted by Ledebur and Youngers, the program has been a success partly because strong growers' unions or federations are on the scene helping to oversee the programme, which they have found to be in their interest. ${ }^{436}$ The cato zones have seen significant reductions in the growing of coca for illicit markets, much more than the reductions that resulted from forced eradication efforts. ${ }^{436}$ There has been a concomitant reduction in reported violence in the cato communities as well. The Bolivia example is a rare case of meaningful participation of drug crop farmers in planning and implementing programmes meant to benefit them.

\section{Conclusions and recommendations}

Policies meant to prohibit or greatly suppress drugs present an apparent paradox. They are portrayed by policy-makers as necessary to preserve public health and safety, and yet they directly and indirectly contribute to lethal violence, disease, discrimination, forced displacement, injustice, and the undermining of people's right to health. 
The framers of international human rights law foresaw that there would be times, especially in the face of security threats, when some individual rights would have to be abrogated in favor of preserving collective safety and well-being. ${ }^{437}$ There is international consensus that if policies that abrogate rights are necessary for the greater good, those policies (1) should pursue a legitimate and transparently defined goal and be proportionate to that goal; (2) must be the least rights-restrictive and the least harmful possible to achieve the stated goal; (3) should include adequate remedies for those whose rights are violated; and (4) should not interfere with the democratic functioning of society. ${ }^{438}$

In our view, policies pursuing drug prohibition or severe suppression do not meet these criteria, even if one accepts that drugs in and of themselves somehow present a serious security threat. Policies that pursue drug prohibition or heavy suppression do not represent the least harmful way to address drugs; the aim they pursue is not well-defined or realistic; their interventions are not proportionate to the problem; they destabilize democratic societies; and those harmed by them often have no recourse to remedies to mitigate those harms. The 'scourge' of drugs and the harms of drug use are exaggerated to justify these measures. These policies also contradict the spirit of the 2030 SDGs and the bedrock human rights norms of the community of nations.

Some experts have argued that the benefits of prohibition are underappreciated. Proponents of prohibition have noted that while the results in drug supply and demand reduction have left something to be desired, consumption, supply and related harms would be even more plentiful without the interdiction and criminalization of use associated with prohibition - a difficult argument to refute (or confirm). UNODC has asserted that without elements of prohibition, drug use could be as widespread as alcohol use, with disastrous consequences. ${ }^{439}$ Caulkins' thoughtful analysis suggests that no proponent of prohibition should ever have expected complete eradication of drug markets, but that driving drug activity underground has benefits for some individuals and society, especially reductions in drug dependence that are the result of very high drug prices in illicit markets and other barriers to obtaining drugs. ${ }^{440}$ We appreciate efforts such as his to bring empirical rigour to this question, but based on the evidence identified and analysed by the Commission, we conclude that the harms of prohibition far outweigh the benefits. 
The violence associated both with illicit drug markets and with policing, including policing by military and paramilitary forces, is a deeply traumatic violation of the right to health. The cost of incarceration of enormous numbers of people - men, women and children -- for minor, nonviolent offenses weighs heavily on societies. The misuse of the important social tool of the criminal justice system to discriminate against racial and ethnic minorities is unacceptable. The cost of infectious disease made more likely, more severe, and more difficult to address by law enforcement practices and incarceration is completely preventable illness and death. Overdose death is also preventable and affects some of society's most marginalised persons. The eradication of crops used in the manufacture of drugs is harmful to whole communities and families as well as to the environment. And there is untold suffering of millions whose pain cannot be relieved by effective analgesics because of fears of diversion of medicines to illicit use.

Standard public health and scientific approaches that should be part of policy-making on drugs are dismissed in the pursuit of drug prohibition and suppression. The idea of reducing the harm of many kinds of human behavior is central to public policy in the areas of traffic safety, tobacco and alcohol regulation, food safety, safety in sports and recreation, and many other areas of human life where the behavior in question is not prohibited. But explicitly seeking to reduce drug-related harms through policy and programmes is regularly resisted in drug control. The idea that all drug use is 'abuse' and that therefore only immediate abstinence is acceptable seems to impede making harm reduction a drug policy priority.

The persistence of unsafe injection-linked HIV transmission that could be stopped with proven, cost-effective measures is one of the great failures of the global HIV response. People who use drugs, even if they do not immediately stop using drugs, can make good decisions to protect themselves and those around them. Denying them the chance to do so by failing to offer harm reduction services dehumanises them, violates their rights, undermines the public's health, causes needless death and disease, and costs society money and needless suffering. We agree with the conclusion of the UNAIDS-Lancet Commission that too many countries are letting people who 
inject drugs die rather than remove the barriers, including drug law and policy, that stand in the way of life-saving services. ${ }^{441}$

Countries have failed to recognise and correct the health and human rights harms that pursuit of prohibition and drug suppression have caused and in so doing neglect their legal responsibilities. They readily incarcerate people for minor offenses but then neglect their responsibility to provide health services in custodial settings that are the equivalent of those in the community. They recognise uncontrolled illegal markets as the consequence of their policies, but they do little to protect people from toxic, adulterated drugs that are inevitable in illegal markets or the trauma and violence of organised criminals, often made worse by repressive policing. They waste public resources on policies that do not demonstrably eliminate drugs or impede the functioning of drug markets, and they miss opportunities to invest public resources wisely in proven cost-effective health services for people often too frightened to seek services.

Calls for 'balanced' drug policy as in the $2009 \mathrm{UN}$ political declaration on drugs have not been heeded. It may be said that the Western European countries that have decriminalised (formally or less formally) drug use and minor possession and sale and have scaled up comprehensive harm reduction services and ensured access to ART for PWUD have not completely rejected prohibition. Drugs are still illegal in these countries. But in our view, these experiences do represent a significant rejection of traditional prohibition, not least because they bring public health goals and policies to the centre of drug control. They are not the end of the reform story, but they give the world an alternative that should continue to be rigourously evaluated as to public health and human rights impact.

We urge the member states participating in the April 2016 UNGASS to bring public health evidence into the debates as they strive to formulate policy directions that are consistent with the principles of the UN Charter, the spirit of the 2030 Sustainable Development Goals, and the human rights norms to which virtually all UN member states are committed, including the right to health. The UNGASS will do itself credit by helping the world move away from a war on 
drugs that is inevitably a war on people who use drugs. Toward this end, we offer the following recommendations:

Decriminalise minor drug offenses - use, possession, and petty sale: The long experiences in Portugal, the Czech Republic and a number of other countries with decriminalisation of minor drug offenses demonstrate the benefits of treating minor infractions without recourse to criminal sanctions. Those benefits include facilitating the offer of health and social support to people who may need it; reduction of incarceration of men, women, and young people with all its harms; and eliminating the wastefulness of the police's pursuit of minor offenders. Decriminalisation of minor offenses also makes it harder to use drug laws as a weapon against racial or ethnic minorities or politically unfavoured groups. Decriminalisation should always be accompanied by measures to ensure the capacity of health and social services to address drug-related harms or problem drug use as needed.

Reduce the violence and other harms of drug policing: Military and paramilitary forces are likely to exacerbate violence in pursuing drug traffickers; their participation should be phased out as much as possible. Police should also desist from practises that directly cause health harms, including all practises that disrupt access to essential services and practises such as seizure of injection equipment. There should be measures to monitor and prevent sexual violence linked to drug markets and to ensure care and support for survivors. Paraphernalia laws should be modified so that possession of sterile injection equipment is not a crime, and possession of syringes with trace amount of drugs is not considered drug possession.

Make harm reduction measures a central pillar of health systems and drug policy: Consistent with the fundamental principles of public health, reducing health harms of drugs and drug control measures should be a high priority for policy-makers. As for tobacco, alcohol, and many other behavior-related policies in most countries, drug policy should include measures to reduce drug-related harm that are not linked to a goal of abstinence that is unrealistic for some people. The deadly harms of HCV are preventable, but not without scale-up of a full range of services for PWID. Fiscal sense, good public health practice, and meeting human rights obligations all come together in a strong harm reduction pillar of drug policy. The 2016 UNGASS should do 
better than previous UN gatherings and call harm reduction by its name with a strong endorsement for its centrality in drug policy.

Invest in HIV, HCV, TB, and drug dependence treatment: The use of involuntary detention, beating, other physical abuse, and forced labour in the name of treatment of drug dependence must stop. Underinvestment in proven treatment for opioid addiction must be rectified. Unscientific ideas about OST as "another form of addiction" should be countered in medical training, by health professionals and their associations, and by policy-makers interested in costeffective and efficacious policy. Research on humane forms of other drug dependence treatment is urgently needed and should not be stopped by over-cautious anti-diversion measures. WHO in collaboration with UNODC should be given the resources to monitor the quality of drug dependence treatment programmes on a regular basis and to signal to governments programmes that are not scientifically sound and may cause harm. Treatment of HIV, HCV, and TB must prioritise people who use drugs. People in prison and pretrial detention should be included in treatment programmes. Health professionals should counter myths about the lack of capacity of people who use drugs to adhere to treatment. The advocacy and resulting measures that helped to bring down the prices of early generations of HIV medicines are urgently needed to enable PWUD to benefit from the new class of HCV medicines.

Ensure access to controlled medicines: Action is urgently needed to ensure that decisions on procurement and use of controlled medicines are made by health professionals without inappropriate constraints linked to over-cautious drug control measures. Countries in which the vast majority of patients needing pain medications and other controlled medicines are not getting them should urgently review their drug control laws and policies against WHO guidelines and INCB recommendations and weigh the costs of drug control against the rights and needs of patients. At the international level, WHO's role in determining the health dangers of drugs, specified in the drug conventions, needs to be reinforced. Overriding WHO's expertise in this area should not be undertaken lightly or on the basis of the inertia of adherence to strict drug control. 
Formulate policies that do not harm women: Alternatives to incarceration for women who have committed minor drug infractions benefit families and communities and should be a high priority. For the minority of drug-using women who are drug-dependent, there should be appropriate health and social support, including treatment programmes that take account of gender-based differences in initiation of and motivation for drug use. Protection of women and children from violence in law enforcement and supply reduction efforts must be a policy priority and should be an indicator of the success of drug policy.

Integrate health concerns in supply-side efforts: Providing alternatives to people who produce coca, opium poppies or cannabis or to people who produce methamphetamine or other synthetic drugs should be part of integrated development or anti-poverty measures in which the people affected play a meaningful role in deciding what constitutes an alternative livelihood and not separate areas of development that have drug control goals more than development or welfare goals. Cultivators must be meaningfully engaged as stakeholders in supply policies.

Improve UN governance of drug policy: WHO must be allowed to do the job established for it in international law with regard to assessing the science of potential harms of drugs. The INCB should not oppose WHO expert views on the dangerousness of drugs, and the CND should not overrule public health expertise without compelling evidence of the benefit of doing so. It is high time for health and social sector authorities to be equal partners in national drug policy-making bodies in all countries, as well as in CND delegations. Global and regional multilateral drug policy-making bodies and supporting technical agencies should include public health expert bodies in all aspects of their work.

Include health, human rights, and development in metrics to judge success of drug policy: If drug policy is meant to protect the health and well-being of populations, then health outcomes should be part of the measurement of drug policy's success or lack thereof. WHO and UNDP should help formulate health and human development metrics of drug policy. As UNDP suggested in its paper in the lead-up to the 2016 drugs UNGASS, indicators such as access to treatment, rate of overdose deaths, and access to social welfare programmes for people who use drugs are feasible to measure and would say more about policies than the number of arrests. ${ }^{13}$ All drug policies 
should also be studied as to their impact on racial and ethnic minorities, women, children and young people, and people living in poverty.

Better and broader research on drugs and drug policy: Bilateral development assistance agencies, private foundations concerned about health, and other donors should broaden their support for rigorous evaluation of drug policy experiences and experiments. The best social science and policy analysis methods should be brought to bear in an objective and non-ideological way to understand the impact of drug policy change on the public's health and well-being. Research on drug dependence should be guided by the best science, should allow people who use drugs themselves to have a meaningful voice, and should interrogate the excessive pathologising of drug use. We also urge the United Nations, UNODC in particular, to reconstitute the independent Reference Group to the UN on HIV and Drug Use or a similar group on health and drug use to contribute to high-quality, policy-relevant research on drug use and health.

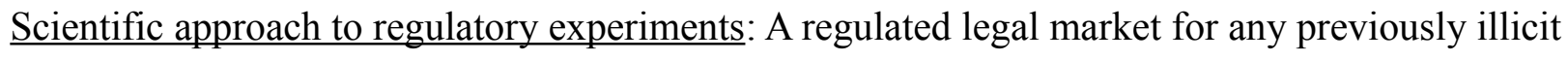
drug in the US and Uruguay seemed very unlikely before 2008. It is clear that regulated legal markets for substances that have long been harshly criminalised are not politically possible in the short term in many countries. But we believe that the weight of evidence of the health and other harms of criminal markets and other consequences of prohibition catalogued in this report is likely to lead more countries (and more US states) to move gradually toward regulated drug markets, a direction we endorse. Regulation of the harms of human activity is the essence of public health, as with tobacco and alcohol. As those decisions are taken, we urge governments and researchers to apply the scientific method and ensure independent and rigorous evaluation of regulated markets to draw lessons and inform improvements in regulatory practices, and then to evaluate and improve again.

We urge health professionals in all countries to inform themselves and join debates on drug policy at all levels. True to the goals of the international drug control regime, it is possible to have drug policy that contributes to the health and well-being of humankind, but not without bringing to bear the evidence of the health sciences and the voices of health professionals. 



\section{ACKNOWDLEDGMENTS}

The work of the Johns Hopkins-Lancet Commission on Drug Policy and Health was supported, in part, by a grant to the Johns Hopkins Center for Public Health and Human Rights from the Open Society Foundation; by the Johns Hopkins University Center for AIDS Research, a National Institute of Health (NIH/NIAID)-funded program, (1 P30AI094189) which supported CB and SGS; by the Johns Hopkins Training Program in HIV Epidemiology and Prevention Science (1T32AI102623-01A1) of the NIH/NIAID which supported J Cepeda; and with support from the International AIDS Society, Geneva, Switzerland. AK acknowledges funding from the University of Malaya High Impact Research Grant (HIRGA E000001-20001). NM and PV acknowledge funding from National Institute for Drug Abuse R01 DA037773-01A1. PV acknowledges funding from the Bill and Melinda Gates Foundation-funded HIV modelling consortium and the National Institute for Health Research Health Protection Research Unit (NIHR HPRU) in Evaluation of Interventions at University of Bristol, UK. JS acknowledges funding from the Engineering and Physical Sciences Research Council (ESPRC). The views expressed are those of the authors and not necessarily those of the US NIH, the UK NHS, NIHR, or the UK Department of Health. 
FIGURES AND TABLES (separate file)

\section{Appendix 1: Glossary}

This glossary is an excerpt from definitions agreed upon by the Board of Science of the British Medical Association and published in BMA Board of Science, Drugs of dependence: the role of medical professionals, London, 2013.

\section{Addiction}

Repeated use of a psychoactive substance or substances, to the extent that the user (referred to as an addict) is periodically or chronically intoxicated, shows a compulsion to take the preferred substance (or substances), has great difficulty in voluntarily ceasing or modifying substance use, and exhibits determination to obtain psychoactive substances by almost any means. Typically, tolerance is prominent and a withdrawal syndrome frequently occurs when substance use is interrupted. The life of the addict may be dominated by substance use to the virtual exclusion of all other activities and responsibilities....Addiction is a term of long-standing and variable usage. It is regarded by many as a discrete disease entity, a debilitating disorder rooted in the pharmacological effects of the Drug, which is often progressive. Addiction is not a diagnostic term in the International Classification of Diseases 10th revision (ICD-10), but continues to be very widely employed by professionals and the general public.

\section{Decriminalisation}

A process in which the seriousness of a crime or of the penalties the crime attracts is reduced. More specifically, it refers to the move from a criminal sanction to the use of civil or administrative sanctions. An example in relation to illicit drugs would be where possession of cannabis is downgraded from a crime that warrants arrest, prosecution and a criminal record to an infraction to be punished with a warning or fine. Decriminalisation is often distinguished from Legalisation, which involves the complete repeal of any legal definition as a crime, often coupled with a governmental effort to control or influence the market for the affected behaviour or product. A distinction is also made between de jure decriminalisation, which involves specific reforms to the legal framework, and de facto decriminalisation, which involves a similar outcome, but is achieved through 'turning a blind eye' to tolerant policing - effectively nonenforcement of criminal laws that technically remain in force.

\section{Dependence}

As a general term, dependence is the state of needing or depending on something or someone for support or to function or survive. As applied to alcohol and other drugs, the term includes psychological and physiological aspects. Psychological dependence involves impaired control over drug use and a need (craving) for repeated doses of the drug, to feel good or avoid feeling bad. Physiological, or physical, dependence is associated with tolerance, where increased doses of the drug are required to produce the effects originally produced by lower doses, and development of withdrawal syndrome when the drug is withdrawn. The Diagnostic and Statistical Manual of Mental Disorders, 4th edition revised (DSM-IV) defines it as: 
'When an individual persists in use of alcohol or other drugs despite problems related to use of the substance, substance dependence may be diagnosed. Compulsive and repetitive use may result in tolerance to the effect of the drug and withdrawal symptoms when use is reduced or stopped.'

The DSM-IV definition is roughly equivalent to the dependence syndrome of the ICD-10. In the ICD-10 context, the term dependence could refer generally to any of the elements in the syndrome. The term can be used generally with reference to the whole range of psychoactive drugs (drug dependence, chemical dependence, substance use dependence), or with specific reference to a particular drug or class of drugs (eg opioid dependence). While the ICD-10 describes dependence in terms that are applicable across drug classes, there are differences in the characteristic dependence symptoms for different drugs. In biologically oriented discussion, dependence is often used to refer only to physical dependence. Dependence or physical dependence is also used in the psychopharmacological context in a still narrower sense, referring solely to the development of withdrawal symptoms on cessation of drug use.

\section{Dependence potential}

The propensity of a substance, as a consequence of its pharmacological effects on physiological or psychological functions, to give rise to dependence on that substance. Dependence potential is determined by those intrinsic pharmacological properties that can be measured in animal and human drug-testing procedures. It is a term used in applying international drug treaties.

\section{Diversion}

From a medical perspective, diversion is the inappropriate use of a drug by those for whom it has been prescribed, or use by a person for whom the medication was not prescribed. The term may be used to describe diversion of a shipment of drugs out of legal channels at wholesale level or, for example, to describe the sale of prescription methadone to, and use by, an individual for whom it was not prescribed. The term diversion is also used in a criminal justice context to refer to measures that take an arrestee out of the criminal justice system and into education, medical management or another type of intervention.

\section{Drug}

A term of varied usage. In medicine, it refers to any substance with the potential to prevent or cure disease or enhance physical or mental welfare, and in pharmacology it refers to any chemical agent that alters the biochemical or physiological processes of tissues or organisms. Hence, a drug is a substance that is, or could be, listed in a pharmacopoeia. In common usage, the term often refers specifically to psychoactive drugs, and often, even more specifically, to illicit drugs, of which there is non-medical use in addition to any medical use. Professional formulations (e.g. 'alcohol and other drugs') often seek to make the point that caffeine, tobacco, alcohol and other substances in common non-medical use are also drugs in the sense of being taken, at least in part, for their psychoactive effects.

\section{Drug abuse}

A term in wide use but of varying meaning. The DSM-IV defines 'psychoactive substance abuse' as: 


\begin{abstract}
'A maladaptive pattern of substance use leading to clinically significant impairment or distress, as manifested by one (or more) of the following, occurring within a 12-month period: (1) Recurrent substance use resulting in a failure to fulfil major role obligations at work, school, or home (e.g. repeated absences or poor work performance related to substance use; substance-related absences, suspensions or expulsions from school; neglect of children or household); (2) Recurrent substance use in situations in which it is physically hazardous (e.g. driving an automobile or operating a machine when impaired by substance use); (3) Recurrent substance-related legal problems (e.g. arrests for substance-related disorderly conduct); (4) Continued substance use despite having persistent or recurrent social or interpersonal problems caused or exacerbated by the effects of the substance (e.g. arguments with spouse about consequences of intoxication, physical fights).'
\end{abstract}

The term 'abuse' is sometimes used disapprovingly to refer to any use at all, particularly of illicit drugs. The term is not used in ICD-10 because of its ambiguity and to avoid including social consequences in the definition of a diagnosis. Harmful use is the closest equivalent in ICD-10. In other contexts, abuse has referred to non-medical or unsanctioned patterns of use, irrespective of consequences. Thus the definition published in 1969 by the WHO Expert Committee on Drug Dependence was 'persistent or sporadic excessive drug use inconsistent with or unrelated to acceptable medical practice'. The term drug use is often preferred as it is non-judgemental.

\title{
Drug control
}

The regulation, by a system of laws and agencies, of the production, distribution, sale and use of specific psychoactive drugs (controlled substances) locally, nationally or internationally. This is the legal aspect of drug policy.

\section{Drug policy}

In the context of psychoactive drugs, the aggregate of policies designed to affect the supply and/or demand for Illicit drugs, locally or nationally, including education, treatment, control and other programmes and polices to reduce the harms related to illicit drug use. In this context, 'drug policy' often does not include pharmaceutical policy (except with regard to diversion to non-medical use), or tobacco or alcohol policy. In the context of the WHO's Action Programme on Essential Drugs, 'national drug policy' refers to a national pharmaceutical policy concerning the marketing, availability and therapeutic use of medicines.

\section{Harm reduction}

In the context of alcohol or other drugs, harm reduction describes policies or programmes that focus directly on reducing the harm resulting from the use of alcohol or other drugs. The term is used particularly of policies or programmes that aim to reduce the harm without necessarily affecting the underlying drug use; examples include maintenance treatment in opioid dependence and needle/syringe exchanges to counteract needle sharing among heroin users. Harm reduction can be used either to refer to goals (focusing on the harm rather than on use per se) or to means (e.g. needle exchanges, opioid substitution therapy, etc); in the latter sense, it is often contrasted to the dichotomy of supply reduction and demand reduction.

\section{Illicit drug}


A psychoactive substance, the possession, production, sale or use of which is prohibited.

Strictly speaking, it is not the Drug that is illicit, but its possession, production, sale or use in particular circumstances in a given jurisdiction. Illicit drug market, a more exact term, refers to the production, distribution, and sale of any drug outside legally sanctioned channels.

\section{Legalisation}

Legalisation is a process of repealing a prohibition (in criminal law) on a given behaviour or product - in this context, supply, possession or use of an illicit drug. The process is often coupled with a governmental effort to control or influence the market for the affected behaviour or product. The term should be distinguished from decriminalisation, which refers to a reduction in the seriousness of an offence or of the penalties it attracts, and specifically the move from a criminal sanction to a civil or administrative one.

\section{Maintenance treatment}

A method of medical management that involves prescribing and administration of a pharmaceutical drug as a 'substitute' for an illicit drug, to patients who have become dependent. It is most commonly used for opioid dependence (e.g. treatment with methadone or buprenorphine - commonly called opioid substitution treatment). The aim is to attenuate withdrawal symptoms, diminish opioid craving and arrive at a tolerance threshold, while preventing euphoria and sedation from overmedication.

\section{Opiate}

An opiate is an addictive drug, derived from the opium poppy, which reduces pain, induces sleep and may alter mood or behaviour (see opioids). This term excludes synthetic opioids.

\section{Opioid}

A generic term applied to alkaloids from the opium poppy (opiates), their synthetic analogues and compounds synthesised in the body that interact with specific receptors in the brain and reduce pain, induce sleep and may alter mood or behaviour. In high doses they can cause stupor, coma and respiratory depression. Opium alkaloids and their semi-synthetic analogues include morphine, diacetylmorphine (diamorphine, heroin), hydromorphine, codeine and oxycodone. Synthetic opioids include buprenoprhine, methadone, pethidine, pentazocine and tramadol.

\section{Overdose}

The use of any drug in such an amount that acute adverse physical or mental effects are produced. It usually implies an amount that constitutes a mortal risk. Deliberate overdose is a common means of suicide and attempted suicide. In absolute numbers, overdoses of licit drugs are usually more common than those of illicit drugs. Overdose may produce transient or lasting effects, or death; the lethal dose of a particular drug varies with the individual and with circumstances. Poisoning is a near-synonym in external-cause diagnostic codes.

\section{Problem drug use}

There are varying definitions for problem drug use. In its broadest sense, according to the United Nations Office on Drugs and Crime (UNODC), problem drug use is used to describe individuals who inject Drugs and/or are considered dependent, facing serious social and health consequences as a result. For statistical purposes, the definitions and methods of calculation 
differ from country to country. The European Monitoring Centre for Drugs and Drug Addiction (EMCDDA) defines problem drug use as 'injecting drug use or long duration/regular use of opioids, cocaine and/or amphetamines'.

\section{Prohibition}

Policy under which the cultivation, manufacture, and/or sale (and sometimes the use) of a psychoactive drug are prohibited under criminal law (although pharmaceutical sales are usually permitted).

\section{Psychoactive drug or substance}

A substance that, when ingested, affects mental processes (e.g. cognition, mood, sensation and behaviour). This term and its equivalent, Psychotropic drug, are the most neutral and descriptive terms for the whole class of substances, licit and illicit, of interest to drug policy. 'Psychoactive' does not necessarily imply dependence producing, and in common parlance the term is often left unstated, as in drug use/drug abuse or substance abuse/substance use.

\section{Recreational use}

Use of a drug, usually an illicit drug, in sociable or relaxing circumstances, by implication without dependence or other problems. The term is not favoured by those seeking to define all illicit drug use as a problem.

\section{Relapse}

A return to drug use after a period, of abstinence or controlled use, often accompanied by reinstatement of dependence symptoms. Some distinguish between relapse and lapse ('slip'), with the latter denoting an isolated occasion of alcohol or drug use.

\section{Substitution treatment}

Treatment of dependence on a psychoactive drug with a substitute drug with cross-dependence and cross-tolerance. The goal is to reduce or eliminate use of the original drug and/or to reduce harm from a particular method of administration.

\section{Tolerance}

A decrease in response to a drug dose that occurs with continued use. Increased doses of alcohol or other drugs are required to achieve the effects originally produced by lower doses.

Physiological and psychosocial factors may contribute to the development of tolerance, which may be physical, behavioural or psychological. With respect to physiological factors, both metabolic and/or functional tolerance may develop. By increasing the rate of metabolism of the substance, the body may be able to eliminate the substance more readily. Functional tolerance is defined as a decrease in sensitivity of the central nervous system to the substance. Behavioural tolerance is a change in the effect of a drug as a result of learning or alteration of environmental constraints. Acute tolerance is rapid, temporary accommodation to the effect of a substance following a single dose. Reverse tolerance, also known as sensitisation, refers to a condition in which the response to a substance increases with repeated use. Tolerance is one of the criteria for the dependence syndrome. 


\section{Withdrawal syndrome}

A group of symptoms of variable clustering and degree of severity that occur on cessation or reduction of use of a Psychoactive substance that has been taken repeatedly, usually for a prolonged period and/or in high doses. The syndrome may be accompanied by signs of physiological disturbance. A withdrawal syndrome is one of the indicators of a dependence syndrome. It is also the defining characteristic of the narrower psychopharmacological meaning of dependence. The onset and course of the withdrawal syndrome are time limited and are related to the type of substance and dose being taken immediately before cessation or reduction of use. Typically, the features of a withdrawal syndrome are the opposite of those of acute intoxication. 


\section{References}

1. Ban Ki-moon (UN Secretary General). Message on International Day Against Drug Trafficking and Abuse, 26 June 2015. New York: United Nations Information Office. 2015.

http://www.unis.unvienna.org/unis/en/pressrels/2015/unissgsm645.html (accessed 15 August 2015).

2. United Nations General Assembly. Transforming our world: the 2030 agenda for sustainable development. New York: United Nations. 2015.

3. West Africa Commission on Drugs. Not just in transit: drugs, the state and society in West Africa. Accra, 2014.

4. United Nations High Commissioner for Human Rights. Study on the impact of the world drug problem on the enjoyment of human rights. Human Rights Council, 30th session. 2015.

5. United Nations General Assembly. Political Declaration of the UN General Assembly Special Session on the World Drug Problem. 1998.

6. United Nations Single Convention on Narcotic Drugs. 1961 as amended by the 1972 Protocol amending the Single Convention on Narcotic Drugs. New York: United Nations; 1961.

7. United Nations Office on Drugs and Crime (UNODC). World Drug Report. Vienna; 2015.

8. McAllister WB. Reflections on a century of international drug control. In Collins J, ed.

Governing the global drug wars. London: London School of Economics, 2012: 10-6.

9. Collins J. The economics of new global strategy. In Collins J, ed. Ending the drug wars: Report of the LSE Expert Group on the Economics of Drug Policy. London School of Economics; 2014. p. 8-15.

10. United Nations International Drug Control Programme. Key Statistics: Illicit Drug Production, Trafficking and Consumption. Information sheet no. 2 for UN General Assembly Special Session on the World Drug Problem. Vienna; 1998.

11. United Nations Office on Drugs and Crime. World drug report. Vienna; 2008.

12. United Nations Commission on Narcotic Drugs. Joint Ministerial Statement of the 2014 High-

Level Review by the Commission on Narcotic Drugs of the implementation by member states of the Political Declaration and Plan of Action on International Cooperation towards an integrated and balanced strategy to counter the world drug problem. 2014.

13. United Nations Development Programme. Addressing the development dimensions of drug policy. New York 2015.

14. World Health Organization Executive Board. Public health dimension of the world drug problem including in the context of the Special Session of the United Nations General Assembly on the World Drug Problem, to be held in 2016: Report of the secretariat. $138^{\text {th }}$ session, doc. EB 138/11, 2016.

15. Organization of American States. The drug problem in the Americas. Washington, D.C.; 2013.

16. Global Commission on Drug Policy. War on Drugs. 2011.

17. Latin American Commission on Drugs and Democracy. Drugs and democracy: toward a paradigm shift. Rio de Janeiro; 2010.

18. Global Commission on HIV and the Law. HIV and the law: risks, rights, and health. New York; 2012.

19. United Nations Office on Drugs and Crime Regional Centre for East Asia and the Pacific. Drugfree ASEAN 2015: status and recommendations. Bangkok; 2008.

20. Fawthrop T. 'Drug free' ASEAN by 2015? Diplomat, 8 August 2015.

http://thediplomat.com/2015/08/drug-free-asean-by-2015/ (accessed 15 August 2015).

21. Centers for Disease Control and Prevention. CDC Vital Signs: Today's heroin epidemic. 2015. http://www.cdc.gov/vitalsigns/heroin/ (accessed 16 August 2015).

22. King NB, Fraser V, Boikos C, Richardson R, Harper S. Determinants of increased opioid-related mortality in the United States and Canada, 1990-2013: a systematic review. Am J Public Health 2014; 104: e32-e42.

23. Canadian HIV/AIDS Legal Network CDPC. Drug policy and overdose prevention and response. Toronto and Vancouver; 2015. 
24. Zezima K. Presidential candidates are actually talking about America's heroin issue. Washington Post 3 June 2015. https://www.washingtonpost.com/politics/drug-epidemic-shapes-messages-on-thepresidential-campaign-trail/2015/06/03/2f63761c-00d0-11e5-805c-c3f407e5a9e9 story.html (accessed 4 Sept 2015).

25. Case A, Deaton A. Rising morbidity and mortality in midlife among white non-Hispanic Americans in the 21st century. Proc Natl Acad Sci USA 2015; 112: 15078-83.

26. Seelye KQ. In heroin crisis, white families seek gentler war on drugs. New York Times 30 October 2015. http://www.nytimes.com/2015/10/31/us/heroin-war-on-drugs-parents.html?_r=0 (accessed 16 January 2016).

27. Pardo B. Cannabis policy reforms in the Americas: a comparative analysis of Colorado, Washington, and Uruguay. Int J Drug Policy 2014; 25: 727-35.

28. Ingold J. Marijuana case filings plummet in Colorado following legalization. Denver Post. 2014.

29. World Health Organization. World Report on Violence and Health. Geneva; 2002.

30. World Health Organization, UN Office on Drugs and Crime, UN Development Programme. Global status report on violence prevention 2014. Geneva; 2014.

31. Collaborators in the Global Burden of Disease Study. Global, regional, and national age-sex specific all-cause and cause-specific mortality for 240 causes of death, 1990-2013: a systematic analysis for the Global Burden of Disease Study 2013. Lancet 2015; 385: 117-71.

32. Osorio J. The contagion of drug violence: spatiotemporal dynamics of the Mexican war on drugs. J Conflict Resolution 2015; 59: 1403-32.

33. United Nations Office on Drugs and Crime (UNODC). World crime trends and emerging issues and responses in the field of crime prevention and criminal justice. 23rd session, Commission on Crime Prevention and Criminal Justice. Vienna, 2014.

34. United Nations Office on Drugs and Crime (UNODC). Transnational organized crime in Central America and the Caribbean: a threat assessment. Vienna; 2012.

35. Center for Gender and Refugee Studies. A treacherous journey: child migrants navigating the U.S. immigration system. Hastings College of Law, San Francisco; 2014.

36. Mares A. The Rise of femicide and women in drug trafficking. Washington, DC: Council on Hemispheric Affairs, 2011.

37. Fox E. How the drug trade fuels femicide in Central America. InsightCrime, 19 July 2012. http://www.insightcrime.org/news-analysis/how-the-drug-trade-fuels-femicide-in-central-america (accessed 19 September 2015).

38. Cantor DJ. The new wave: forced displacement caused by organized crime in Central America and Mexico. Refugee Surv $Q$ 2014; 33: 34-68.

39. Atuesta Becerra L. Addressing the costs of prohibition: Internally displaced populations in Colombia and Mexico. In: Collins J, ed. Ending the Drug Wars: Report of the LSE Expert Group on the Economics of Drug Policy. London School of Economics; 2014: 49-54.

40. Norwegian Refugee Council. Displacement in the wake of violence in Central America: Humanitarian implications and protection needs. Oslo; 2014.

41. Robinson LK. Arrived: the crisis of unaccompanied children at our southern border. Pediatrics 2015; 135: 205-7.

42. Canudas-Romo V, García-Guerrero VM, Echarri-Cánovas CJ. The stagnation of the Mexican male life expectancy in the first decade of the 21st century: the impact of homicides and diabetes mellitus. $J$ Epidemiol Comm Health 2015; 69: 28-34.

43. Gonzalez-Perez GJ, Vega-Lopez MG, Cabrera-Pivaral CE. Impact of homicide on male life expectancy in Mexico. Pan Am J Public Health 2012; 32: 335-42.

44. Kim HJ, Fay MP, Feuer EJ, Midthune DN. Permutation tests for joinpoint regression with applications to cancer rates. Stat Med 2000; 19: 335-51.

45. Mexican National Institute of Statistics and Geography (INEGI). Administrative registers of death. 2014. http://www.inegi.org.mx/est/contenidos/proyectos/registros/vitales/mortalidad/default.aspx (accessed 17 August 2015). 
46. Heinle K, Molzahn C, Shirk DA. Drug violence in Mexico; data analysis through 2014.

University of San Diego: Justice in Mexico Project; 2015.

47. Espinosa V, Rubin DB. Did the military interventions in the Mexican drug war increase violence? Am Statistician 2015; 69: 17-27.

48. Perez Correa C, Azeola E. Resultados de la primera encuesta realizada en los Centros Federales de Readaptación Social Mexico City: CIDE, 2012.

49. Madrazo Lajous A. The constitutional costs of the 'war on drugs'. In: Collins J, ed. Ending the war on drugs: Report of the LSE Expert Group on the Economics of Drug Policy. London School of Economics; 2014: 55-60.

50. Mejia D, Restrepo P. Why is strict prohibition collapsing? In: Collins J, ed. Ending the war on drugs: Report of the LSE Expert Group on the Economics of Drug Policy. London School of Economics; 2014: 26-32.

51. Legalising marijuana: the view from Mexico. Economist, 2 November 2012.

52. Grillo I. Legalization of marijuana has hit Mexican cartels' cross-border trade. Time, 8 April

2015.

53. Mejia D, Restrepo P. Bushes and bullets: Illegal cocaine markets and violence in Colombia.

Documento CEDE \# 53. Bogotá: Universidad de los Andes; 2013.

54. United Nations General Assembly. Resolution adopted by the General Assembly on 20 December 2012: international cooperation against the world drug problem. UN doc. A/RES/67/193, 23 April 2013.; 2012.

55. Degenhardt L, Mathers B, Vickerman P, Rhodes T, Latkin C, Hickman M. Prevention of HIV infection for people who inject drugs: why individual, structural, and combination approaches are needed. Lancet 2010; 376: 285-301.

56. Degenhardt L, Mathers BM, Wirtz AL, et al. What has been achieved in HIV prevention, treatment and care for people who inject drugs, 2010-2012? A review of the six highest burden countries. Int J Drug Policy 2014; 25: 53-60.

57. UNAIDS. The gap report. Geneva; 2014.

58. UNAIDS. How AIDS changed everything. Geneva; 2015.

59. World Health Organization. Guidelines for the screening, care and treatment of persons with hepatitis C infection. Geneva; 2014.

60. Hagan H, Pouget ER, Des Jarlais DC, Lelutiu-Weinberger C. Meta-regression of hepatitis C virus infection in relation to time since onset of illicit drug injection: the influence of time and place. Am J Epidemiol 2008; 168: 1099-109.

61. Vickerman P, Martin NK, Roy A, et al. Is the HCV-HIV co-infection prevalence amongst injecting drug users a marker for the level of sexual and injection related HIV transmission? Drug Alcohol Dep 2013; 132: 172-81.

62. World Health Organization, United Nations Office on Drugs and Crime, UN Joint Programme on HIV/AIDS. Technical guide for countries to set targets for universal access to HIV prevention, treatment and care for injecting drug users - 2012 revision. . Geneva; 2012.

63. Wodak A, Cooney A. Effectiveness of sterile needle and syringe programming in reducing HIV/AIDS among injecting drug users. Geneva: World Health Organization; 2004.

64. Aspinall EJ, Nambiar D, Goldberg DJ, et al. Are needle and syringe programmes associated with a reduction in HIV transmission among people who inject drugs: a systematic review and meta-analysis.

Int J Epidemiol 2014; 43: 235-48.

65. MacArthur GJ, van Velzen E, Palmateer N, et al. Interventions to prevent HIV and Hepatitis C in people who inject drugs: a review of reviews to assess evidence of effectiveness. Int J Drug Policy 2014; 25: $34-52$.

66. Turner KM, Hutchinson S, Vickerman P, et al. The impact of needle and syringe provision and opiate substitution therapy on the incidence of hepatitis $\mathrm{C}$ virus in injecting drug users: pooling of UK evidence. Addiction 2011; 106: 1978-88. 
67. MacArthur GJ, Minozzi S, Martin N, et al. Opiate substitution treatment and HIV transmission in people who inject drugs: systematic review and meta-analysis. BMJ (Clinical Research Ed.) 2012; 345: e5945.

68. Tsui JI, Evans JL, Lum PJ, Hahn JA, Page K. Association of opioid agonist therapy with lower incidence of hepatitis $\mathrm{C}$ virus infection in young adult injection drug users. JAMA Intern Med 2014; 174: 1974-81.

69. Nolan S, Lima VD, Fairbairn N, et al. The impact of methadone maintenance therapy on heptatis C incidence among illicit drug users. Addiction 2014; 109: 2053-9.

70. White B, Dore GJ, Lloyd AR, Rawlinson WD, Maher L. Opioid substitution therapy protects against hepatitis $\mathrm{C}$ virus acquisition in people who inject drugs: the HITS-c study. The Medical journal of Australia 2014; 201: 326-9.

71. Palmateer NE, Taylor A, Goldberg DJ, et al. Rapid decline in HCV incidence among people who linject drugs associated with national scale-up in coverage of a combination of harm reduction interventions. PLoS One 2014; 9(8): e104515.

72. van Den Berg C, Smit C, Van Brussel G, Coutinho R, Prins M. Full participation in harm reduction programmes is associated with decreased risk for human immunodeficiency virus and hepatitis C virus: evidence from the Amsterdam Cohort Studies among drug users. Addiction 2007; 102: 1454-62. 73. Vickerman P, Martin N, Turner K, Hickman M. Can needle and syringe programmes and opiate substitution therapy achieve substantial reductions in hepatitis $\mathrm{C}$ virus prevalence? Model projections for different epidemic settings. Addiction 2012; 107: 1984-95.

74. Guise A, Kazatchkine M, Rhodes T, Strathdee SA. Successful methadone delivery in East Africa and its global implications. Clin Infect Dis 2014; 59: 743-44.

75. European Monitoring Centre on Drugs and Drug Addiction (EMCDDA). European drug report 2015: trends and development. Lisbon; 2015.

76. Harm Reduction International. Global state of harm reduction. London; 2014.

77. Vagenas P, Azbel L, Polonsky M, et al. A review of medical and substance use co-morbidities in Central Asian prisons: implications for HIV prevention and treatment. Drug Alcohol Dep2013; 132 Suppl 1: S25-31.

78. Hoang TV, Ha TT, Hoang TM, Nhu NT, Quoc NC, Tam N et al. Impact of a methadone maintenance therapy pilot in Vietnam and its role in a scaled-up response. Harm Reduct J 2015;12:39.

79. Vickerman P, Platt L, Jolley E, Rhodes T, Kazatchkine MD, Latypov A. Controlling HIV among people who inject drugs in Eastern Europe and Central Asia: Insights from modelling. Int J Drug Policy 2014; 25: 1163-73.

80. Strathdee SA, Hallett TB, Bobrova N, et al. HIV and risk environment for injecting drug users: the past, present, and future. Lancet 2010; 376: 268-84.

81. Wolfe D. Paradoxes in antiretroviral treatment for injecting drug users: access, adherence and structural barriers in Asia and the former Soviet Union. Int J Drug Policy 2007; 18: 246-54.

82. Kerr T, Marshall BD, Milloy MJ, et al. Patterns of heroin and cocaine injection and plasma HIV-1 RNA suppression among a long-term cohort of injection drug users. Drug Alcohol Dep 2012; 124: 10812.

83. Wolfe D, Carrieri MP, Shepard D. Treatment and care for injecting drug users with HIV infection: a review of barriers and ways forward. Lancet 2010; 376: 355-66.

84. Reddon H, Milloy MJ, Simo A, Montaner J, Wood E, Kerr T. Methadone maintenance therapy decreases the rate of antiretroviral therapy discontinuation among HIV-positive illicit drug users. AIDS Behav 2014; 18: 740-6.

85. Bach P, Wood E, Dong H, et al. Association of patterns of methadone use with antiretroviral therapy discontinuation: a prospective cohort study. BMC Infect Dis 2015; 15: 537.

86. Lappalainen L, Nolan S, Dobrer S, et al. Dose-response relationship between methadone dose and adherence to antiretroviral therapy among HIV-positive people who use illicit opioids. Addiction 2015; 110(8): 1330-9. 
87. Lin C, Cao X, Li L. Integrating antiretroviral therapy in methadone maintenance therapy clinics: service provider perceptions. Int J Drug Policy 2014; 25: 1066-70.

88. Bachireddy C, Soule MC, Izenberg JM, Dvoryak S, Dumchev K, Altice FL. Integration of health services improves multiple healthcare outcomes among HIV-infected people who inject drugs in Ukraine. Drug Alcohol Dep2014; 134: 106-14.

89. Latypov A, Grund J-P, El-Bassel N, Platt L, Stöver H, Strathdee S. Illicit drugs in Central Asia: What we know, what we don't know, and what we need to know. Int J Drug Policy 2014; 25: 1155-62.

90. Momenghalibaf A. Hepatitis C treatment: Price, profits, and barriers to access. New York: Open Society Foundations, 2013.

91. Ford N, Singh K, Cooke GS, et al. Expanding access to treatment for hepatitis C in resourcelimited settings: lessons from HIV/AIDS. Clin Infect Dis 2012; 54: 1465-72.

92. Grebely J, Haire B, Taylor LE, et al. Excluding people who use drugs or alcohol from access to hepatitis C treatments - Is this fair, given the available data? J Hepatol 2015; 63: 779-82.

93. Aspinall EJ, Corson S, Doyle JS, et al. Treatment of hepatitis C virus infection among people who are actively injecting drugs: a systematic review and meta-analysis. Clin Infect Dis 2013; 57 Suppl 2: S80-9.

94. Martin NK, Vickerman P, Grebely J, et al. Hepatitis C virus treatment for prevention among people who inject drugs: Modeling treatment scale-up in the age of direct-acting antivirals. Hepatol 2013; 58: $1598-609$.

95. Martin NK, Vickerman P, Miners A, et al. Cost-effectiveness of hepatitis C virus antiviral treatment for injection drug user populations. Hepatol 2012; 55: 49-57.

95. Martin NK, Hickman M, Hutchinson SJ, Goldberg DJ, Vickerman P. Combination interventions to prevent HCV transmission among people who inject drugs: modeling the impact of antiviral treatment, needle and syringe programs, and opiate substitution therapy. Clin Infect Dis 2013; 57 Suppl 2: S39-45. 97. Wolfe D, Luhmann N, Harris M, et al. Human rights and access to hepatitis C treatment for people who inject drugs. Int J Drug Policy 2015; 26: 1072-80.

98. World Health Organization U, UN Office on Drugs and Crime, et al. HIV and young men who have sex with men: Technical brief. Geneva: WHO, 2015.

99. Shoptaw S, Reback CJ. Methamphetamine use and infectious disease-related behaviors in men who have sex with men: implications for interventions. Addiction 2007; 102: 130-5.

100. Daskalopoulou M, Rodger A, Phillips AN, et al. Recreational drug use, polydrug use, and sexual behaviour in HIV-diagnosed men who have sex with men in the UK: results from the cross-sectional ASTRA study. Lancet HIV 2014; 1(1): e22-31.

101. Nguyen TV, Van Khuu N, Nguyen PD, et al. Sociodemographic factors, sexual behaviors, and alcohol and recreational drug use associated with HIV among men who have sex with men in Southern Vietnam. AIDS Behav 2016 (epub ahead of print).

102. Melendez-Torres GJ, Bourne A. Illicit drug use and its association with sexual risk behaviour among MSM: more questions than answers? Curr Opin Infect Dis 2016; 29: 58-63.

103. Milloy MJ, Wood E. Emerging role of supervised injecting facilities in human immunodeficiency virus prevention. Addiction 2009; 104: 620-1.

104. Pinkerton SD. How many HIV infections are prevented by Vancouver Canada's supervised injection facility? Int J Drug Policy 2011; 22: 179-83.

105. Coffin PO, Rowe C, Santos GM. Novel interventions to prevent HIV and HCV among persons who inject drugs. Curr HIV/AIDS Rep 2015; 12: 145-63.

106. Choopanya K, Martin M, Suntharasamai P, et al. Antiretroviral prophylaxis for HIV infection in injecting drug users in Bangkok, Thailand (the Bangkok Tenofovir Study): a randomised, double-blind, placebo-controlled phase 3 trial. Lancet 2013; 381: 2083-90.

107. Atun R, Kazatchkine M. The Global Fund's leadership on harm reduction: 2002-2009. Int J Drug Policy 2010; 21: 103-6. 
108. Bridge J, Hunter BM, Albers E, et al. The Global Fund to Fight AIDS, Tuberculosis and Malaria's investments in harm reduction through the rounds-based funding model (2002-2014). Int J Drug Policy 2016; 27: 132-7.

109. Panitchpakdi P. The imbalance between government and civil society in Global Fund processes: A View from Thailand. Glob Fund Obs 2006; (65).

110. C. Cook C, Bridge J, McLean S, Phelan M, Barrett D. The funding crisis for harm reduction: donor retreat, government neglect and the way forward. London: Harm Reduction International, International HIV/AIDS Alliance and International Drug Policy Consortium, 2014.

111. Eurasian Harm Reduction Network. Alert announcement: Serbia is losing harm reduction! (online), 2015.http://www.harm-reduction.org/blog/alert-announcement-serbia-losing-harm-reduction (accessed 24 Sept 2015).

112. Harm Reduction International. 10 by 20: a call to redirect resources from the war on drugs to harm reduction $-10 \%$ by 2020 . London, 2015.

113. Niculescu I, Paraschiv S, Paraskevis D, et al. Recent HIV-1 Outbreak Among Intravenous Drug Users in Romania: Evidence for Cocirculation of CRF14_BG and Subtype F1 Strains. AIDS Res Human Retrovir2014; 31: 488-95.

114. Botescu A, Abagiu A, Mardarescu M, Ursan M. HIV/AIDS among injecting drug users in Romania: Report of a recent outbreak and initial response policies. European Monitoring Centre on Drugs and Drug Addiction (EMCDDA), Lisbon; 2012.

115. Oprea C. Victor Babes Hospital, Bucharest, personal communication; 2015.

116. Paraskevis D, Nikolopoulos G, Fotiou A, et al. Economic Recession and Emergence of an HIV-1 Outbreak among Drug Injectors in Athens Metropolitan Area: A Longitudinal Study. PLoS ONE 2013; 8(11): e78941.

117. Sarafis P, Tsounis A. Debt burden of Greece and HIV among injecting drug users. Lancet Infect Dis 2014; 14: 180-1.

118. European Monitoring Centre on Drugs and Drug Addiction (EMCDDA). Harm Reduction Overview for Greece (online). http://www.emcdda.europa.eu/country-data/harm-reduction/Greece (accessed 24 August 2015).

119. Strathdee SA, Beyrer C. Threading the needle — how to stop the HIV outbreak in rural Indiana. N Engl J Med 2015; 373: 397-9.

120. Ungar L. Funding ban on needle exchanges effectively lifted. 2016.

http://www.usatoday.com/story/news/nation/2016/01/07/funding-ban-needle-exchanges-effectivelylifted/78420894/ (accessed 18 January 2016).

121. Conrad C, Bradley HM, Broz D, et al. Community outbreak of HIV Infection linked to injection drug use of oxymorphone--Indiana, 2015. MMWR CDC Surveillance Summaries 2015; 64: 443-4.

122. Government of Australia National Centre in HIV Epidemiology and Clinical Research. Return on investment 2: evaluating the costeffectiveness of needle and syringe programs in Australia. Canberra; 2009.

123. Naning H, Kerr C, Kamarulzaman A, et al. Return on investment and cost-effectiveness of harm reduction program in Malaysia. Washington, DC: World Bank, 2014.

124. Wilson DP, Donald B, Shattock AJ, Wilson D, Fraser-Hurt N. The cost-effectiveness of harm reduction. Int J Drug Policy 2015; 26 Suppl 1: S5-11.

125. Brooner R, Kidorf M, King V, Beilenson P, Svikis D, Vlahov D. Drug abuse treatment success among needle exchange participants. Public Health Rep 1998;113(Suppl 1):129-39.

126. World Health Organization, United Nations Office on Drugs and Crime, UN Joint Programme on HIV/AIDS. Substitution maintenance therapy in the management of opioid dependence and HIV/AIDS prevention. Geneva; 2004.

127. Burris S. Law in a social determinants strategy: a public health law research perspective. Public Health Rep 2011; 126 Suppl 3: 22-7.

128. Lunze K, Raj A, Cheng DM, et al. Punitive policing and associated substance use risks among HIV-positive people in Russia who inject drugs. J Int AIDS Soc 2014; 17(1): 19043. 
129. Government of the Russian Federation. HIV infection in the Russian Federation. 2014.

http://www.hivrussia.ru/files/spravkaHIV2014.pdf (accessed 20 Sept 2015).

130. Canadian HIV AIDS Legal Network. egislating for health and human rights - model law on drug use and HIV/AIDS; Module 2: treatment for drug dependence. Toronto, 2006.

131. Tanguay P, Ngamee V. CHAMPION-IDU: Innovations, best practices, lessons learned. Bangkok, Population Services International; 2015.

132. Sarang A, Rhodes T, Sheon N. Systemic barriers accessing HIV treatment among people who inject drugs in Russia: a qualitative study. Health Policy Planning 2013; 28: 681-91.

133. Ti L, Hayashi K, Kaplan K, Suwannawong P, Wood E, Kerr T. Contextual factors associated with rushed injecting among people who inject drugs in Thailand. Prevention Sci 2015; 16: 313-20.

134. Ahmed T, Long TN, Huong PT, Stewart DE. Drug injecting and HIV risk among injecting drug users in Hai Phong, Vietnam: a qualitative analysis. BMC Public Health 2015; 15: 32.

135. Beletsky L, Heller D, Jenness SM, Neaigus A, Gelpi-Acosta C, Hagan H. Syringe access, syringe sharing, and police encounters among people who inject drugs in New York City: a community-level perspective. Int J Drug Policy 2014; 25(1): 105-11.

136. VOCAL-NY Users Union. Beyond methadone: improving health and empowering patients in opioid treatment programs. New York; 2015.

137. Open Society Foundations. To protect and serve: How police, sex workers, and people who use drugs are joining forces to improve health and human rights. New York; 2013.

138. Wood E, Kerr T, Small W, Jones J, Schechter MT, Tyndall MW. The Impact of a Police Presence on Access to Needle Exchange Programs. J Acquir Immune Defic Syndr 2003; 34: 116-7.

139. Maher L, Dixon D. Cost of Crackdowns: Policing Cabramatta's Herion Market, The. Curr Issues Crim Just 2001; 13: 5.

140. Kerr T, Small W, Wood E. The public health and social impacts of drug market enforcement: A review of the evidence. Int J Drug Policy 2005; 16: 210-20.

141. Bazazi AR, Zelenev A, Fu JJ, Yee I, Kamarulzaman A, Altice FL. High prevalence of non-fatal overdose among people who inject drugs in Malaysia: Correlates of overdose and implications for overdose prevention from a cross-sectional study. Int J Drug Policy 2015; 26: 675-81.

142. World Health Organization. Global tuberculosis report. Geneva, 2014.

143. World Health Organization, United Nations Office on Drugs and Crime, UN Joint Programme on HIV/AIDS. Policy guidelines for collaborative TB and HIV services for injecting and other drug users: an integrated approach (Evidence for Action Technical Papers. Geneva, 2008.

144. Getahun H, Gunneberg C, Sculier D, Verster A, Raviglione M. Tuberculosis and HIV in people who inject drugs: evidence for action for tuberculosis, HIV, prison and harm reduction services. Curr Opin HIV AIDS 2012; 7(4): 345-53.

145. Deiss RG, Rodwell TC, Garfein RS. Tuberculosis and Drug Use: Review and Update. Clin Infect Dis 2009; 48(1): 10.1086/594126.

146. World Health Organization. Drug-resistant tuberculosis: frequently asked questions. Geneva, 2012.

147. Schluger NW, El-Bassel N, Hermosilla S, et al. Tuberculosis, drug use and HIV infection in Central Asia: an urgent need for attention. Drug Alcohol Dep2013; 132 Suppl 1: S32-6.

148. World Health Organization. Policy guidelines for integrating collaborative TB and HIV services within the comprehensive package of harm reduction for people who inject drugs. Geneva, 2015.

149. Keshavjee S, Sweeney C, Yedilbayev A, Taran D, Solovyova A, Gelmanova I. The Sputnik Initiative: Patient-centered accompaniment for tuberculosis in Russia. Partners in Health Reports 2014; 1(2).

150. Al-Darraji HA, Wong KC, Yeow DG, et al. Tuberculosis screening in a novel substance abuse treatment center in Malaysia: implications for a comprehensive approach for integrated care. $J$ Subst Abuse Treat 2014; 46(2): 144-9.

151. Getahun H, Baddeley A, Raviglione M. Managing tuberculosis in people who use and inject illicit drugs. Bull World Health Organ 2013; 91(2): 154-6. 
152. World Health Organization. Consolidated guidelines on HIV prevention, diagnosis, treatment and care for key populations. Geneva; 2014.

153. Rosmarin A, Eastwood N. A quiet revolution: drug decriminalisation policies in practice across the globe. London: Release 2012.

154. United Kingdom Home Office. International comparators. London; 2014.

155. DeBeck K, Kerr T, Li K, Milloy MJ, Montaner J, Wood E. Incarceration and drug use patterns among a cohort of injection drug users. Addiction 2009; 104: 69-76.

156. Reinarman C, Cohen PD, Kaal HL. The limited relevance of drug policy: cannabis in Amsterdam and in San Francisco. Am J Public Health 2004; 94: 836-42.

157. Uprimny R, Esther D, Parra J. Addicted to punishment: The disproportionality of drug laws in Latin America. Colectivo de Estudios de Drogas y Derecho (CEDD). Mexico City; 2013.

158. Penal Reform International. Global prison trends 2015. London, 2015.

159. Giacomello C. How the drug trade criminalizes women disproportionately. NACLA Report on the Americas 2014; 47: 38-41.

160. Organization of American States Inter-American Commission of Women. Women and drugs in the Americas: A policy working paper. Washington, D.C., 2014.

161. Carson A. Prisoners in 2014. Washington, D.C.: Bureau of Justice Statistics (NCJ 248955), 2015.

162. O'Hara M. International drug crime measures 'lead to executions'. The Guardian. 2010.

163. Gallahue P, Gunawan R, Rahman F, El Mufti K, Din NU, Felten R. The death penalty for drug offences: global overview 2012. London: International Harm Reduction Association, 2012.

164. United Nations. Commentary on the Single Convention on Narcotic Drugs 1961, E.73.XI.1. 1971. p. 449-50.

165. Lines R, Barrett D, Gallahue P. The death penalty for drug offenses: Asian values or treaty influence? OpinioJuris, 21 May 2015. http://opiniojuris.org/2015/05/21/guest-post-the-death-penalty-fordrug-offences-asian-values-or-drug-treaty-influence/ (accessed 23 Sept 2015).

166. Grover A. Report of the Special Rapporteur on the right of everyone to the enjoyment of the highest attainable standard of physical and mental health, Human Rights UN General Assembly, 65th Session. UN doc. A/65/255. 2010.

167. Phipps C. Who were the eight people executed by Indonesia? Guardian, 29 April 2015. At: http://www.theguardian.com/world/2015/apr/29/bali-nine-who-are-the-nine-people-being-executed-byindonesia (accessed 14 Oct 2015).

168. Gallahue P. Drugs and the death penalty. New York: Open Society Foundations, 2015.

169. Walmsley R. World prison population list (10th ed.). Essex: International Centre for Prison Studies, 2013.

170. Snyder HN, Mulako-Wangota J. Arrests in the United States, 1980-2012. Bureau of Justice Statistics, Washington, D.C.; 2014.

171. Sentencing Project. Facts about prisons and people in prisons. Washington, DC, 2014. http://sentencingproject.org/doc/publications/inc_Facts\%20About\%20Prisons.pdf (accessed 2 Oct 2015).

172. Sentencing Project. Trends in U.S. corrections. Washington, D.C., 2014.

http://sentencingproject.org/doc/publications/inc_Trends_in_Corrections_Fact_sheet.pdf (accessed 2 October 2015)

173. Carson A. Prisoners in 2013. Washington, D.C.: U.S. Bureau of Justice Statistcs (NCJ 247282); 2014.

174. Levine HG, Siegel L. Marijuana madness: The scandal of New York City's racist marijuana possession arrests. In: Eterno JA, ed. The New York City Police Department: the impact of its policies and practices. New York: CRC Press; 2015: 117-61.

175. Snyder HN. Arrests in the United States, 1990-2010. Bureau of Justice Statistics, Washington, D.C.; 2012.

176. Widman L, Noar SM, Golin CE, Willoughby JF, Crosby R. Incarceration and unstable housing interact to predict sexual risk behaviours among African American STD clinic patients. Int $J$ STD \& AIDS 2014; 25(5): 348-54. 
177. Adimora AA, Schoenbach VJ, Martinson FE, Donaldson KH, Stancil TR, Fullilove RE. Concurrent partnerships among rural African Americans with recently reported heterosexually transmitted HIV infection. J Acquir Immune Defic Syndr 2003; 34: 423-9.

178. Johnson RC, Raphael S. The effects of male incarceration dynamics on acquired immune deficiency syndrome infection rates among African American women and men. J Law Econ 2009; 52(2): 251-93.

179. Jeffries S, Stenning P. Sentencing, aboriginal offenders: law, policy, and practice in three Countries. Can J Criminol Criminal Justice 2014; 56: 447-94.

180. Statistics Canada. Prison Statistics 2013-14. 2014. http://www.statcan.gc.ca/pub/85-002-x/2015001/article/14163-eng.htm\#a8 (accessed 4 October 2015). 181. Minority Rights Group International. World directory of minorities and indigenous peoples: Brazil -- Afro-Brazilians. London, 2014.

182. Horwitz S. Justice Department set to free 6,000 prisoners, largest one-time release. Washington Post, 6 October 2015. : https://www.washingtonpost.com/world/national-security/justice-departmentabout-to-free-6000-prisoners-largest-one-time-release/2015/10/06/961f4c9a-6ba2-11e5-aa5bf78a98956699 story.html (accessed 10 October 2015).

183. United Nations Economic and Social Council. United Nations Rules for the Treatment of Women Prisoners and Non-custodial Measures for Women Offenders (the Bangkok Rules). Doc. 2010/16. . New York; 2010.

184. Iakobishvili E. Cause for Alarm: The Incarceration of Women for Drug offences in Europe and Central Asia, and the need for legislative and Sentencing reform. London: International Harm Reduction Association, 2012.

185. UNODC, UN Women, World Health Organization, International Network of People Who Use Drugs. Women who inject drugs and HIV: addressing specific needs. Vienna; 2015.

186. Green KM, Ensminger ME, Robertson JA, Juon HS. Impact of adult sons' incarceration on African American mothers' psychological distress. J Marriage Family 2006; 68: 430-41.

187. Lee H, Wildeman C. Things fall apart: Health consequences of mass imprisonment for African American women. Rev Black Political Econ 2013; 40: 39-52.

188. Lee H, Wildeman C, Wang EA, Matusko N, Jackson JS. A heavy burden: the cardiovascular health consequences of having a family member incarcerated. Am J Public Health 2014; 104: 421-7. 189. Turney K. Stress proliferation across generations? Examining the relationship between parental incarceration and childhood health. J Health Soc Behav 2014; 55: 302-19.

190. Wakefield S, Wildeman C. Children of the prison boom: Mass incarceration and the future of American inequality: Oxford University Press; 2013.

191. Wildeman C, Lee H, Comfort M. A new vulnerable population? The health of female partners of men recently released from prison. Women's Health Issues 2013; 23: e335-e40.

192. Wildeman C, Muller C. Mass imprisonment and inequality in health and family life. Ann Rev Law Social Sci 2012; 8: 11-30.

193. Wildeman C, Schnittker J, Turney K. Despair by association? The mental health of mothers with children by recently incarcerated fathers. Am Sociolog Rev 2012; 77: 216-43.

194. Christian J. Riding the bus barriers to prison visitation and family management strategies. $J$ Contemporary Criminal Justice 2005; 21: 31-48.

195. Codd H. In the shadow of prison: Families, imprisonment and criminal justice: Willan; 2013.

196. Comfort M. Punishment beyond the legal offender. Annu Rev Law Soc Sci 2007; 3: 271-96.

197. Mannelli P. The burden of caring: drug users and their families. Indian J Medical Res 2013; 137:

636-8.

198. Comfort M. Doing time together: Love and family in the shadow of the prison: University of Chicago Press; 2009.

199. Richie BE. The social impact of mass incarceration on women. In Mauer M, Chesney-Lind M, eds. Invisible punishment: The collateral consequences of mass imprisonment. New York: New Press, 2002: $136-49$. 
200. Girshick LB. Soledad women: Wives of prisoners speak out. Westport, CT (USA): Greenwood Publishing Group; 1996.

201. Comfort M. "A twenty hour a day job": The repercussive effects of frequent low-level criminal justice involvement on family life. Ann Am Acad Pol Soc Sci In press.

202. Dolan K, Moazen B, Noori A, Rahimzadeh S, Farzadfar F, Hariga F. People who inject drugs in prison: HIV prevalence, transmission and prevention. Int J Drug Policy 2015; 26 Suppl 1: S12-5.

203. Culbert GJ, Waluyo A, Iriyanti M, Muchransyah AP, Kamarulzaman A, Altice FL. Within-prison drug injection among HIV-infected male prisoners in Indonesia: a highly constrained choice. Drug Alcohol Dep 2015; 149: 71-9.

204. Carpentier C, Royuela L, Noor A, Hedrich D. Ten years of monitoring illicit drug use in prison populations in Europe: issues and challenges. Howard J Criminal Justice 2012; 51: 37-66.

205. Jurgens R, Ball A, Verster A. Interventions to reduce HIV transmission related to injecting drug use in prison. Lancet Infect Dis 2009; 9: 57-66.

206. United Nations Office on Drugs and Crime (UNODC), UNAIDS, World Bank. HIV in prisons: Sub-Saharan Africa - opportunities for action. Vienna, 2007.

207. Hagan $\mathrm{H}$. The relevance of attributable risk measures to HIV prevention planning. Aids 2003; 17(6): 911-3.

208. Larney S, Kopinski H, Beckwith CG, et al. Incidence and prevalence of hepatitis $\mathrm{C}$ in prisons and other closed settings: results of a systematic review and meta-analysis. Hepatol 2013; 58(4): 1215-24.

209. Treloar C, McCredie L, Lloyd AR. Acquiring hepatitis C in prison: the social organisation of injecting risk. Harm Reduct $J$ 2015; 12: 10.

210. Bretana NA, Boelen L, Bull R, et al. Transmission of Hepatitis C Virus among prisoners, Australia, 2005-2012. Emerg Infect Dis 2015; 21: 765-74.

211. Bocai A, Iliuta C, Ursan M, Corciova M. HIV, HBV and HCV behavioral surveillance survey among injecting drug users in Bucharest, Romania. United Nations Office on Drugs and Crime, 2010. 212. Grau LE, White E, Niccolai LM, et al. HIV disclosure, condom use, and awareness of HIV infection among HIV-positive, heterosexual drug injectors in St. Petersburg, Russian Federation. AIDS Behav 2011; 15: 45-57.

213. Hope VD, Hickman M, Ngui SL, et al. Measuring the incidence, prevalence and genetic relatedness of hepatitis $\mathrm{C}$ infections among a community recruited sample of injecting drug users, using dried blood spots. $J$ Viral Hepat 2011; 18: 262-70.

214. Li L, Assanangkornchai S, Duo L, McNeil E, Li J. Risk behaviors, prevalence of HIV and hepatitis $\mathrm{C}$ virus infection and population size of current injection drug users in a China-Myanmar border city: results from a Respondent-Driven Sampling Survey in 2012. PLoS One 2014; 9(9): e106899.

215. Butler T, Boonwaat L, Hailstone S, et al. The 2004 Australian prison entrants' blood-borne virus and risk behaviour survey. Aust N Z J Public Health 2007; 31: 44-50.

216. Hickman M, Hope V, Brady T, et al. Hepatitis C virus (HCV) prevalence, and injecting risk behaviour in multiple sites in England in 2004. J Viral Hepat 2007; 14: 645-52.

217. Kheirandish P, SeyedAlinaghi S, Jahani M, et al. Prevalence and correlates of hepatitis C infection among male injection drug users in detention, Tehran, Iran. J Urban Health 2009; 86: 902-8. 218. Oliveira Mde L, Bastos FI, Telles PR, et al. Epidemiological and genetic analyses of Hepatitis C virus transmission among young/short- and long-term injecting drug users from Rio de Janeiro, Brazil. $J$ Clin Virol 2009; 44: 200-6.

219. Wood E, Kerr T, Stoltz J, et al. Prevalence and correlates of hepatitis C infection among users of North America's first medically supervised safer injection facility. Public Health 2005; 119: 1111-5.

220. Allen EJ, Palmateer NE, Hutchinson SJ, Cameron S, Goldberg DJ, Taylor A. Association between harm reduction intervention uptake and recent hepatitis $\mathrm{C}$ infection among people who inject drugs attending sites that provide sterile injecting equipment in Scotland. Int J Drug Policy 2012; 23: 346-52. 221. Cepeda JA, Niccolai LM, Lyubimova A, Kershaw T, Levina O, Heimer R. High-risk behaviors after release from incarceration among people who inject drugs in St. Petersburg, Russia. Drug Alcohol Dep 2015; 147: 196-202. 
222. Milloy MJ, Wood E, Small W, et al. Incarceration experiences in a cohort of active injection drug users. Drug Alcohol Rev 2008; 27: 693-9.

223. Milloy MJ, Buxton J, Wood E, Li K, Montaner JS, Kerr T. Elevated HIV risk behaviour among recently incarcerated injection drug users in a Canadian setting: a longitudinal analysis. BMC Public Health 2009; 9: 156.

224. Wood E, Li K, Small W, Montaner JS, Schechter MT, Kerr T. Recent incarceration independently associated with syringe sharing by injection drug users. Public Health Rep 2005; 120(2): 150-6.

225. Stone J, Martin NK, Hickman M. Incarceration of people who inject drugs: modelling its role in HCV transmission and the impact of scaled-up HCV treatment. Submitted.

226. Martin NK, Vickerman P, Brew I, et al. Is increased HCV case-finding combined with current or 8-12 week interferon-free DAA therapy cost-effective in UK prisons? A prevention benefit analysis. Hepatol 2016; In press.

227. Taylor A, Munro A, Allen E, et al. Low incidence of hepatitis $\mathrm{C}$ virus among prisoners in Scotland. Addiction 2013; 108: 1296-304.

228. Dolan K, Teutsch S, Scheuer N, et al. Incidence and risk for acute hepatitis C infection during imprisonment in Australia. Eur J Epidemiol 2010; 25: 143-8.

229. Luciani F, Bretana NA, Teutsch S, et al. A prospective study of hepatitis C incidence in Australian prisoners. Addiction 2014; 109: 1695-706.

230. Buavirat A, Page-Shafer K, van Griensven GJ, et al. Risk of prevalent HIV infection associated with incarceration among injecting drug users in Bangkok, Thailand: case-control study. BMJ (Clinical research ed) 2003; 326: 308.

231. Hayashi K, Ti L, Csete J, et al. Reports of police beating and associated harms among people who inject drugs in Bangkok, Thailand: a serial cross-sectional study. BMC Public Health 2013; 13: 733.

232. Biadglegne F, Rodloff AC, Sack U. Review of the prevalence and drug resistance of tuberculosis in prisons: a hidden epidemic. Epidemiol Infect 2015; 143(5): 887-900.

233. Stuckler D, Basu S, McKee M, King L. Mass incarceration can explain population increases in TB and multidrug-resistant TB in European and central Asian countries. Proc Natl Acad Sci USA 2008; 105(36): 13280-5.

234. World Health Organization - Europe, UNODC. Good governance for prison health in the 21st century. A policy brief on the organization of prison health. Copenhagen, 2013.

235. European Centre for Disease Prevention and Control. Thematic report: prisoners -- Monitoring implementation of the Dublin Declaration on Partnership to fight HIV/AIDS in Europe and Central Asia: 2012 progress report. Stockholm, 2013.

236. UNAIDS (Joint United Nations Programme on HIV/AIDS). Country report - Ukraine (online). http://www.unaids.org/en/regionscountries/countries/ukraine/ (accessed 26 August 2015).

237. Russian Federation. Statistics of the federal pentitentiary system (online). http://xn--h1akkl.xn-p1ai/statistics/ (accessed 4 September 2015).

238. United Nations General Assembly. Basic principles for the treatment of prisoners. UN doc. A/RES/45/111, 14 December 1990.

239. United Nations Office on Drugs and Crime (UNODC), World Health Organizations, UNAIDS, UN Development Programme, International Labour Organization. Policy brief: HIV prevention, treatment and care in prisons and other closed settings: a comprehensive package of interventions. Vienna, 2013. 240. European Monitoring Centre on Drugs and Drug Addiction (EMCDDA). Prisons and drugs in Europe: the problem and responses. Lisbon, 2012.

241. Kopak AM. Breaking the addictive cycle of the system: improving US criminal justice practices to address substance use disorders. Int J Prison Health 2015; 11: 4-16.

242. Martin NK, Vickerman P, Dore GJ, Hickman M. The hepatitis C virus epidemics in key populations (including people who inject drugs, prisoners and MSM): the use of direct-acting antivirals as treatment for prevention. Curr Opin HIV AIDS 2015; 10: 374-80.

243. Spaulding AS, Kim AY, Harzke AJ, et al. Impact of new therapeutics for hepatitis C virus infection in incarcerated populations. Topics Antiviral Med 2013; 21: 27-35. 
244. Mitruka K, Tsertsvadze T, Butsashvili M, et al. Launch of a nationwide hepatitis C elimination program - Georgia, April 2015. MMWR CDC Surveillance Summaries 2015; 64: 753-7.

245. Westergaard RP, Spaulding AC, Flanigan TP. HIV among persons incarcerated in the USA: a review of evolving concepts in testing, treatment, and linkage to community care. Curr Opin Infect Dis 2013; 26: 10-6.

246. Small W, Wood E, Betteridge G, Montaner J, Kerr T. The impact of incarceration upon adherence to HIV treatment among HIV-positive injection drug users: a qualitative study. AIDS Care 2009; 21: 70814.

247. Milloy MJ, Kerr T, Buxton J, et al. Dose-response effect of incarceration events on nonadherence to HIV antiretroviral therapy among injection drug users. J Infect Dis 2011; 203: 1215-21.

248. Westergaard RP, Kirk GD, Richesson DR, Galai N, Mehta SH. Incarceration predicts virologic failure for HIV-infected injection drug users receiving antiretroviral therapy. Clin Infect Dis 2011; 53(7): 725-31.

249. Werb D, Milloy MJ, Kerr T, Zhang R, Montaner J, Wood E. Injection drug use and HIV antiretroviral therapy discontinuation in a Canadian setting. AIDS Behav 2013; 17: 68-73.

250. Wakeman SE, Rich JD. HIV treatment in US prisons. HIV Therapy 2010; 4: 505-10.

251. Jurgens R. Interventions to address HIV in prison (Evidence for Action series). Geneva: World Health Organization, 2007.

252. Culbert G, Bazazi A, Waluyo A, et al. The Influence of Medication Attitudes on Utilization of Antiretroviral Therapy (ART) in Indonesian Prisons. AIDS Behav 2015: 1-13.

253. Todrys KW, Amon JJ, Malembeka G, Clayton M. Imprisoned and imperiled: access to HIV and TB prevention and treatment, and denial of human rights, in Zambian prisons. J Int AIDS Soc 2011; $14: 8$. 254. Shalihu N, Pretorius L, van Dyk A, Vander Stoep A, Hagopian A. Namibian prisoners describe barriers to HIV antiretroviral therapy adherence. AIDS Care 2014; 26: 968-75.

255. Chakrapani V, Kamei R, Kipgen H, Kh JK. Access to harm reduction and HIV-related treatment services inside Indian prisons: experiences of formerly incarcerated injecting drug users. Int J Prison Health 2013; 9(2): 82-91.

256. Alpert M, Wickersham JA, Vazquez M, Altice FL. Alcohol use disorders and antiretroviral therapy among prisoners in Argentina. Int J Prison Health 2013; 9: 40-50.

257. Prellwitz IM, Alves BM, Ikeda ML, et al. HIV behind bars: human immunodeficiency virus cluster analysis and drug resistance in a reference correctional unit from southern Brazil. PLoS One 2013; 8(7): e69033.

258. Wilson D, Ford N, Ngammee V, Chua A, Kyaw MK. HIV prevention, care, and treatment in two prisons in Thailand. PLoS Med 2007; 4(6): e204.

259. World Health Organization. Guidelines for intensified tuberculosis case-finding and isoniazid preventive therapy for people living with HIV in resource-constrained settings. Geneva, 2011.

260. Dara M, Acosta CD, Melchers NV, et al. Tuberculosis control in prisons: current situation and research gaps. Int J Infect Dis 2015; 32: 111-7.

261. Lee D, Lal SS, Komatsu R, Zumla A, Atun R. Global fund financing of tuberculosis services delivery in prisons. J Infect Dis 2012; 205 Suppl 2: S274-83.

262. Iroh PA, Mayo H, Nijhawan AE. The HIV Care Cascade Before, During, and After Incarceration: A Systematic Review and Data Synthesis. Am J Public Health 2015; 105(7): e5-16.

263. Pan American Health Organization. Improving access of key populations to comprehensive HIV Health Services: Towards a Caribbean consensus. Washington, DC: PAHO, 2011.

264. Mathers BM, Degenhardt L, Bucello C, Lemon J, Wiessing L, Hickman M. Mortality among people who inject drugs: a systematic review and meta-analysis. Bull World Health Organ 2013; 91: $102-$ 23.

265. World Health Organization. Community management of opioid overdose. Geneva, 2014.

266. Quan VM, Minh NL, Ha TV, et al. Mortality and HIV transmission among male Vietnamese injection drug users. Addiction 2011; 106: 583-9. 
267. Vanichseni S, Martin M, Suntharasamai P, et al. High mortality among non-HIV-infected people who inject drugs in Bangkok, Thailand, 2005-2012. Am J Public Health 2015; 105(6): 1136-41.

268. van Amsterdam J, van den Brink W. The misuse of prescription opioids: a threat for europe?

Current Drug Abuse rev 2015; 8: 3-14.

269. Polomeni P, Schwan R. Management of opioid addiction with buprenorphine: French history and current management. Int J Gen Med 2014; 7: 143-8.

270. Paone D, Tuazon E, Stajic M, et al. Buprenorphine infrequently found in fatal overdose in New York City. Drug Alcohol Dep 2015; 155: 298-301.

271. Hammersley R, Cassidy MT, Oliver J. Drugs associated with drug-related deaths in Edinburgh and Glasgow, November 1990 to October 1992. Addiction 1995; 90: 959-65.

272. Matusow H, Dickman SL, Rich JD, et al. Medication assisted treatment in US drug courts: Results from a nationwide survey of availability, barriers and attitudes. J Subst Abuse Treatment 2013; 44: 473-80.

273. Cole C, Jones L, McVeigh J, Kicman A, Syed Q, Bellis M. Adulterants in illicit drugs: a review of empirical evidence. Drug Festing Analysis 2011; 3: 89-96.

274. Mounteney J, Giraudon I, Denissov G, Griffiths P. Fentanyls: Are we missing the signs? Highly potent and on the rise in Europe. Int J Drug Policy 2015; 26: 626-31.

275. Farrell M, Hall W. Heroin-assisted treatment: has a controversial treatment come of age? $\mathrm{B} r J$ Psychiatry 2015; 207: 3-4.

276. Bohnert ASB, Nandi A, Tracy M, et al. Policing and risk of overdose mortality in urban neighborhoods. Drug Alcohol Dep 2011; 113: 62-8.

277. Farrell M, Marsden J. Acute risk of drug-related death among newly released prisoners in England and Wales. Addiction 2008; 103: 251-5.

278. European Monitoring Centre for Drugs and Drug Abuse (EMCDDA). Perspectives on drugs: preventing overdose deaths in Europe. Lisbon, 2015.

279. Carter C., B. G. Opioid overdose prevention and response in Canada. Vancouver: Canadian Drug Policy Coalition, 2013.

280. Marshall BD, Milloy MJ, Wood E, Montaner JS, Kerr T. Reduction in overdose mortality after the opening of North America's first medically supervised safer injecting facility: a retrospective population-based study. Lancet 2011; 377: 1429-37.

281. Kerr T, Stoltz JA, Tyndall M, et al. Impact of a medically supervised safer injection facility on community drug use patterns: a before and after study. BMJ (Clinical Research Ed.) 2006; 332: 220-2. 282. Kerr T, Tyndall MW, Zhang R, Lai C, Montaner JS, Wood E. Circumstances of first injection among illicit drug users accessing a medically supervised safer injection facility. Am J Public Health 2007; 97: 1228-30.

283. Wood E, Tyndall MW, Lai C, Montaner JS, Kerr T. Impact of a medically supervised safer injecting facility on drug dealing and other drug-related crime. Subst Abuse Treatment Prev Policy 2006; 1: 13.

284. Alexander L, Mannion RO, Weingarten B, Fanelli RJ, Stiles GL. Development and impact of prescription opioid abuse deterrent formulation technologies. Drug Alcohol Dep 2014; 138: 1-6.

285. Degenhardt L, Larance B, Bruno R, Lintzeris N, Ali R, Farrell M. Evaluating the potential impact of a reformulated version of oxycodone upon tampering, non-adherence and diversion of opioids: the National Opioid Medications Abuse Deterrence (NOMAD) study protocol. Addiction 2015; 110: 226-37. 286. Delcher C, Wagenaar AC, Goldberger BA, Cook RL, Maldonado-Molina MM. Abrupt decline in oxycodone-caused mortality after implementation of Florida's Prescription Drug Monitoring Program. Drug Alcohol Dep 2015; 150: 63-8.

287. Cassidy TA, DasMahapatra P, Black RA, Wieman MS, Butler SF. Changes in prevalence of prescription opioid abuse after introduction of an abuse-deterrent opioid formulation. Pain Med 2014; 15: 440-51.

288. Leece P, Orkin AM, Kahan M. Tamper-resistant drugs cannot solve the opioid crisis. CMAJ (Ottawa) 2015; 187: 717-8. 
289. Network for Public Health Law. Legal interventions to reduce overdose mortality: naloxone access and overdose Good Samaritan laws. St Paul, MN (USA), 2015.

290. Davis CS, Carr D, Southwell JK, Beletsky L. Engaging law enforcement in overdose reversal initiatives: authorization and liability for naloxone administration. Am J Public Health 2015; 105: 1530 7.

291. Hammett TM, Phan S, Gaggin J, et al. Pharmacies as providers of expanded health services for people who inject drugs: a review of laws, policies, and barriers in six countries. BMC Health Serv Res 2014; 14: 261-.

292. Gallant J. Drug addiction: Ontario buys naloxone, an overdose life-saver, and then locks it up. Star (Toronto) 29 July 2013.

http://www.thestar.com/news/gta/2013/07/29/drug_addiction_ontario_buys_naloxone_an_overdose_lifesa ver_then_locks_it_up.html (accessed 4 Sept 2015).

293. CVS pharmacy expands naloxone access in 12 more states. Pharmacist, 24 September 2015. At: http://www.pharmacist.com/cvspharmacy-expands-naloxone-access-12-more-states (accessed 5 Oct 2015).

294. Drug Policy Alliance. Federal lawmakers introducing naloxone prevention bill to combat heroin and opioid overdose crisis (press statement). New York, 2015.

http://www.drugpolicy.org/news/2015/06/federal-lawmakers-introducing-overdose-prevention-billcombat-heroin-and-opioid-overdos (accessed 15 September 2015).

295. Human Rights Watch. Torture in the name of treatment: Human rights abuses in Vietnam, China, Cambodia and Lao PDR. New York, 2012.

296. World Health Organization Western Pacific Regional Office. Assessment of compulsory treatment of people who use drugs in Cambodia, China, Malaysia and Viet Nam: an application of selected human rights principles. Manila, 2009.

297. International Labour Organization, UN Development Programme, UNAIDS. Joint statement: Compulsory drug detention and rehabilitation centres. Geneva: United Nations, 2012.

298. Saucier R, Wolfe D. Privatizing cruelty — torture, inhumane and degrading Treatment in nongovernmental drug rehabilitation centers. In Center for Human Rights and Humanitarian Law. Torture in health care settings: reflection on the Special Rapporteur on Torture's 2013 report. Washington, DC: American University, 2014.

299. United Nations Office on Drugs and Crime. From coercion to cohesion: treating drug dependence through health care, not punishment. Vienna, 2009.

300. O’Neill KL. On Liberation Crack, Christianity, and Captivity in Postwar Guatemala City. Social Text 2014; 32: 11-28.

301. Wolfe D. Death, drug treatment, and Christ's love (online). New York: Open Society Foundations, 2012.

302. Human Rights Watch. 'Like a death sentence': abuses against persons with mental disabilities in Ghana. New York, 2012.

303. Mendez J. Report of the Special Rapporteur on torture and other cruel, inhuman or degrading treatment or punishment, Addendum: mission to Ghana. UN doc. A/HRC/25/60/Add.1, 2014.

304. Sun HM, Li XY, Chow EP, et al. Methadone maintenance treatment programme reduces criminal activity and improves social well-being of drug users in China: a systematic review and meta-analysis. BMJ Open 2015; 5(1): e005997.

305. Dennis BB, Naji L, Bawor M, et al. The effectiveness of opioid substitution treatments for patients with opioid dependence: a systematic review and multiple treatment comparison protocol. Syst Rev 2014; 3: 105.

306. European Monitoring Centre for Drugs and Drug Addiction (EMCDDA). Guidelines for the treatment of drug dependence: a European perspective. Lisbon, 2011.

307. Faggiano F, Vigna-Taglianti F, Versino E, Lemma P. Methadone maintenance at different dosages for opioid dependence. Cochrane Database Syst Rev 2003; (3): Cd002208. 
308. Fareed A, Casarella J, Amar R, Vayalapalli S, Drexler K. Methadone maintenance dosing guideline for opioid dependence, a literature review. J Addict Dis 2010; 29: 1-14.

309. Fareed A, Casarella J, Roberts M, et al. High dose versus moderate dose methadone maintenance: is there a better outcome? J Addict Dis 2009; 28: 399-405.

310. Lambdin BH, Masao F, Chang O, et al. Methadone treatment for HIV prevention - feasibility, retention, and predictors of attrition in Dar es Salaam, Tanzania: a retrospective cohort study. Clin Infect Dis 2014; 59: 735-42.

311. Donny EC, Brasser SM, Bigelow GE, Stitzer ML, Walsh SL. Methadone doses of $100 \mathrm{mg}$ or greater are more effective than lower doses at suppressing heroin self-administration in opioid-dependent volunteers. Addiction 2005; 100: 1496-509.

312. World Health Organization Regional Office for the Western Pacific. Clinical guidelines for withdrawal management and treatment of drug dependence in closed settings. Manila, 2009.

313. Nordt C, Stohler R. Incidence of heroin use in Zurich, Switzerland: a treatment case register analysis. Lancet 2006; 367: 1830-4.

314. Fischer B, Oviedo-Joekes E, Blanken P, et al. Heroin-assisted treatment (HAT) a decade later: a brief update on science and politics. J Urban Health 2007; 84: 552-62.

315. Fischer B, Murphy Y, Rudzinski K, MacPherson D. Illicit drug use and harms, and related interventions and policy in Canada: A narrative review of select key indicators and developments since 2000. Int J Drug Policy 2015.

316. Keller J. Judge grants injunction allowing doctors to prescribe heroin to group of Vancouver addicts. National Post. 2014.

317. Csete J. Costs and benefits of drug-related health services. In: Collins J, ed. Ending the drug wars: report of the LSE Expert Group on the Economics of Drug Policy. London: London School of Economics; 2014: 70-6.

318. Basu A, Paltiel AD, Pollack HA. Social costs of robbery and the cost-effectiveness of substance abuse treatment. Health Econ 2008; 17: 927-46.

319. McCollister KE, French MT. The relative contribution of outcome domains in the total economic benefit of addiction interventions: a review of first findings. Addiction 2003; 98: 1647-59.

320. Xing Y, Sun J, Cao W, et al. Economic evaluation of methadone maintenance treatment in HIV/AIDS control among injecting drug users in Dehong, China. AIDS Care 2012; 24: 756-62.

321. Ni MJ, Fu LP, Chen XL, Hu XY, Wheeler K. Net financial benefits of averting HIV infections among people who inject drugs in Urumqi, Xinjiang, Peoples Republic of China (2005-2010). BMC Public Health 2012; 12: 572.

322. Dursteler KM, Berger EM, Strasser J, et al. Clinical potential of methylphenidate in the treatment of cocaine addiction: a review of the current evidence. Subst Abuse Rehab 2015; 6: 61-74.

323. Laudet $\mathrm{AB}$, White $\mathrm{W}$. What are your priorities right now? Identifying service needs across recovery stages to inform service development. $J$ Subst Abuse Treat 2010; 38: 51-9.

324. de Jesus Mari J, Tofoli LF, Noto C, et al. Pharmacological and psychosocial management of mental, neurological and substance use disorders in low- and middle-income countries: issues and current strategies. Drugs 2013; 73: 1549-68.

325. Metz VE, Brandt L, Unger A, Fischer G. Substance abuse/dependence treatment: a European perspective. Subst Abuse 2014; 35: 309-20.

326. Andrews C, Abraham A, Grogan CM, et al. Despite Resources From The ACA, Most States Do Little To Help Addiction Treatment Programs Implement Health Care Reform. Health Affairs 2015; 34: 828-35.

327. Burns K. Women, harm reduction and HIV: key findings from Azerbaijan, Georgia, Kyrgyzstan, Russia and Ukraine. New York, Open Society Foundations, 2009.

328. Kenny KS, Barrington C, Green SL. "I felt for a long time like everything beautiful in me had been taken out": Women's suffering, remembering, and survival following the loss of child custody. Int $J$ Drug Policy 2015; 26: 1158-66. 
329. De Bortoli L, Coles J, Dolan M. Linking illicit substance misuse during pregnancy and child abuse: what is the quality of the evidence? Child Family Social Work 2014; 19: 136-48.

330. Crime UNOoDa. Substance abuse treatment and care for women: case studies and lessons learned. Vienna, 2004.

331. Mayes LC, Granger RH, Bornstein MH, Zuckerman B. The problem of prenatal cocaine exposure. A rush to judgment. JAMA 1992; 267(3): 406-8.

332. Hurt H, Betancourt LM, Malmud EK, et al. Children with and without gestational cocaine exposure: a neurocognitive systems analysis. Neurotoxicol Teratol 2009; 31: 334-41.

333. Jones HE, Kaltenbach K, Heil SH, et al. Neonatal abstinence syndrome after methadone or buprenorphine exposure. N Engl J Med 2010; 363: 2320-31.

334. Abrahams R, Albizu-Garcia C, Bakker A, al. e. Open letter regarding alarmist and inaccurate reporting on prescription opioid use by pregnant women. 2013.

335. Roberts A, Mathers B, Degenhardt L. Women who inject drugs: A review of their risks, experiences and needs. A report prepared on behalf of the Reference Group to the United Nations on HIV and Injecting Drug Use. Sydney: National Drug and Alcohol Research Centre (NDARC), University of New South Wales 2010.

336. International Narcotics Control Board. Annual report for 2014. Vienna, 2014.

337. World Health Organization. Ensuring balance in national policies on controlled substances: guidance for availability and accessibility of controlled medicines. Geneva, 2011.

338. Pain \& Policy Studies Group. Achieving balance in state pain policy: A progress report card (CY 2013). University of Wisconsin Carbone Cancer Center. Madison, Wisconsin; 2014.

339. Cherny NI, Baselga J, de Conno F, Radbruch L. Formulary availability and regulatory barriers to accessibility of opioids for cancer pain in Europe: a report from the ESMO/EAPC Opioid Policy Initiative. Ann Oncol 2010; 21: 615-26.

340. Republic of India. Narcotic Drugs and Psychotropic Substances Act 1985. Enactment no. 61, 16. 1985.

341. Global Commission on Drug Policy. The negative impact of drug control on public health: the global crisis of avoidable pain. Rio de Janeiro, 2015.

342. Bandewar SV. Access to controlled medicines for palliative care in India: gains and challenges.

Indian J Med Ethics 2015; 12: 77-82.

343. Human Rights Watch. World report 2014 (India chapter). New York, 2014.

344. Mohapatra S, Rath N. Appraisal of the narcotic drugs and psychotropic substances (amendment) act, 2014. Asian J Psychiatry 2015; 14: 80-1.

345. United Nations Convention on psychotropic substances. Vienna, 1971.

346. Nutt D, King LA, Saulsbury W, Blakemore C. Development of a rational scale to assess the harm of drugs of potential misuse. Lancet 2007; 369: 1047-53.

347. Nutt DJ, King LA, Phillips LD. Drug harms in the UK: a multicriteria decision analysis. Lancet 2010; 376: 1558-65.

348. van Amsterdam J, Nutt D, Phillips L, van den Brink W. European rating of drug harms. $J$ Psychopharmacol 2015; 29: 655-60.

349. Hall W, Carter A, Forlini C. The brain disease model of addiction: challenging or reinforcing stigma? Authors' reply. Lancet Psychiatry 2015; 2: 292.

350. Whiting PF, Wolff RF, Deshpande S, et al. Cannabinoids for Medical Use: A Systematic Review and Meta-analysis. JAMA 2015; 313: 2456-73.

351. Deshpande A, Mailis-Gagnon A, Zoheiry N, Lakha SF. Efficacy and adverse effects of medical marijuana for chronic noncancer pain: Systematic review of randomized controlled trials. Can Family Physician 2015; 61: e372-81.

352. Madras B. Update of cannabis and its medical use. Review for the 37th session of the WHO Expert Committee on Drug Dependence. Geneva: WHO, 2015.

353. World Health Organization, Expert Committee on Drug Dependence.. Extract from the Report of the 37th Expert Committee on Drug Dependence, convened from 16 to 20 November 2015, 
at WHO headquarters in Geneva: Commission on Narcotic Drugs, 2015.

354. Hall W, Weier M. Assessing the public health impacts of legalizing recreational cannabis use in the USA. Clin Pharmacol Ther 2015; 97: 607-15.

355. Shen H. Federal red tape ties up marijuana research. Nature 2014; 507: 407-8.

356. Pacula RL, Powell D, Heaton P, Sevigny EL. Assessing the effects of medical marijuana laws on marijuana use: the devil is in the details. J Policy Analysis Mgt 2015; 34: 7-31.

357. Bachhuber MA, Saloner B, Cunningham CO, Barry CL. MEdical cannabis laws and opioid analgesic overdose mortality in the united states, 1999-2010. JAMA Internal Med 2014; 174: 1668-73.

358. University of New South Wales. Injecting drug users reference group: The Reference Group to the UN on HIV and Drug Use (online introduction). https://ndarc.med.unsw.edu.au/project/injecting-drugusers-reference-group-reference-group-un-hiv-and-injecting-drug-use (accessed 14 October 2015).

359. Degenhardt L, Larance B, Mathers B, et al. on behalf of the Reference Group to the United Nations on HIV and injecting drug use Benefits and risks of pharmaceutical opioids: Essential treatment and diverted medication. A global review of availability, extra-medical use, injection and the association with HIV. Reference Group Thematic Paper Series. Sydney: National Drug and Alcohol Research Centre, University of New South Wales, 2007.

360. Degenhardt L, Mathers B, Guarinieri M, et al. on behalf of the Reference Group to the United Nations on HIV and injecting drug use. The global epidemiology of methamphetamine injection: A review of the evidence on use and associations with HIV and other harm. Reference Group Thematic Paper Series. Sydney: National Drug and Alcohol Research Centre, University of New South Wales, 2007.

361. Mathers BM, Degenhardt L, Ali H, et al. HIV prevention, treatment, and care services for people who inject drugs: a systematic review of global, regional, and national coverage. Lancet 2010; 375: 101428.

362. Mathers BM, Degenhardt L, Phillips B, et al. Global epidemiology of injecting drug use and HIV among people who inject drugs: a systematic review. Lancet 2008; 372: 1733-45.

363. Degenhardt L, Mathers B, Guarinieri M, et al. Meth/amphetamine use and associated HIV: Implications for global policy and public health. Int J Drug Policy 2010; 21: 347-58.

364. UN Development Programme. Request for proposals: national survey on drug use in Nigeria. May 2014. http://procurement-notices.undp.org/view_file.cfm?doc_id=29568 (accessed 16 September 2015).

365. Buxton J. Drugs and development: The great disconnect. Global Drug Policy Observer (Swansea), Policy Report no. 2, 2015. http://www.swansea.ac.uk/media/The\%20Great\%20Disconnect.pdf (accessed 24 Sept 2015).

366. United Nations Office on Drugs and Crime. Southeast Asia opium survey 2014 Lao PDR, Myanmar. Bangkok, 2014.

367. Fishstein P. Despair or hope: rural livelihoods and opium poppy dynamics in rural Afghanistan. Kabul: Afghanstan Research and Evaluation Unit, 2014.

368. Mansfield D. Assessing supply-side policy and practice: eradication and alternative development. Global Commission on Drug Policy Working Paper, 2011.

369. Mejía D, Restrepo P, Rozo SV. On the effects of enforcement on illegal markets: evidence from a quasi-experiment in Colombia. Bogotá: Universidad de los Andes, 2014.

370. Chouvy PA, Afsahi K. Hashish revival in Morocco. Int J Drug Policy 2014; 25: 416-23.

371. United Nations Office on Drugs and Crime (UNODC) Government of Colombia. Colombia coca cultivation survey 2013. Bogotá, 2014.

372. Mansfield D, Pain A. Alternative livelihoods: substance or slogan? (briefing paper) Kabul: Afghanstan Research and Evaluation Unit, 2005.

373. Camacho A, Mejía D. The health consequences of aerial spraying of illicit crops: the case of Colombia (Working Paper 408) Washington, DC: Center for Global Development, 2015.

http://www.cgdev.org/publication/health-consequences-aerial-spraying-illicit-crops-case-colombiaworking-paper-408 (accessed 29 Sept 2015). 
374. Mejía D. Plan Colombia: an analysis of effectiveness and costs. Improving Global Drug Policy series,. Brookings Institution, 2015.

375. United Nations Office on Drugs and Crime, Plurinational State of Bolivia. Estado Plurinacional de Bolivia: Monitoreo de cultivos de coca 2014. La Paz, 2015.

376. United Nations Office on Drugs and Crime, Government of Colombia. Colombia coca cultivation survey 2014. Bogota, 2015.

377. United Nations Office on Drugs and Crime, National Drug Commission of Peru. Peru: Monitoreo de cultivas de coca 2014. Lima, 2015.

378. Solomon KR, Anadón A, Cerdeira AL, Marshall J, Sanin L-H. Environmental and human health assessment of the aerial spray program for coca and poppy control in Colombia. Prepared for the Inter-

American Drug Abuse Control Commission section of the Organization of American States, Washington, DC, 2005.

379. Transnational Institute. The CICAD study on the impacts of glyphosate and the crop figures: the politics of glyphosate. Drug Policy Briefing no. 14. Amsterdam, 2005.

380. Rincón-Ruiz A, Kallis G. Caught in the middle, Colombia's war on drugs and its effects on forest and people. Geoforum 2013; 46: 60-78.

381. Republic of Ecuador. Application instituting proceedings submitted to International Court of Justice, General List no. 138, 2008.

382. Menendez A. Ecuador-Colombia settlement won't end spraying. Inter Press Service. 2013.

http://www.ipsnews.net/2013/10/ecuador-colombia-settlement-wont-end-spraying/ (accessed 2 October 2015).

383. Guyton KZ, Loomis D, Grosse Y, et al. Carcinogenicity of tetrachlorvinphos, parathion, malathion, diazinon, and glyphosate. Lancet Oncol 2015; 16: 490-1.

384. World Health Organization International Agency for Research on Cancer. IARC monographs on the evaluation of carcinogenic risks to humans: Preamble. Lyon, France, 2006.

385. Ospina GA. A new challenge for the Santos Administration: Colombia's end to the aerial coca eradication program. . Washington, DC: Council on Hemispheric Affairs, 2015.

386. Salisbury DS, Fagan C. Coca and conservation: cultivation, eradication, and trafficking in the Amazon borderlands. GeoJournal 2013; 78: 41-60.

387. UN Women. A gender perspective on the impact of drug use, the drug trade, and drug control regimes: UN Women policy brief. New York, 2014.

388. German Federal Ministry for Economic Cooperation and Development (BMZ). Rethinking the approach of alternative development: principles and standards of rural development in drug producing areas. Berlin: GIZ (Deutsche Gesellschaft für Internationale Zusammenarbeit), 2013.

389. Klantschnig G. The politics of law enforcement in Nigeria: lessons from the war on drugs. $J$ Modern Afr Stud 2009; 47: 529-49.

390. McSweeney K, Nielsen EA, Taylor MJ, et al. Conservation. Drug policy as conservation policy: narco-deforestation. Science 2014; 343: 489-90.

391. Rozen L. Holbrooke: I've changed Bush's failed Afghan drug policy. Foreign Policy (blog). 30 July 2009. http://foreignpolicy.com/2009/07/30/holbrooke-ive-changed-bushs-failed-afghan-drug-policy/ (accessed 29 September 2015).

392. Domosławski A. Drug policy in Portugal: the benefits of decriminalizing drug use. New York: Open Society Foundations Global Drug Policy Program, 2011.

393. Hughes CE, Stevens A. What can we learn from the Portuguese decriminalization of illicit drugs? Br J Criminol 2010: azq083.

394. Goulão J. National drug policy director, Portugal. personal communication, 2015.

395. Hughes CE, Stevens A. A resounding success or a disastrous failure: re-examining the interpretation of evidence on the Portuguese decriminalisation of illicit drugs. Drug Alcohol rev 2012; 31: 101-13.

396. European Monitoring Centre for Drugs and Drug Addiction (EMCDDA). Statistical bulletin. 2011. http://www.emcdda.europa.eu/stats11 (accessed September 29 2015). 
397. Csete J, Grob PJ. Switzerland, HIV and the power of pragmatism: lessons for drug policy development. Int J Drug Policy 2012; 23: 82-6.

398. Csete J. From the mountaintops: what the world can learn from drug policy change in Switzerland. New York: Open Society Foundations, 2010.

399. Bozicevic I, Handanagic S, Lepej SZ, Begovac J. The emerging and re-emerging human immunodeficiency virus epidemics in Europe. Clin Microbiol Infect 2013; 19(10): 917-29.

400. Rihs-Middel M, Hämmig R, Jacobshagen N. Heroin-assisted treatment: work in progress. . Bern: Swiss Federal Office of Public Health, 2005.

401. Güttinger F, Gschwend P, Schulte B, Rehm J, Uchtenhagen A. Evaluating long-term effects of heroin-assisted treatment: the results of a 6-year follow-up. Eur Addiction Res 2003; 9: 73-9.

402. Rehm J, Frick U, Hartwig C, Gutzwiller F, Gschwend P, Uchtenhagen A. Mortality in heroinassisted treatment in Switzerland 1994-2000. Drug Alcohol Dep 2005; 79: 137-43.

403. Strang J, Groshkova T, Uchtenhagen A, et al. Heroin on trial: systematic review and metaanalysis of randomised trials of diamorphine-prescribing as treatment for refractory heroin addictiondagger.Br J Psychiatry 2015; 207: 5-14.

404. Withnall A. Switzerland changes law to decriminalise marijuana possession. Independent (UK), . 3 October 2013 2013. http://www.independent.co.uk/news/world/europe/switzerland-changes-law-todecriminalise-marijuana-possession-8856308.html (accessed September 30 2015).

405. Kalina K. Developing the system of drug services in the Czech Republic. J Drug Issues 2007; 37: 181-204.

406. Zábranský T. Czech drug laws as an arena of drug policy battle. J Drug Issues 2004; 34: 661-86.

407. Csete J. A balancing act: policymaking on illicit drugs in the Czech Republic. New York: Open Society Foundation, 2011.

408. European Monitoring Centre for Drugs and Drug Addiction (EMCDDA). Alternatives to punishment for drug using offenders. Lisbon, 2015.

409. Strathdee SA, Patrick DM, Currie SL, et al. Needle exchange is not enough: lessons from the Vancouver injecting drug use study. AIDS 1997; 11: F59-65.

410. Wood E, Kerr T. What do you do when you hit rock bottom? Responding to drugs in the city of Vancouver. Int J Drug Policy 2006; 17: 55-60.

411. Tyndall MW, Currie S, Spittal P, et al. Intensive injection cocaine use as the primary risk factor in the Vancouver HIV-1 epidemic. AIDS 2003; 17: 887-93.

412. Urban Health Research Initiatie, University of British Columbia. Drug situation in Vancouver. Vancouver: Urban Health Research Initiative, 2009.

413. Kerr T, Small W, Buchner C, et al. Syringe sharing and HIV incidence among injection drug users and increased access to sterile syringes. Am J Public Health 2010; 100: 1449-53.

414. Hayashi K, Wood E, Wiebe L, Qi J, Kerr T. An external evaluation of a peer-run outreach-based syringe exchange in Vancouver, Canada. Int J Drug Policy 2010; 21: 418-21.

415. Wood E, Kerr T, Marshall BDL, et al. Longitudinal community plasma HIV-1 RNA concentrations and incidence of HIV-1 among injecting drug users: prospective cohort study. BMJ (Clinical Research Ed.) 2009; 338.

416. Kerr T, Tyndall M, Li K, Montaner J, Wood E. Safer injection facility use and syringe sharing in injection drug users. Lancet 2005; 366: 316-8.

417. Bayoumi AM, Zaric GS. The cost-effectiveness of Vancouver's supervised injection facility. CMAJ (Ottawa) 2008; 179: 1143-51.

418. Canada (Attorney General) v. PHS Community Services Society. 2011.

419. Tran OC, Bruce RD, Masao F, et al. Implementation and operational research: linkage to care among methadone clients living with HIV in Dar es Salaam, Tanzania. J Acquir Immune Defic Syndr 2015; 69: e43-e8.

420. Gupta A, Mbwambo J, Mteza I, et al. Active case finding for tuberculosis among people who inject drugs on methadone treatment in Dar es Salaam, Tanzania. Int J Tuberc Lung Dis 2014; 18: 793-8. 
421. United Nations Office on Drugs and Crime. Drug use and trafficking in Senegal: strengthening monitoring and treatment centres (online statement). 2014.

https://www.unodc.org/westandcentralafrica/en/senegal---drug-monitoring-and-rehabilitation.html (accessed 28 September 2015).

422. Arroyo-Cobo JM. Public health gains from health in prisons in Spain. Public Health 2010; 124: 629-31.

423. Hoover J, Jürgens R. Harm reduction in prison: the Moldova model. New York: Open Society Institute, 2009.

424. Doltu S. Presentation to the UNAIDS Programme Coordination Board. Geneva, 2015. http://www.unaids.org/sites/default/files/media asset/20151012 UNAIDS_PCB37 15-21_EN.pdf (accessed 14 Dec 2015).

425. Open Society Foundations. Stopping overdose: peer-based distribution of naloxone. New York, 2013.

426. Coffin PO, Sullivan SD. Cost-effectiveness of distributing naloxone to heroin users for lay overdose reversal in Russian cities. J Medical Econ 2013; 16: 1051-60.

427. Bird SM, Parmar MKB, Strang J. Take-home naloxone to prevent fatalities from opiate-overdose: Protocol for Scotland's public health policy evaluation, and a new measure to assess impact. Drugs Educ Prev Policy 2014; 22: 66-76.

428. Watt G, Jaquet S, Ellison S, Christie I, Nicholson J. Service evaluation of Scotland's national take-home naloxone programme. Scottish Government Social Research, 2014.

429. Stöver HJ, Schäffer D. SMOKE IT! Promoting a change of opiate consumption pattern-from injecting to inhaling. Harm Reduct $J$ 2014; 11(18): 1-8.

430. Kamarulzaman A, McBrayer JL. Compulsory drug detention centers in East and Southeast Asia. Int J Drug Policy 2015; 26: S33-S7.

431. Ghani MA, Brown S-E, Khan F, et al. An exploratory qualitative assessment of self-reported treatment outcomes and satisfaction among patients accessing an innovative voluntary drug treatment centre in Malaysia. Int J Drug Policy 2015; 26: 175-82.

432. Amon JJ, Pearshouse R, Cohen JE, Schleifer R. Compulsory drug detention in East and Southeast Asia: evolving government, UN and donor responses. Int J Drug Policy 2014; 25(1): 13-20.

433. UNAIDS. Alternative action on compulsory detention: innovative responses in Asia (press statement). 5 October 2012.

http://www.unaids.org/en/resources/presscentre/featurestories/2012/october/20121005detentioncenters/ (accessed 9 October 2015).

434. Stolberg VB. The use of coca: prehistory, history, and ethnography. J Ethnicity Subst Abuse 2011; 10: $126-46$.

425. United Nations Office on Drugs and Crime. Bolivia to re-acceded to UN drug convention while making exception on coca leaf chewing (media statement). 2013.

https://www.unodc.org/unodc/en/frontpage/2013/January/bolivia-to-re-accede-to-un-drug-conventionwhile-making-exception-on-coca-leaf-chewing.html (accessed 23 September 2015).

436. Ledebur K, Youngers CA. From Conflict to Collaboration: An Innovative Approach to Reducing Coca Cultivation in Bolivia. Stability 2013; 2(1): Art. 9.

437. International Covenant on Civil and Political Rights. UNGA res. 2200A (XXI) 16 December 1966.

438. Siracusa principles on the limitation and derogation provisions in the International Covenant on Civil and Political Rights. UN doc. E/CN.4/1985/4 Annex. 1985.

439. United Nations Office on Drugs and Crime. Making drug control 'fit for purpose': Building on the UNGASS decade. Vienna, 2008.

440. Caulkins JP. Effects of prohibition, enforcement and interdiction on drug use. Ending the drug wars: report of the LSE Expert Group on the Economics of Drug Policy. London: London School of Economics; 2014: 16-25. 
441. Piot P, Abdool Karim SS, Hecht R, et al. Defeating AIDS — advancing global health. The Lancet 2015; 386: 171-218. 
Figure 1: Percentage of homicides involving gangs or organized criminal groups by region, 2011 or latest year

60

50

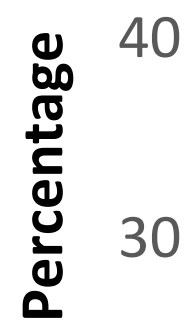

20

10

0

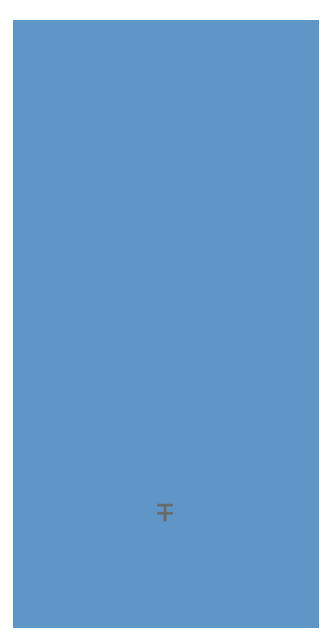

Americas (18 countries)
Asia and Oceania

(12 countries)
Europe

(19 countries)

From UNODC crime trends ${ }^{33}$ 


\section{Figure 2: Number of homicides in Mexico, $1989-2013$}

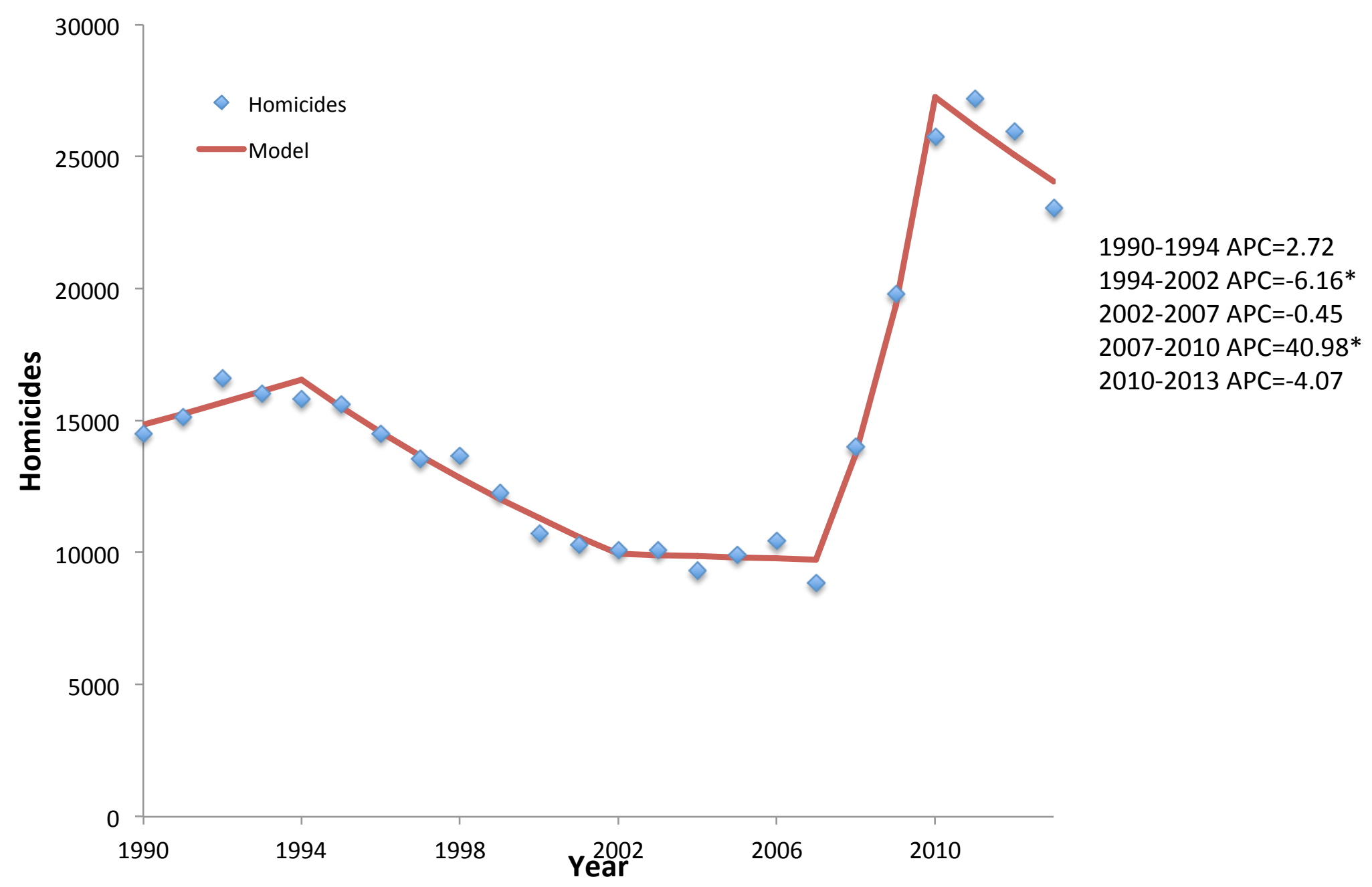

Data from INEGI ${ }^{45}$; analysis by Javier Cepeda, PhD 
Figure 3: Proportion of people incarcerated for drug offenses and non-drug offenses who were interrogated by the military before and after the 'war on drugs' in Mexico

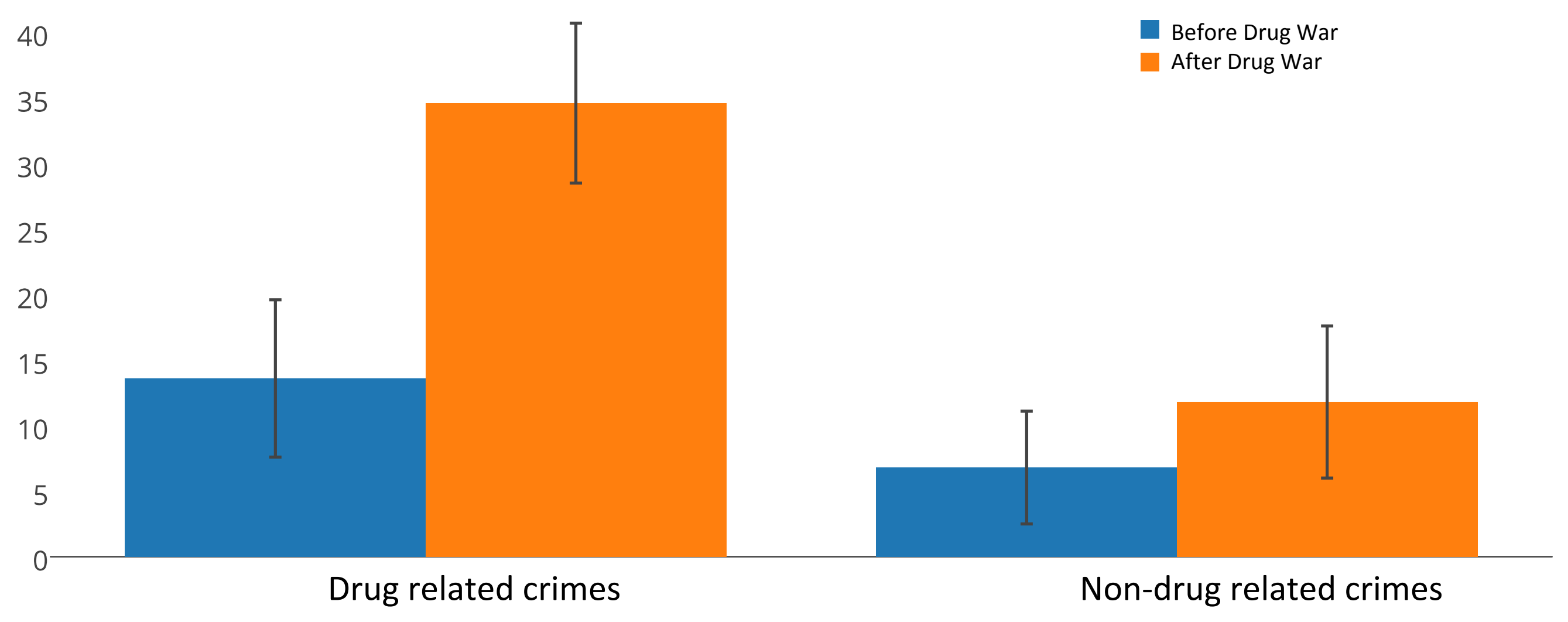

Analysis by Javier Cepeda, PhD 
Figure 4: Homicide rate in Colombia, 1985-2012, highlighting key periods of intensive counter-narcotics activities

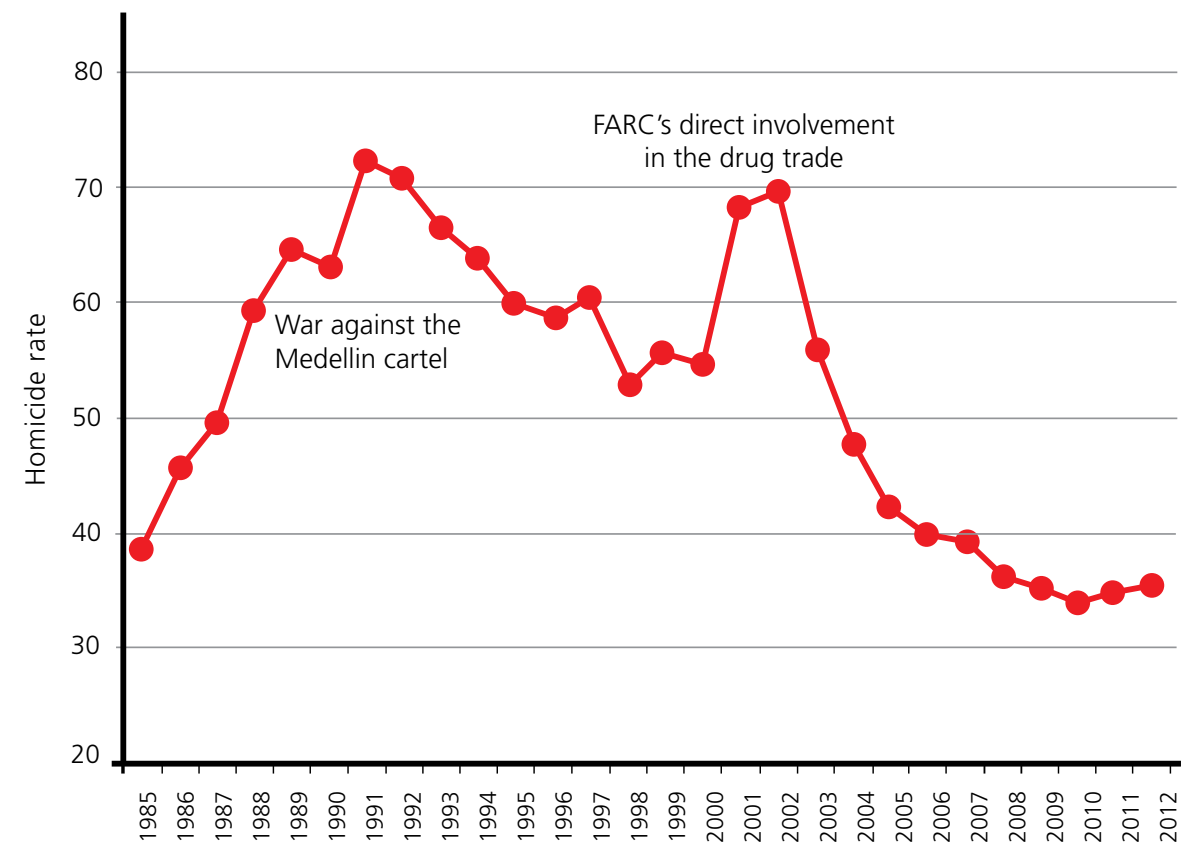

From Mejia and Restrepo, $2014^{50}$ 


\section{Figure 5: HIV Prevalence among PWID compared to the general population in countries with >30,000 PWID, 2009 - 2014}

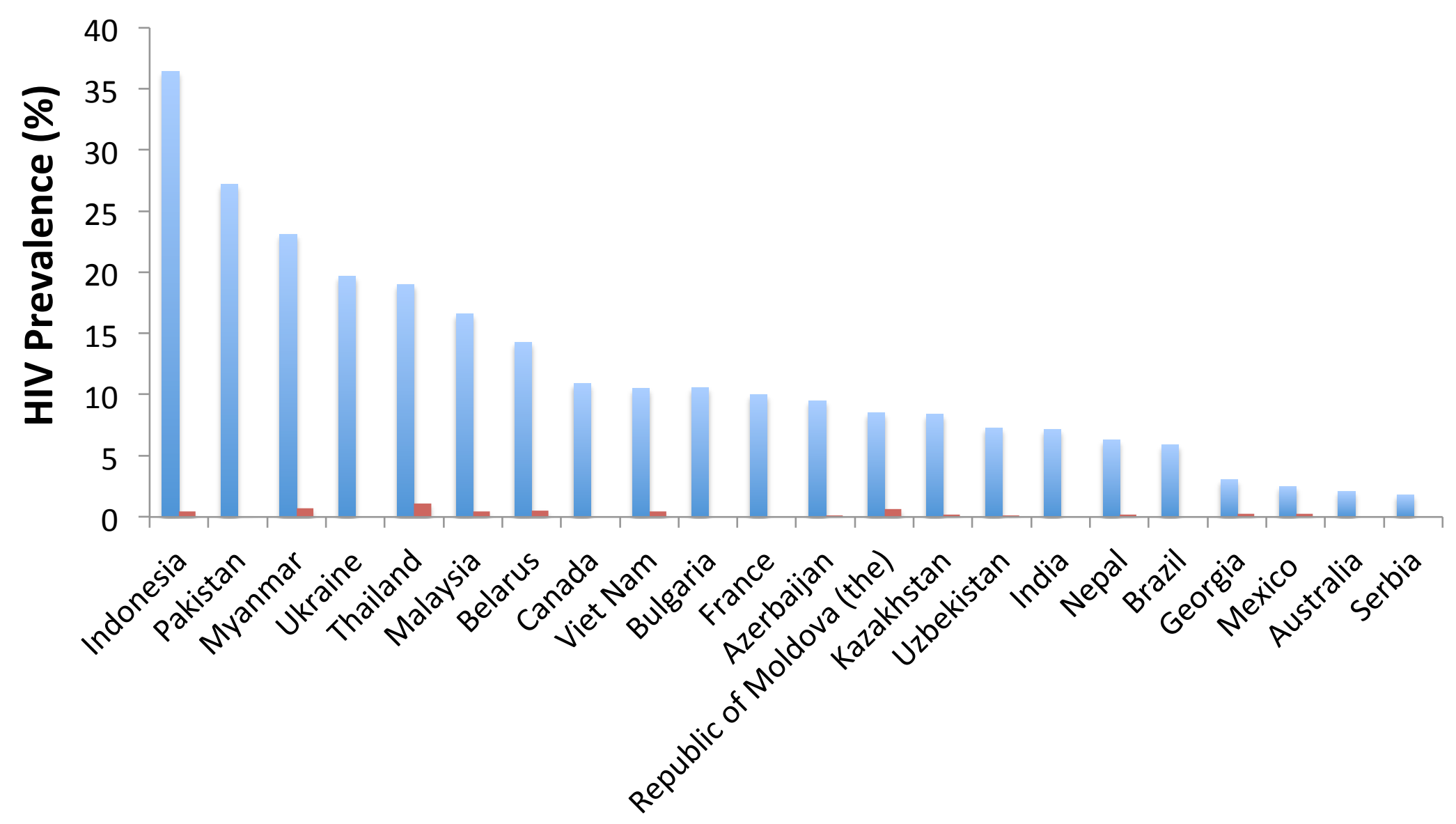

HIV prev in PWID HIV prev in general population in 2014

From UNAIDS, Gap Report, $2014^{57}$ 
Figure 6: Impact on hepatitis C virus (HCV) prevalence among people who inject drugs (PWID) over time for different coverage levels of opiate substitution therapy (OST) and high coverage needle and syringe programmes (NSP) $(100 \% \mathrm{NSP})$ for three epidemic scenarios with a baseline chronic HCV prevalence among PWID of 20,40 or $60 \%$ with no OST or $100 \%$ NSP. $100 \%$ NSP is defined as obtaining one or more sterile syringes from a NSP for each injection reported per month.

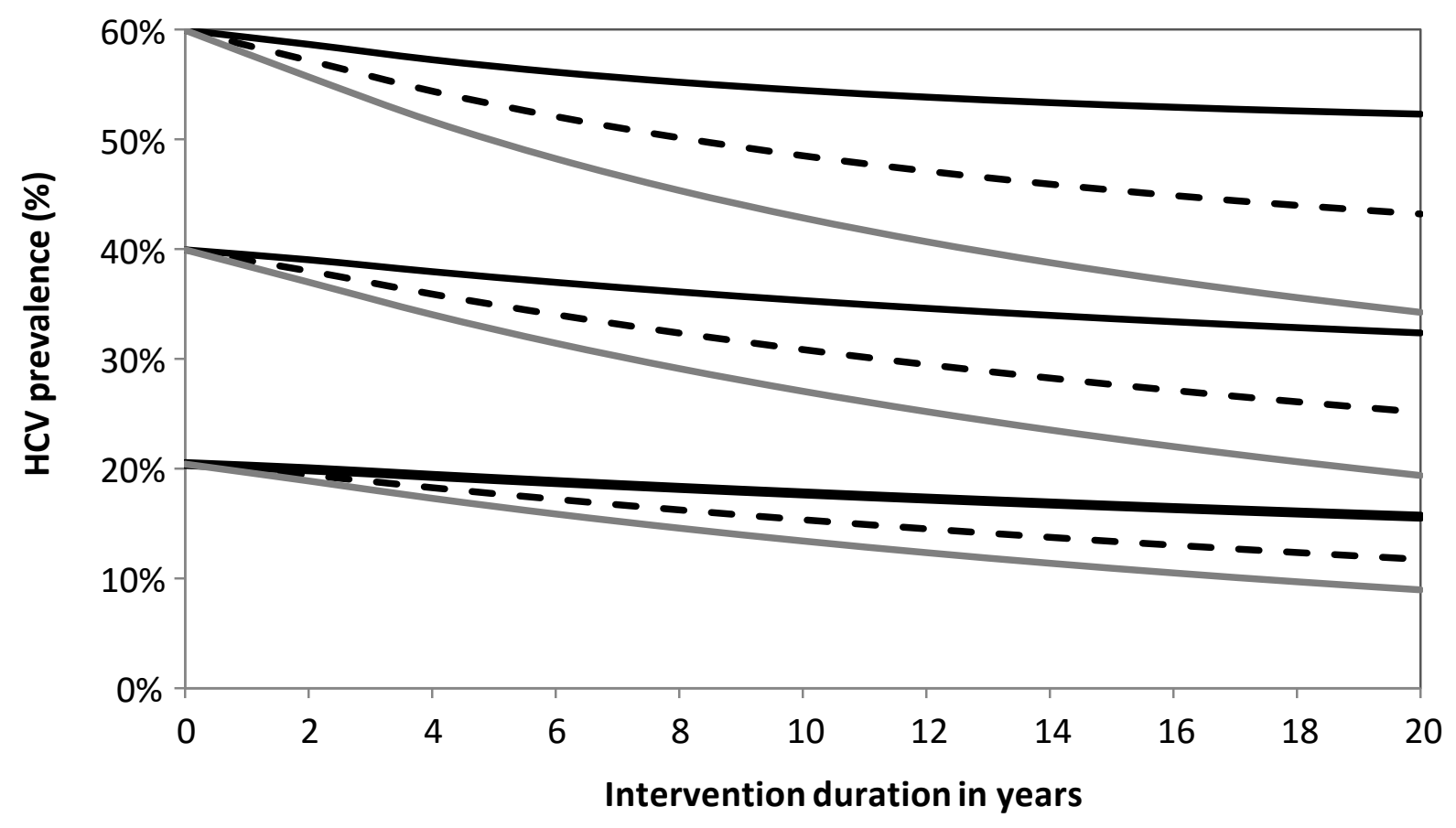

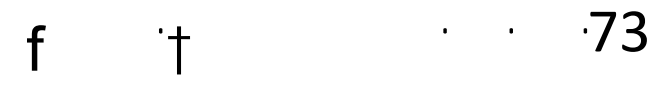

$20 \%$ coverage $\quad-\quad-40 \%$ coverage $\quad-60 \%$ coverage 


\section{Figure 7: Coverage required of ART, NSP, and OST to achieve $30 \%$ and $50 \%$ decreases in HIV incidence and prevalence among PWID over 10 years}
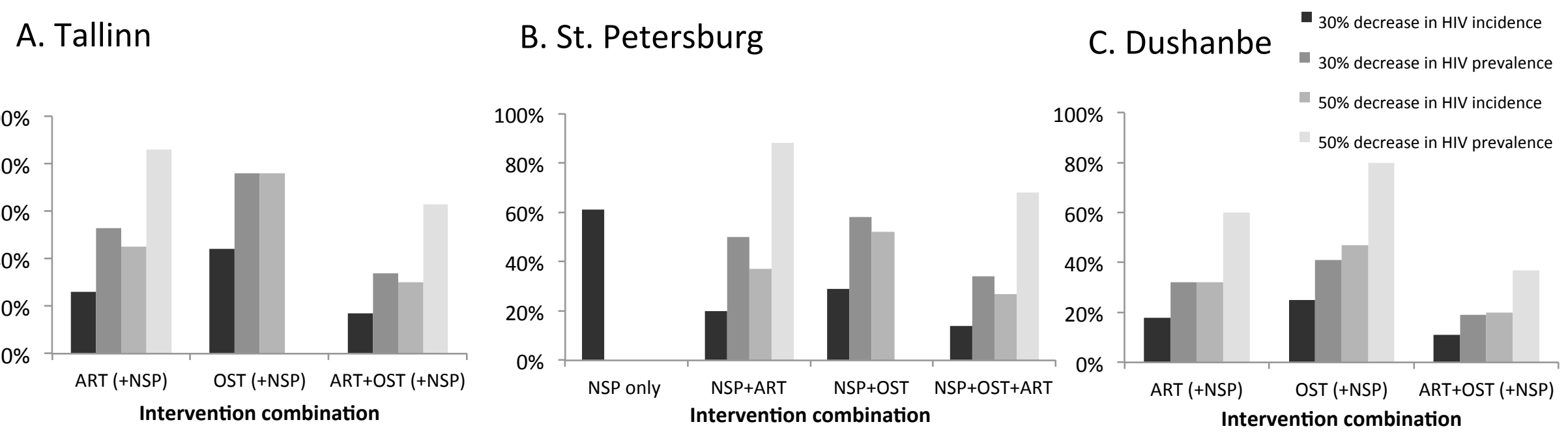

From Vickerman et al. $2014^{79}$ 


\section{Figure 8: Proportion of people who inject drugs living with HIV who receive antiretroviral therapy by region}

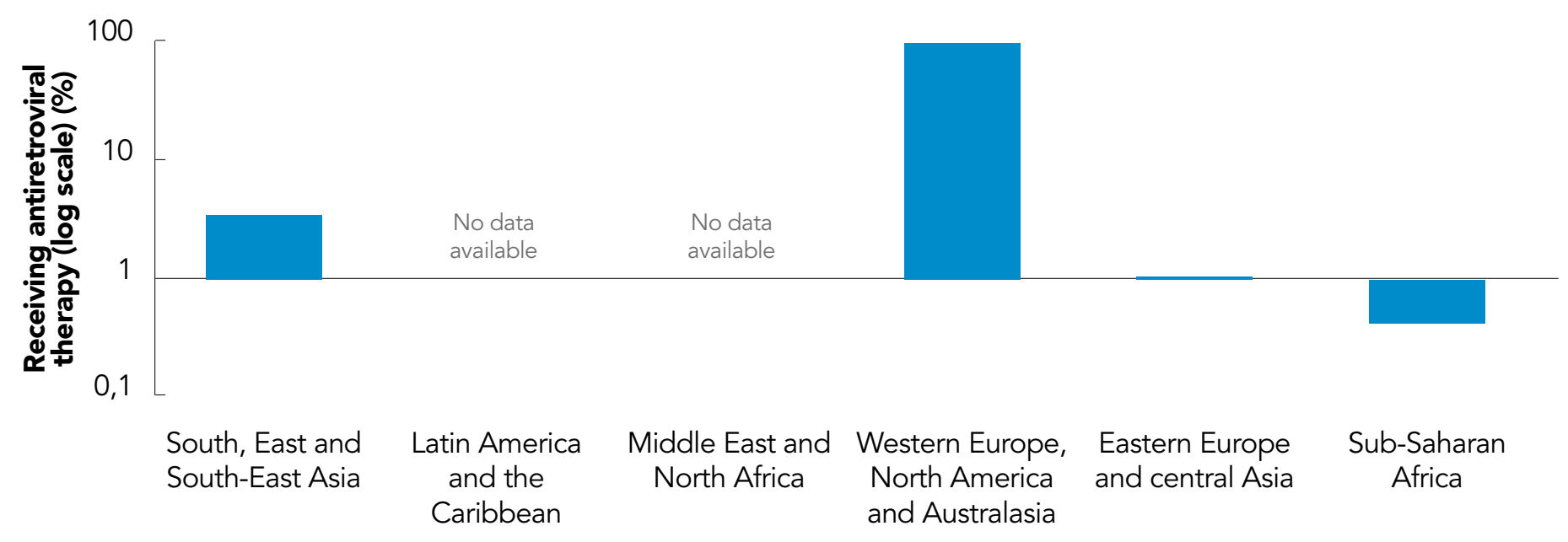

From UNAIDS, $2014^{57}$ 


\section{Figure 9: Barriers to HCV treatment for people who inject drugs}

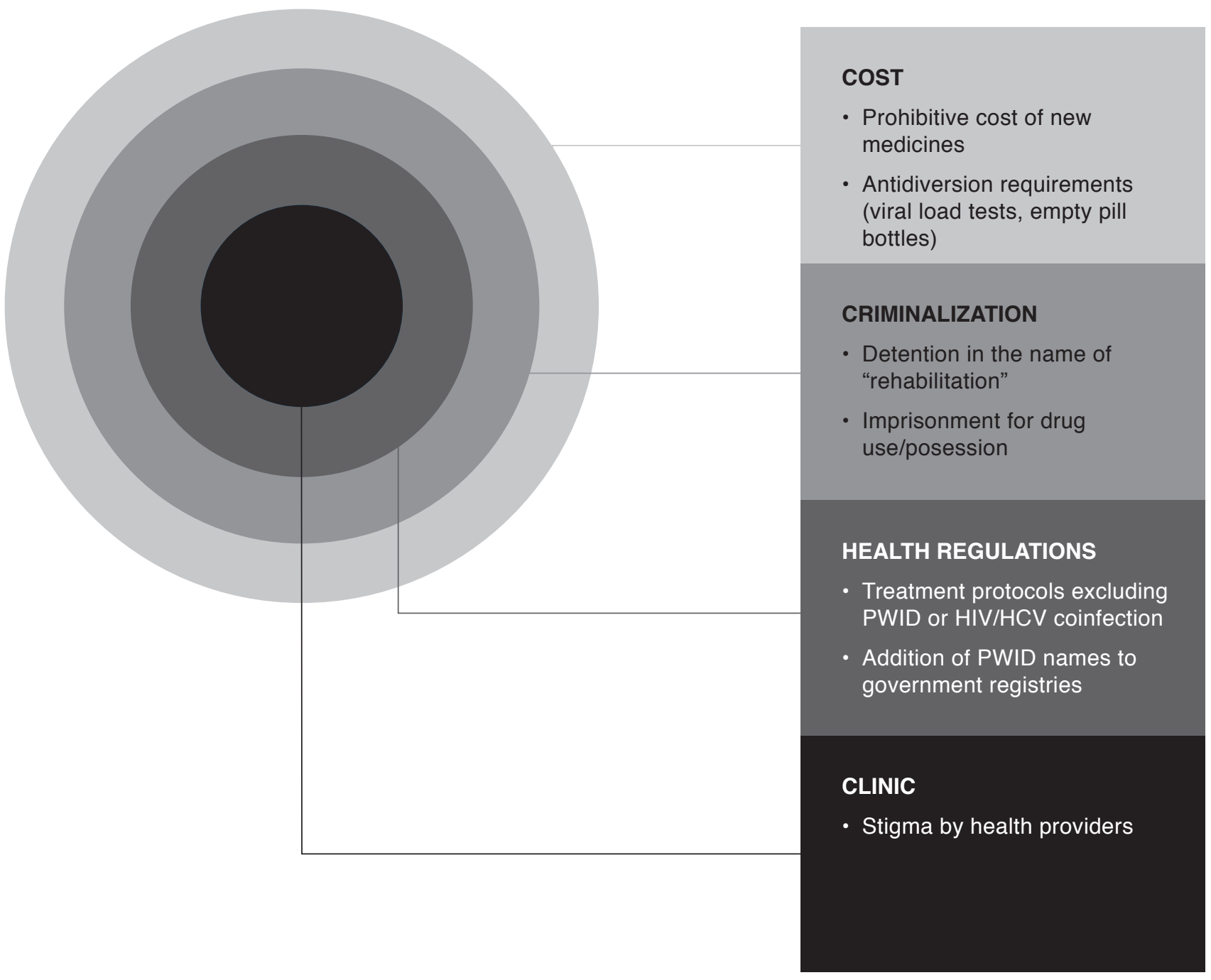

From Wolfe et al., $2015^{97}$ 


\section{Figure 10: Increase in HIV transmission among people who inject drugs, Romania, 2007-2013}

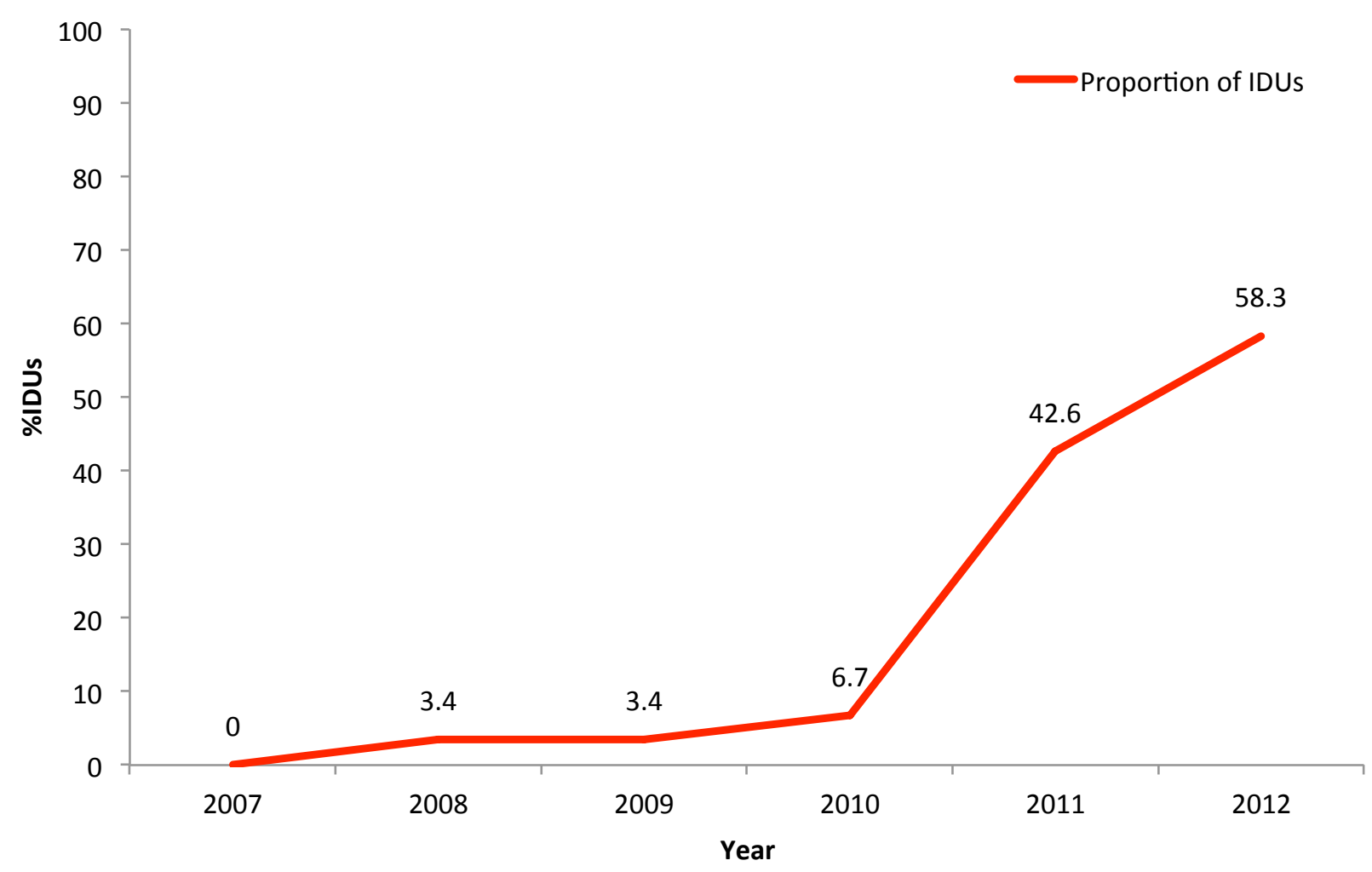

From Dr. Christina Oprea, Victor Babes Hospital, Bucharest ${ }^{115}$ 


\section{Figure 11: Global trends in crimes reported by police, 2003-2012}

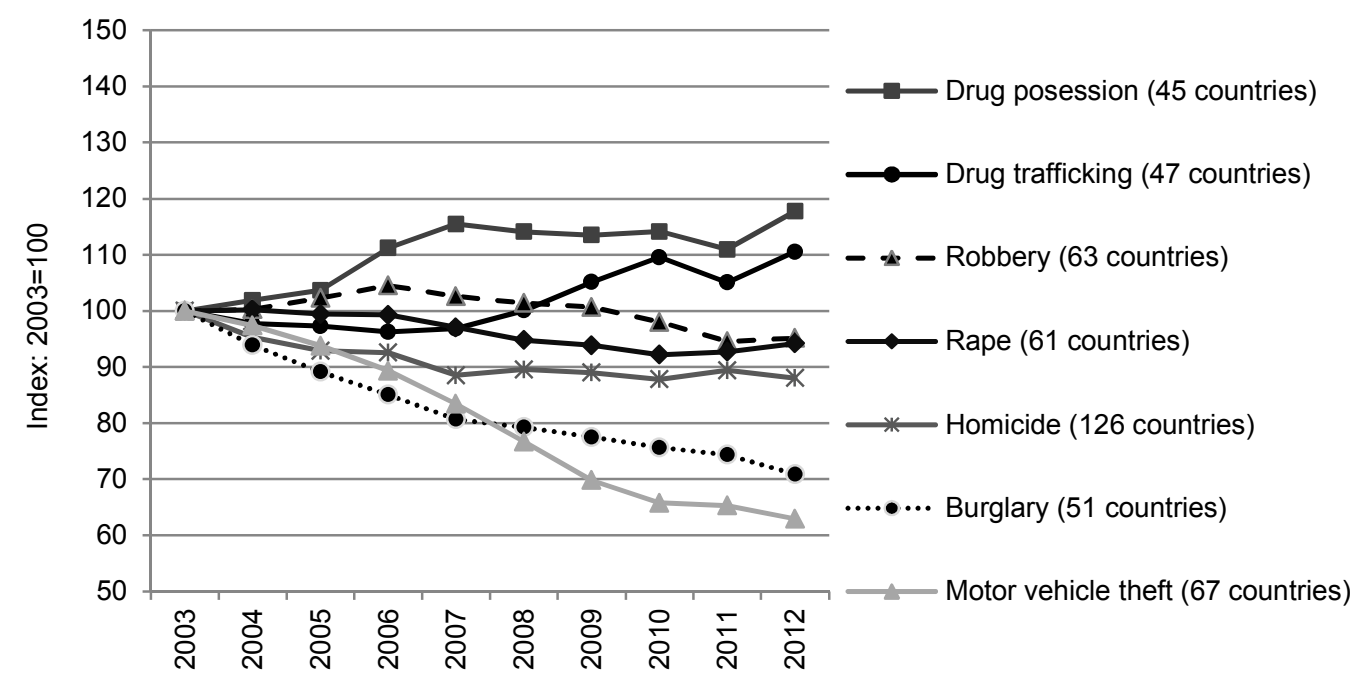

Note: Trends are calculated as weighted crime rates per 100,000 population relative to the base year 2003.

From UNODC, World Crime Trends $2014^{32}$ 
Figure 12: Trend in highest minimum penalty for drug offenses, selected countries in Latin America

120

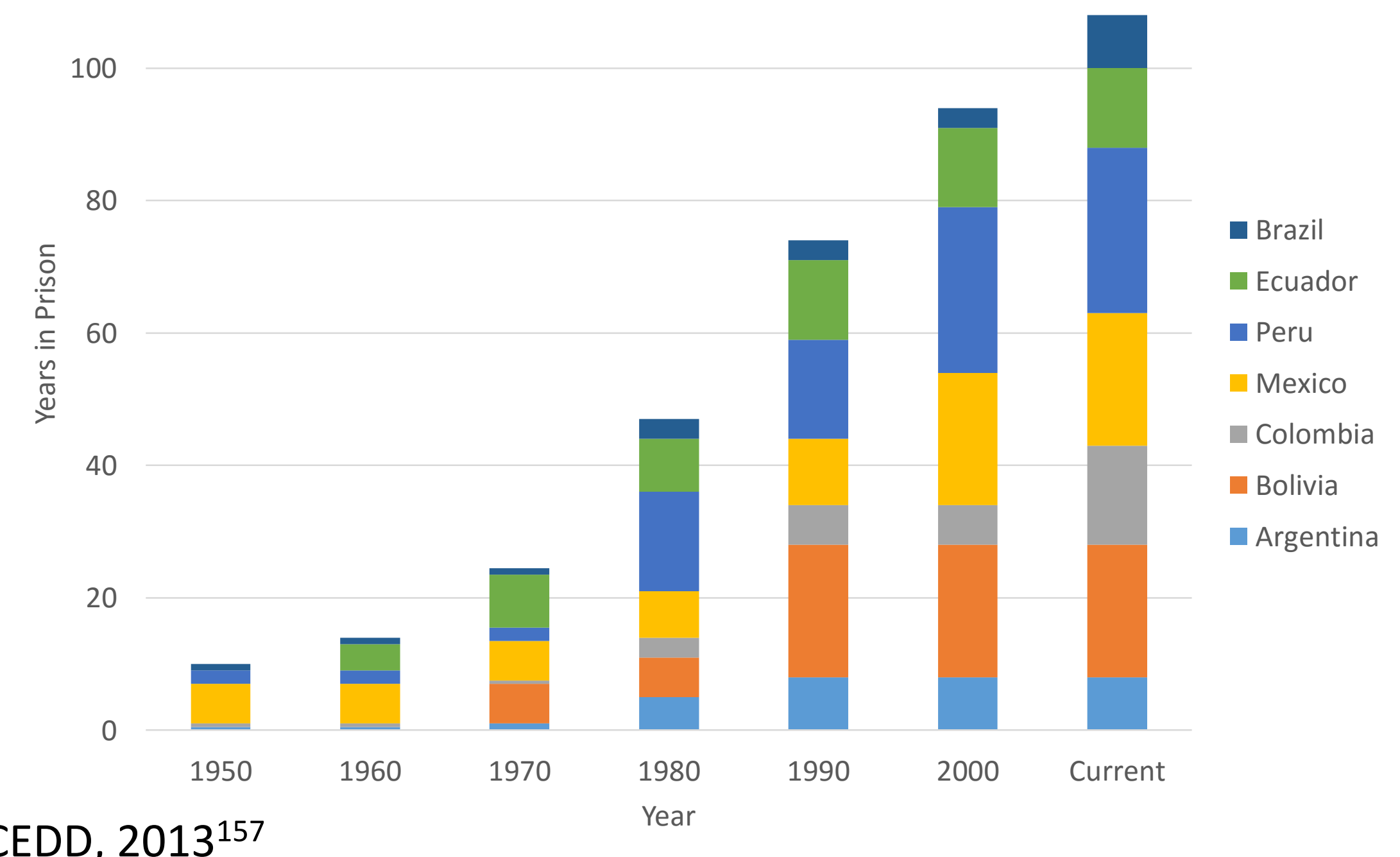

From CEDD, $2013^{157}$ 


\section{Figure 13: Drug arrests in the US, 1980-2012}

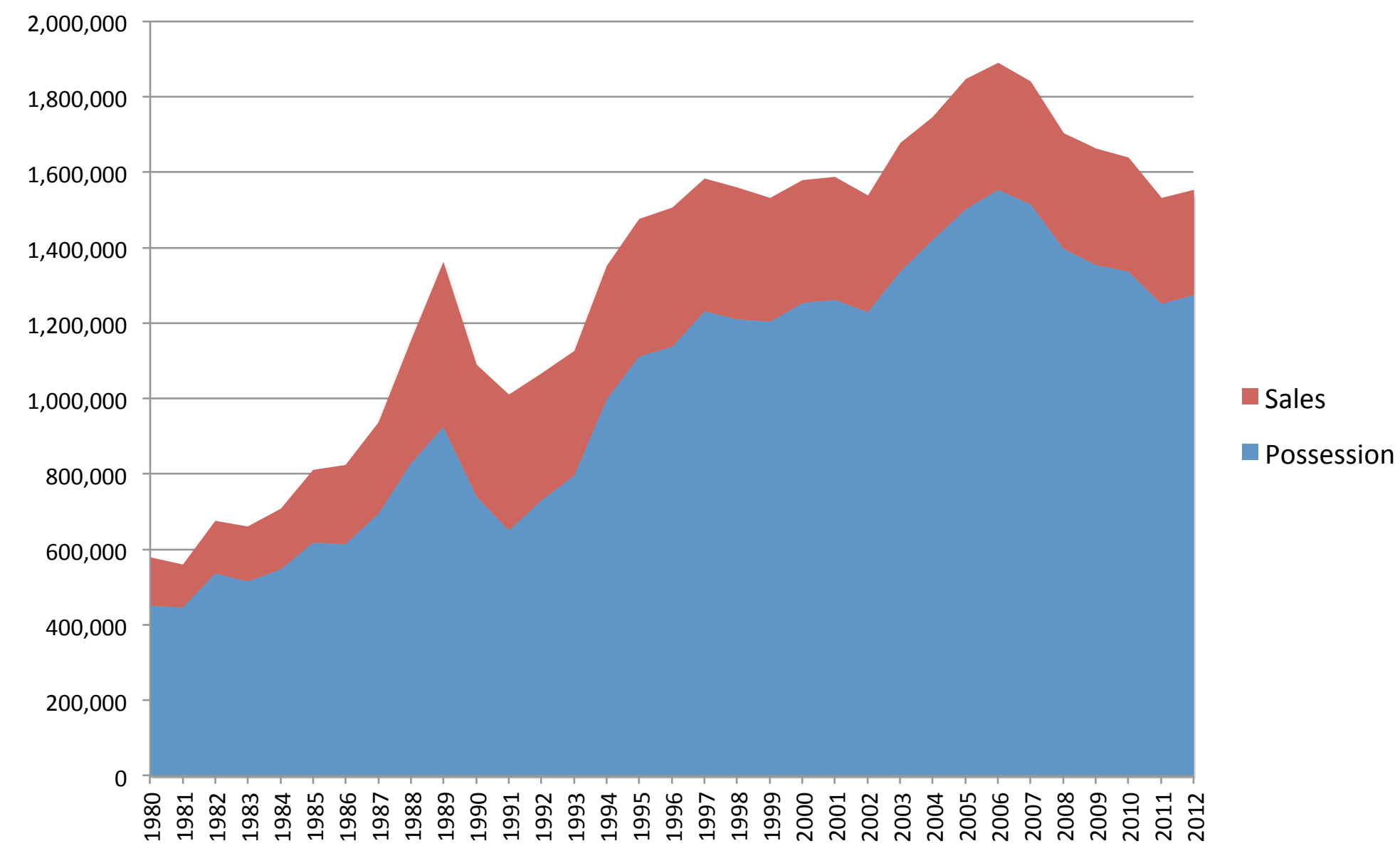

From Snyder and Mulako-Wangota ${ }^{170}$ 
Figure 14: Drug-related incarceration by race in the US, 2013-2014

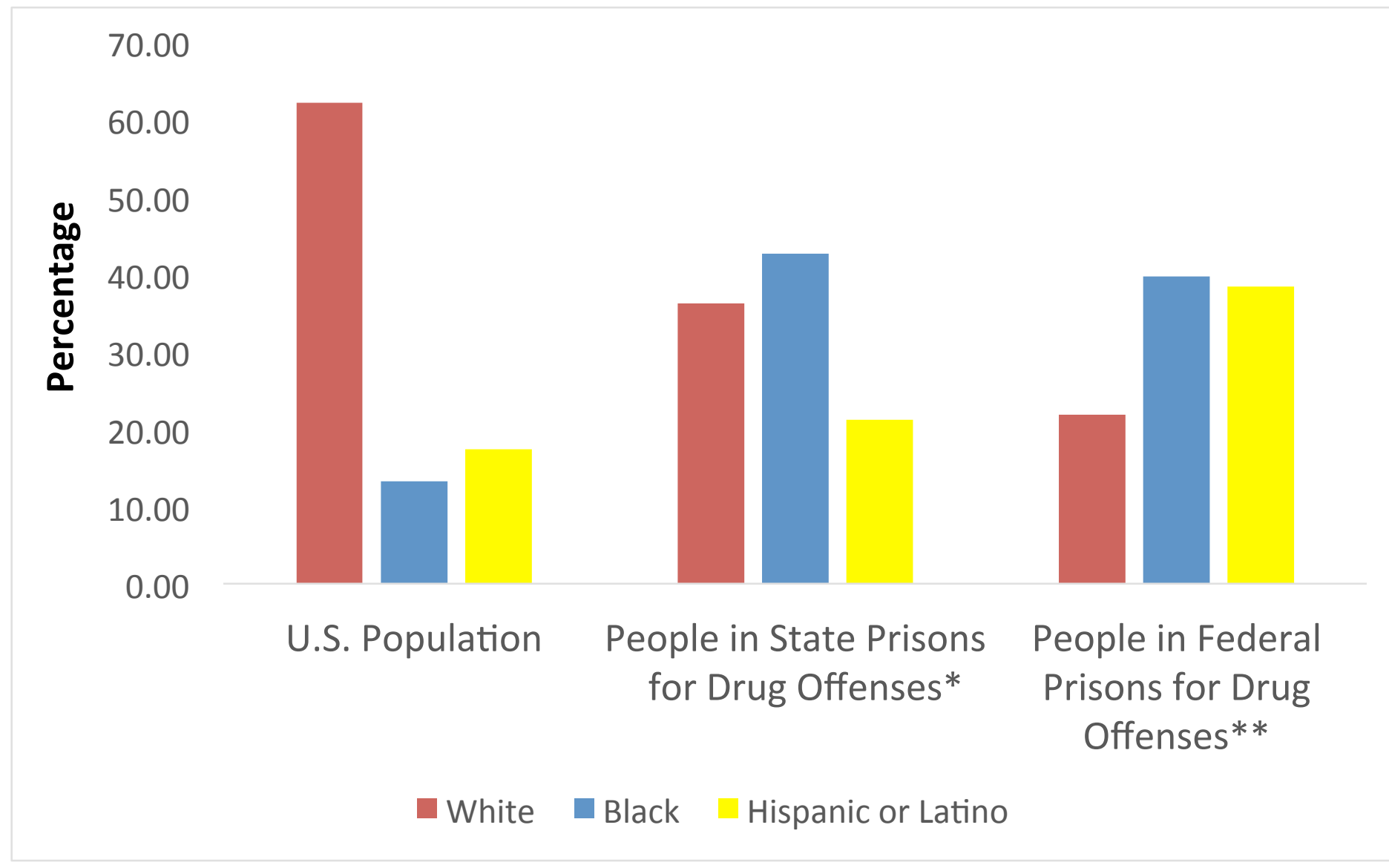

*2013

**2014

From: Carson, Bureau of Justice Statistics ${ }^{173}$ 
Figure 15: Juvenile arrest rates by race for drug offenses in the US, 1980-2010

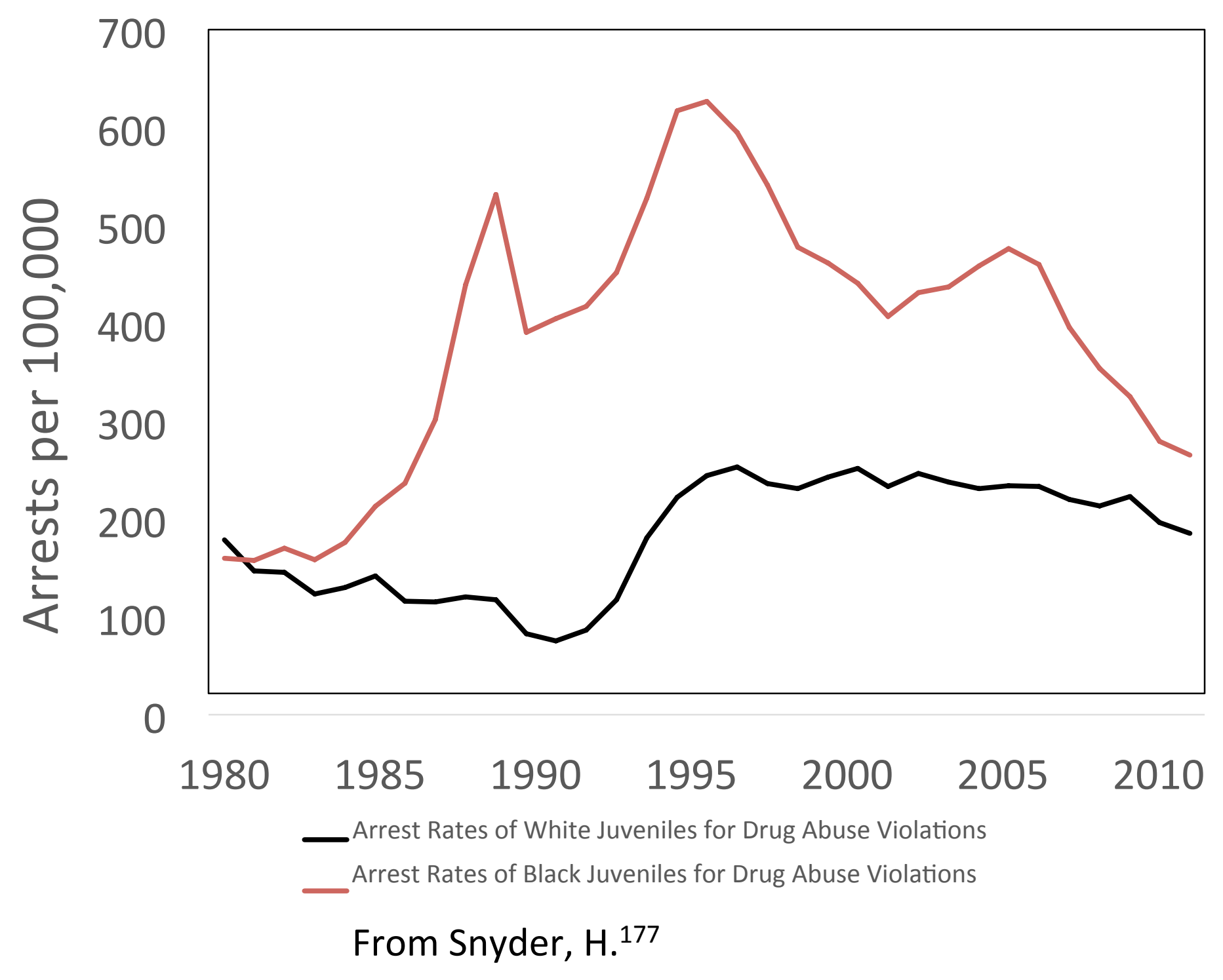


Figure 16: Lifetime, annual, and past-month prevalence of drug use while in prison

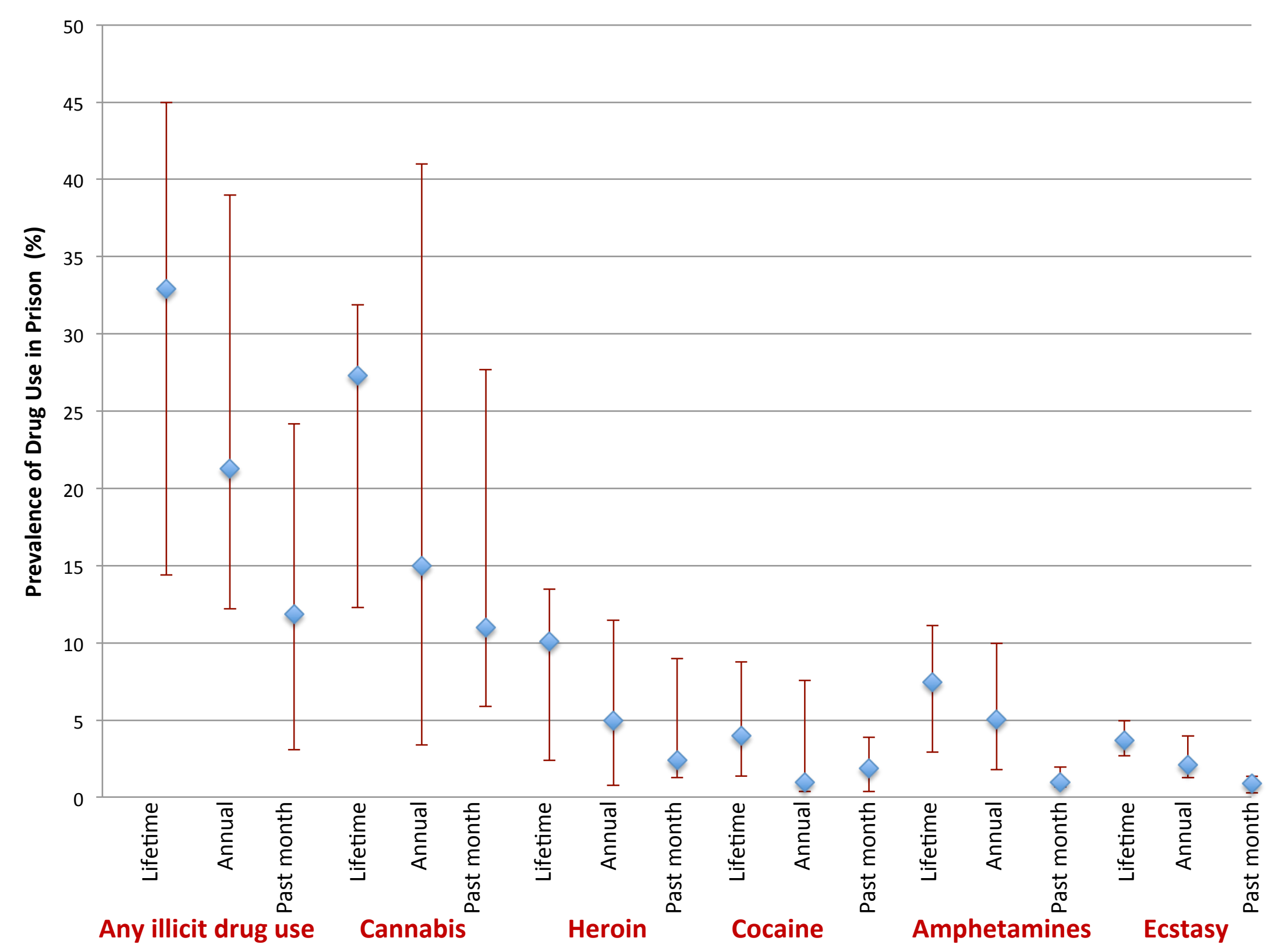

From UNODC country reporting, World Drug Report $2015^{7}$ 


\section{Figure 17: Modelled overall endemic HCV incidence amongst PWID resulting from various effects of incarceration in several illustrative global settings}

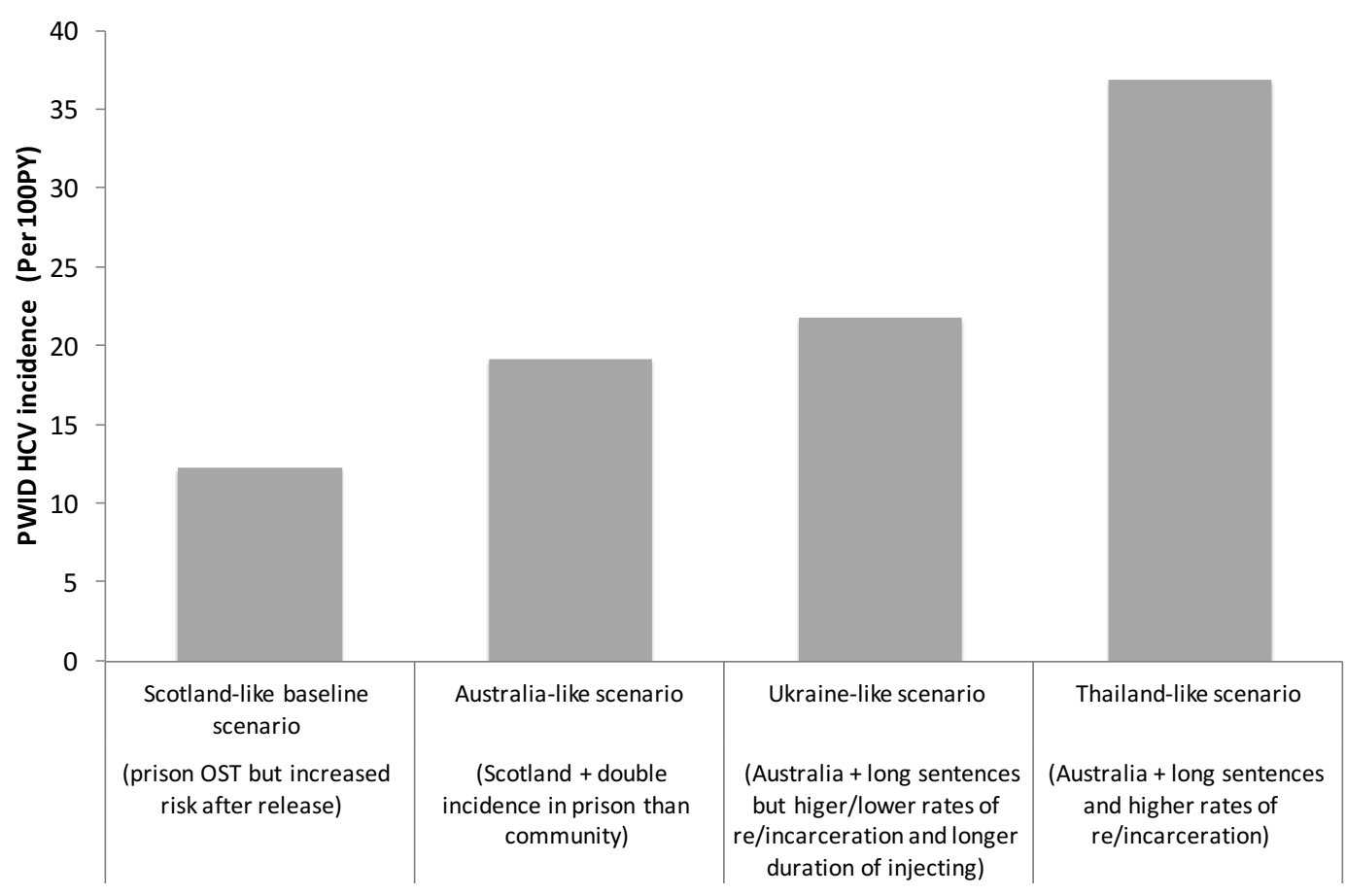

From Prof. Vickerman and colleagues 
Figure 18: Modelled relative reduction in the overall endemic HCV incidence among PWID for each illustrative scenario if there was no elevated risk associated with incarceration (light gray bars) or if there was high scaleup of prison OST and no elevated risk post-release (dark gray bars)

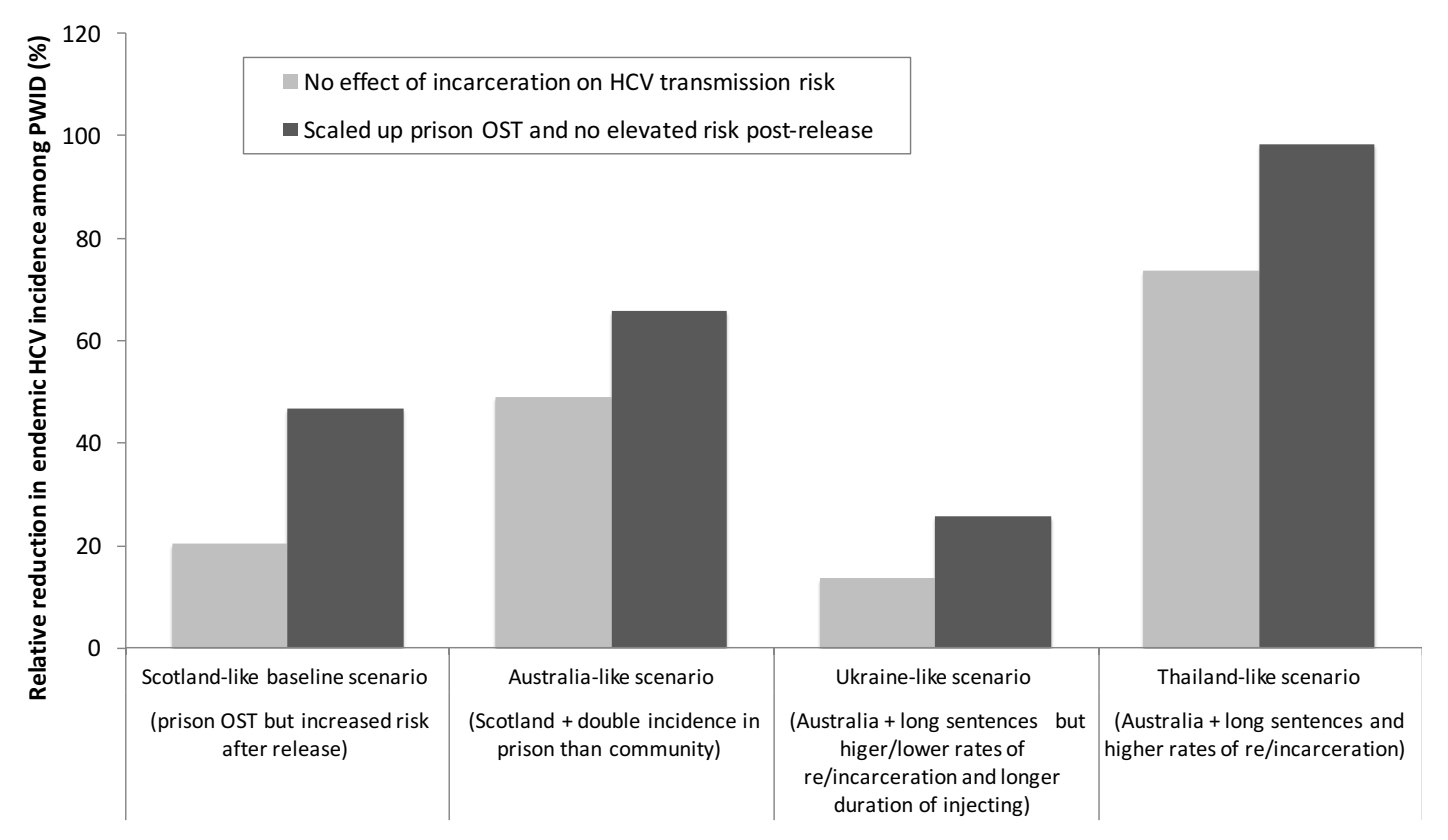

From Prof. Vickerman and colleagues 
Figure 19: Number of EU countries with OST offered in the community and in prisons, 1965-2010

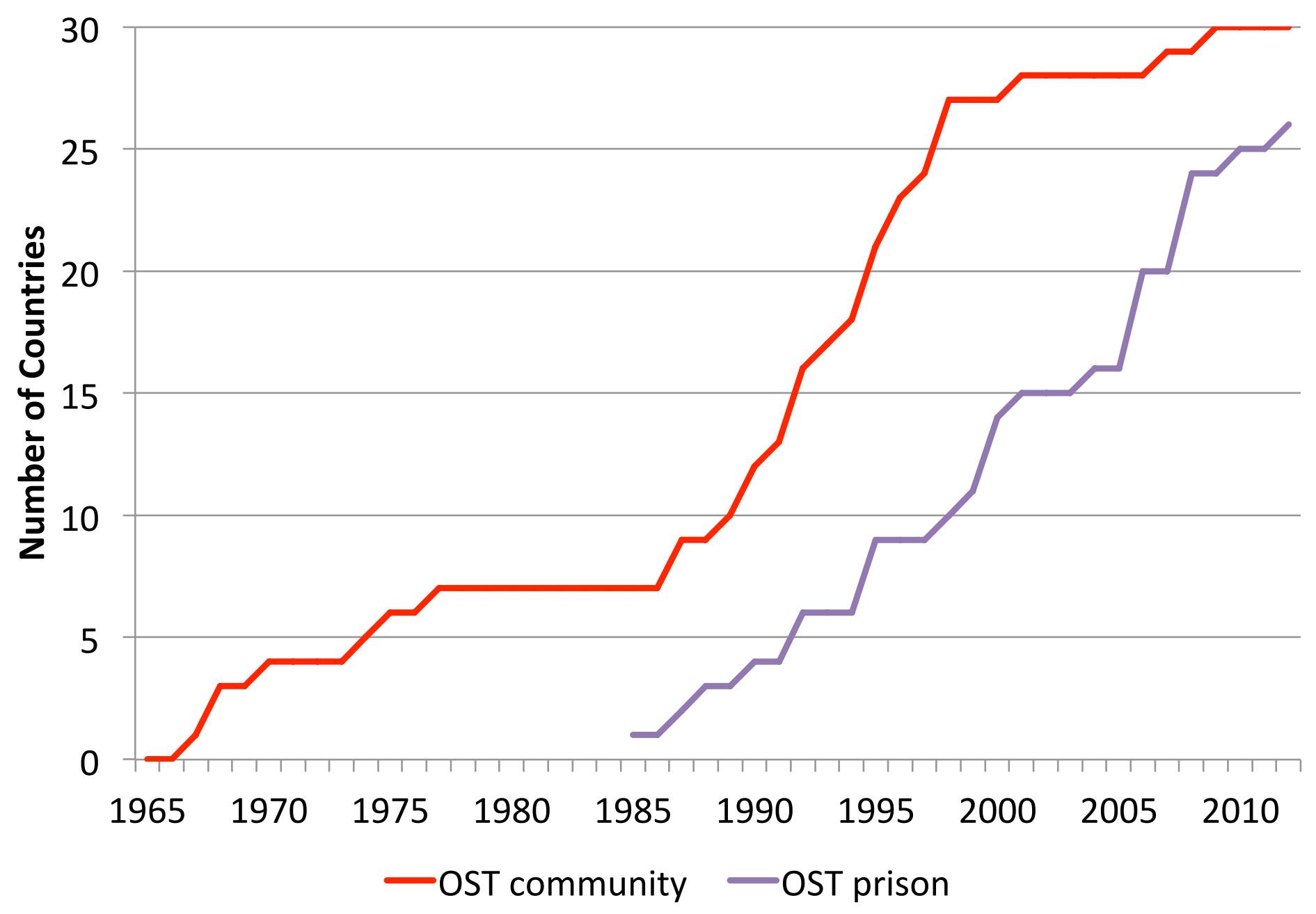

From EMCDDA 240 


\section{Figure 20: HIV care cascade for people in prison, US and Canada}

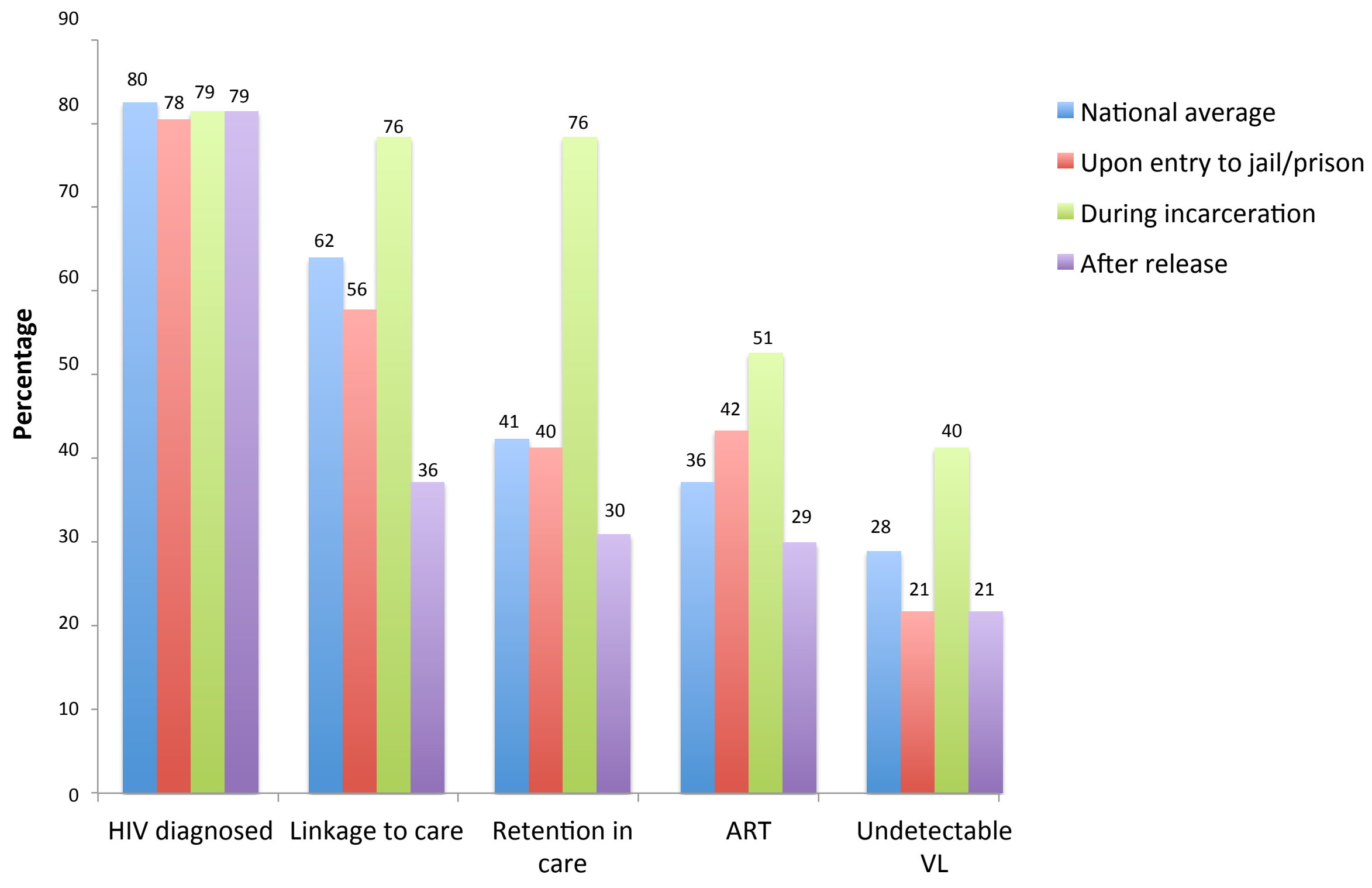

From Iroh ${ }^{262}$ 
Figure 21: Extent of drug dependence services by region, 2013

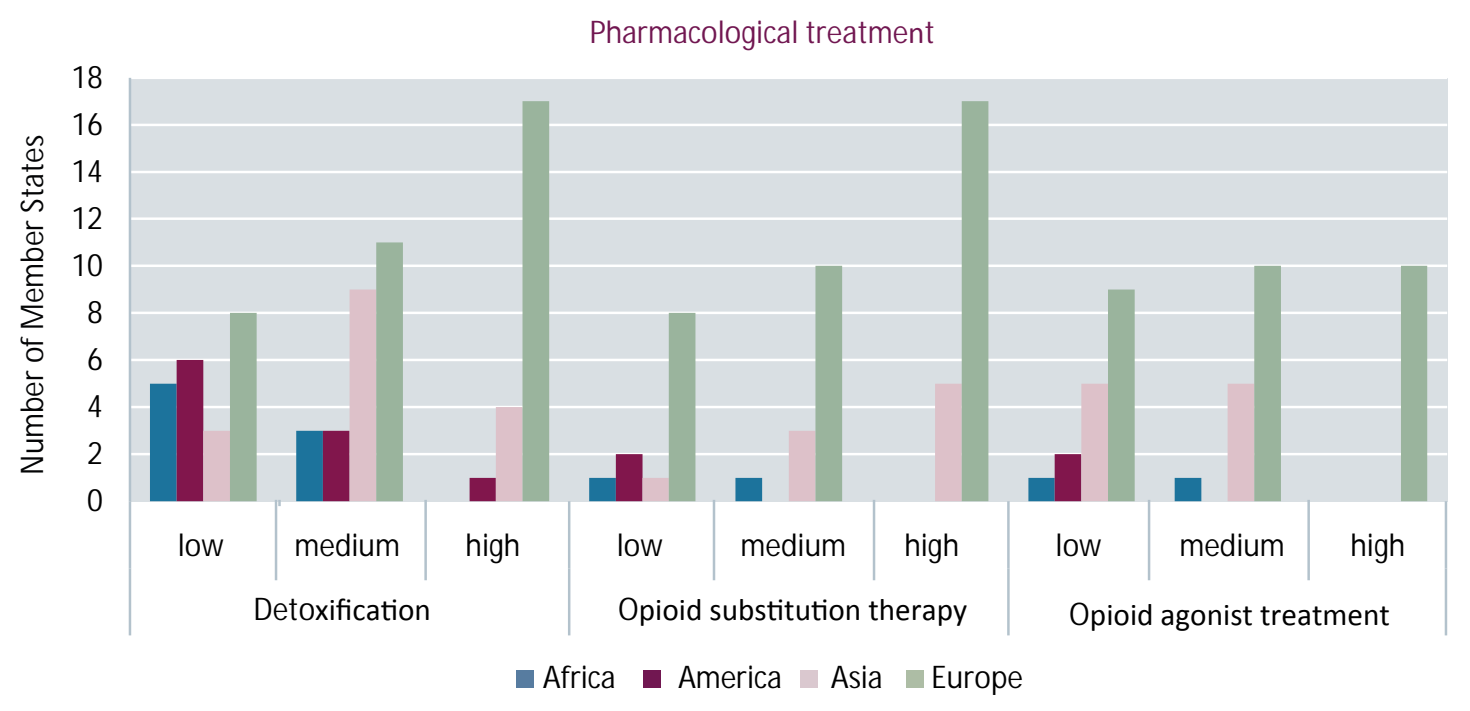

From UNODC, World Drug Report 20157 
Figure 22: Estimated production of opium poppy for illicit markets

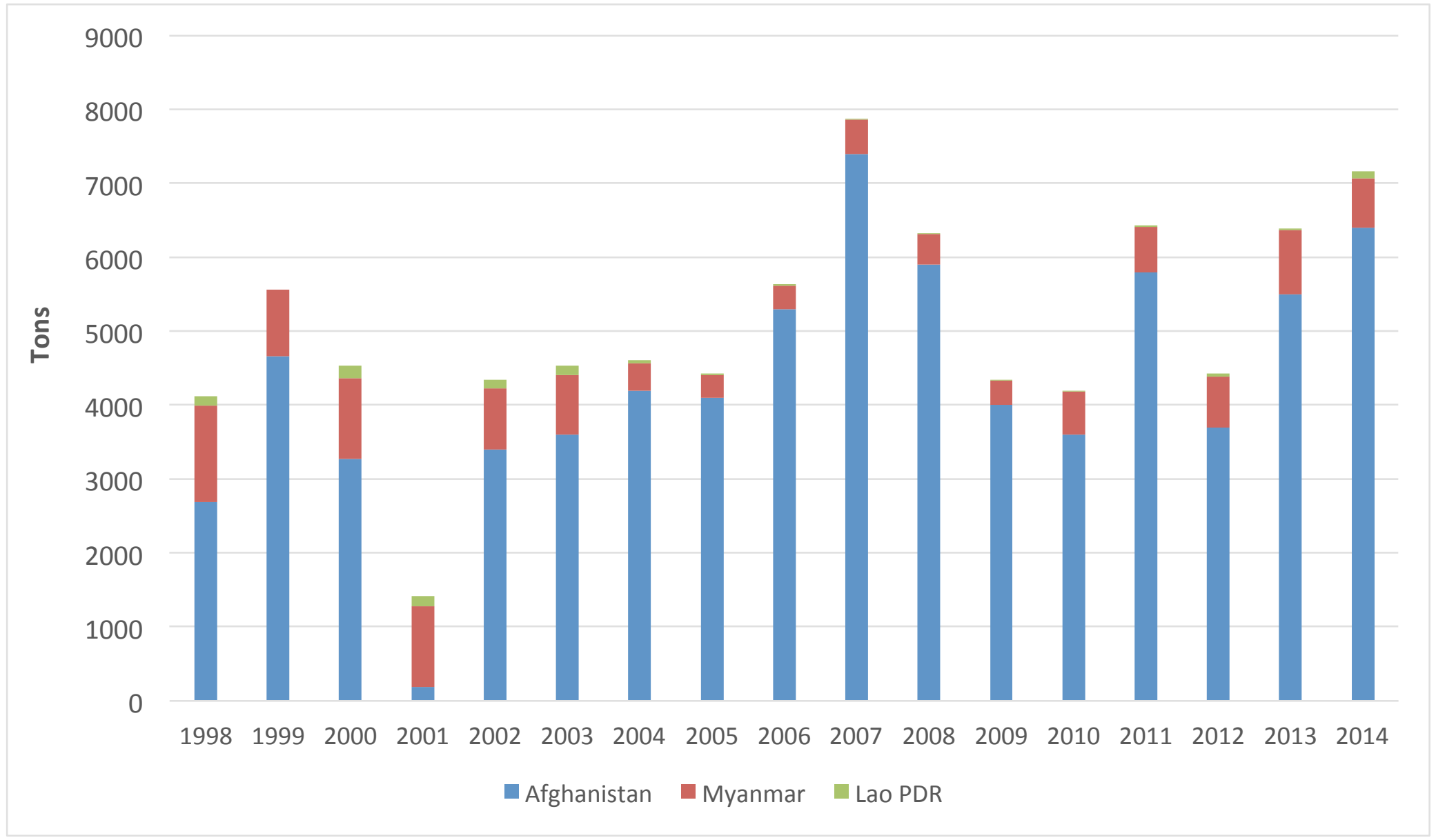

From UNODC SE Asia survey ${ }^{366}$ 
Figure 23: Coca bush cultivation in the Andes, 1994-2014

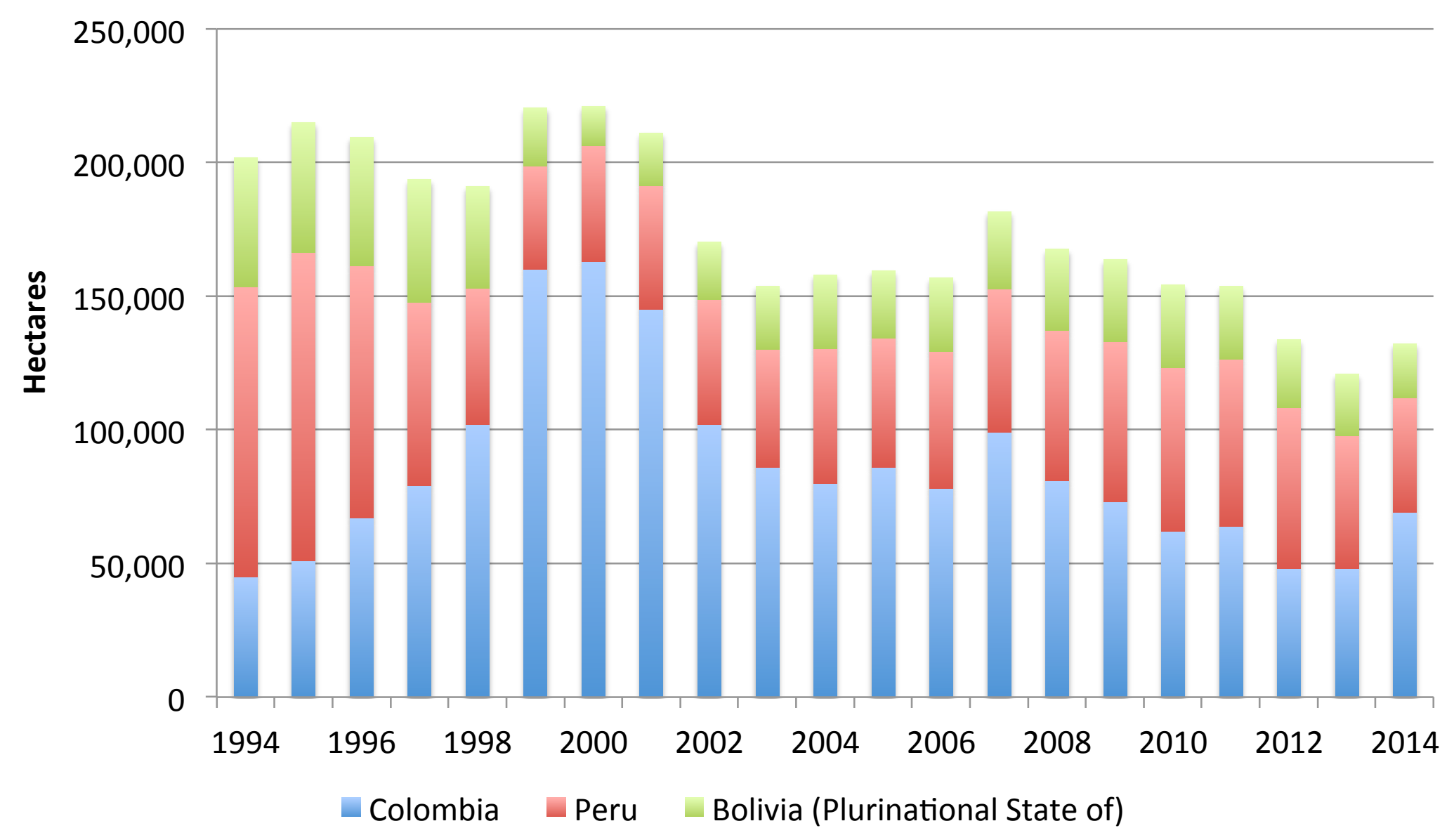

From UNODC crop monitoring reports ${ }^{375-377}$ 
Figure 24: Deforestation in Honduras and major trafficking of cocaine, 2004-2012

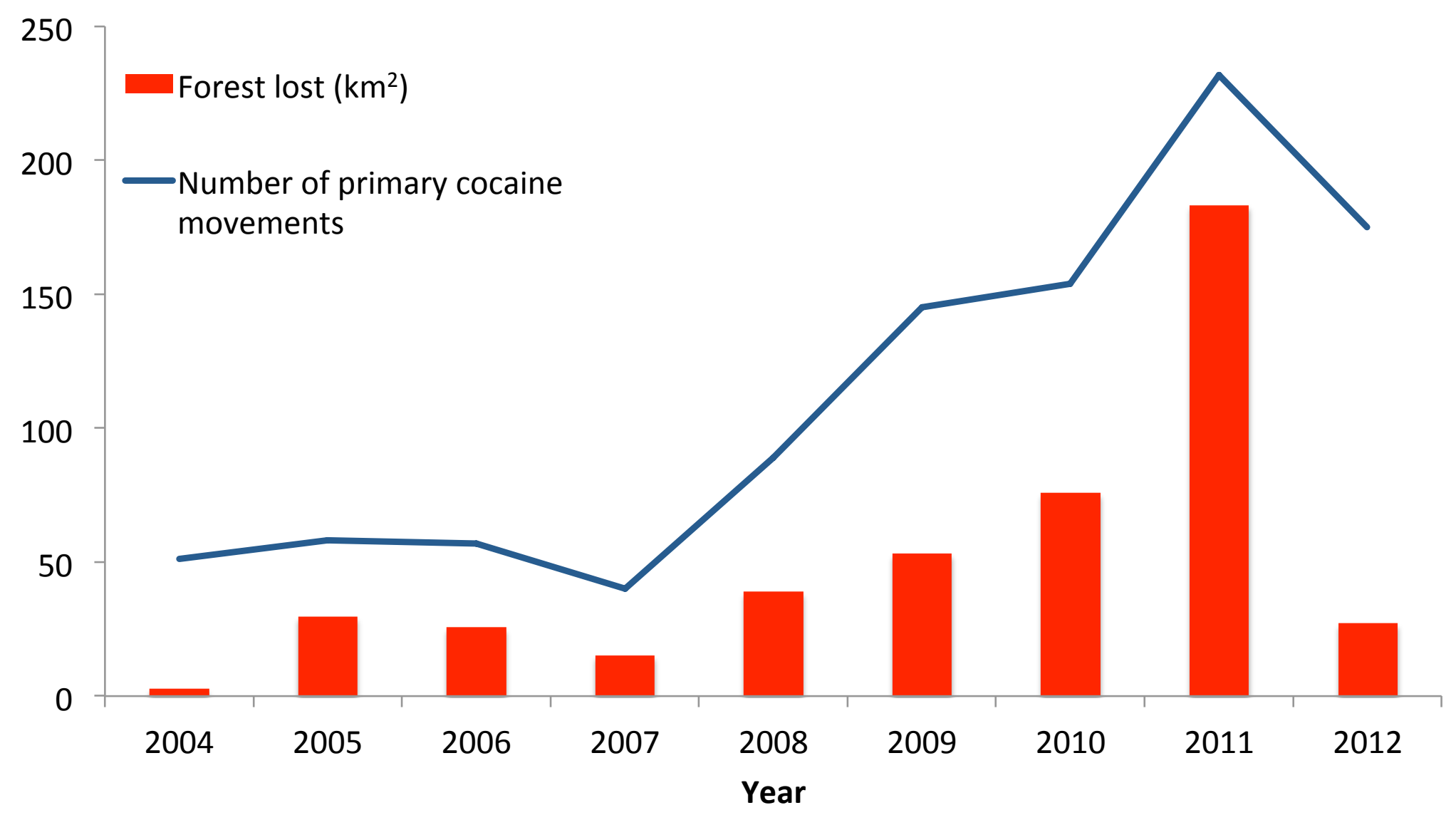

From McSweeney 390 
Figure 25: HIV incidence, Portugal, by mode of transmission, 2003-2012

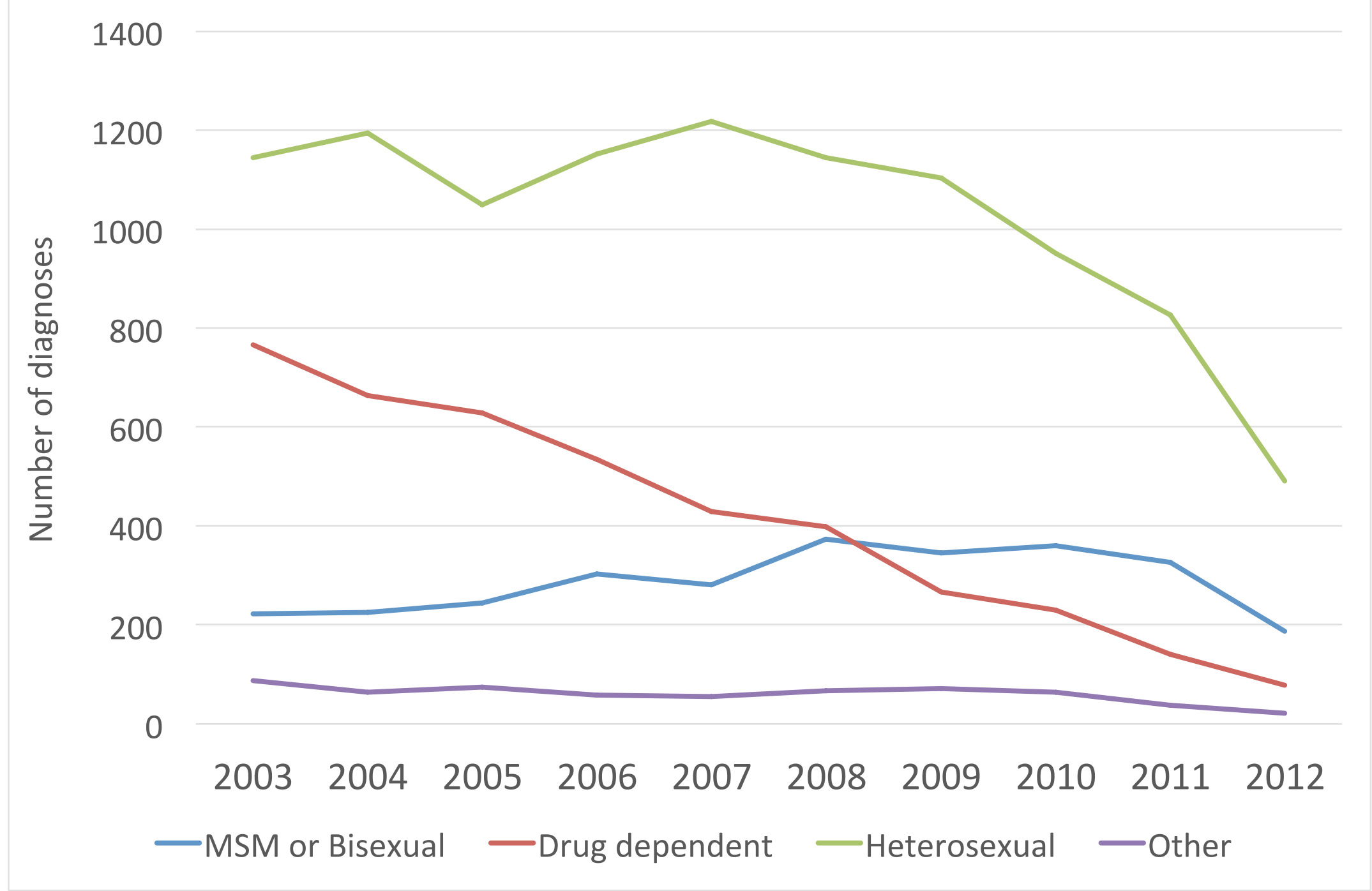

From Goulão, J. 394 
Figure 26: Use of cannabis in last 12 months, adults by age group, EU countries

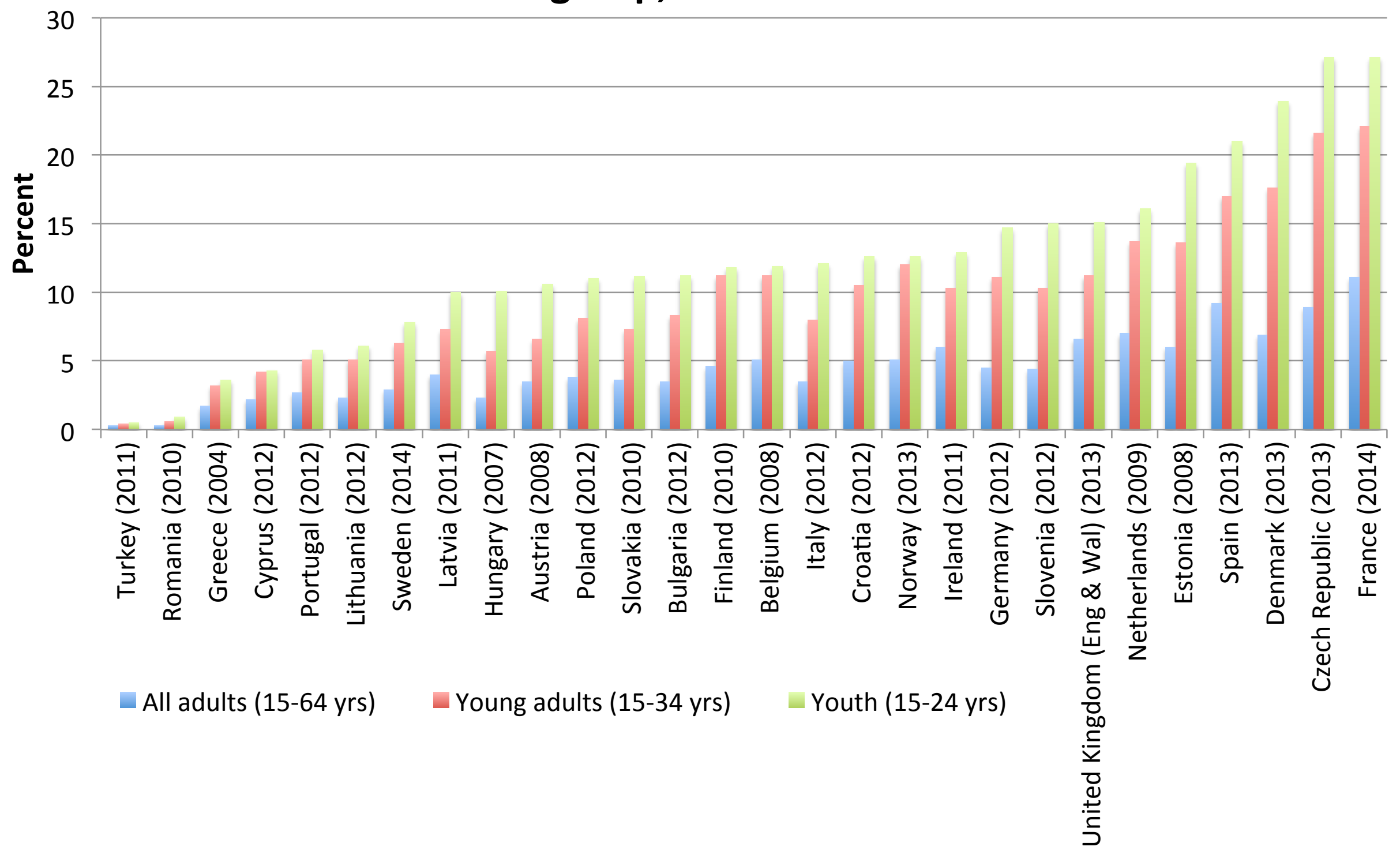


Figure 27: Newly diagnosed cases of HIV related to injection drug use, European Union, Norway and Turkey, 2013

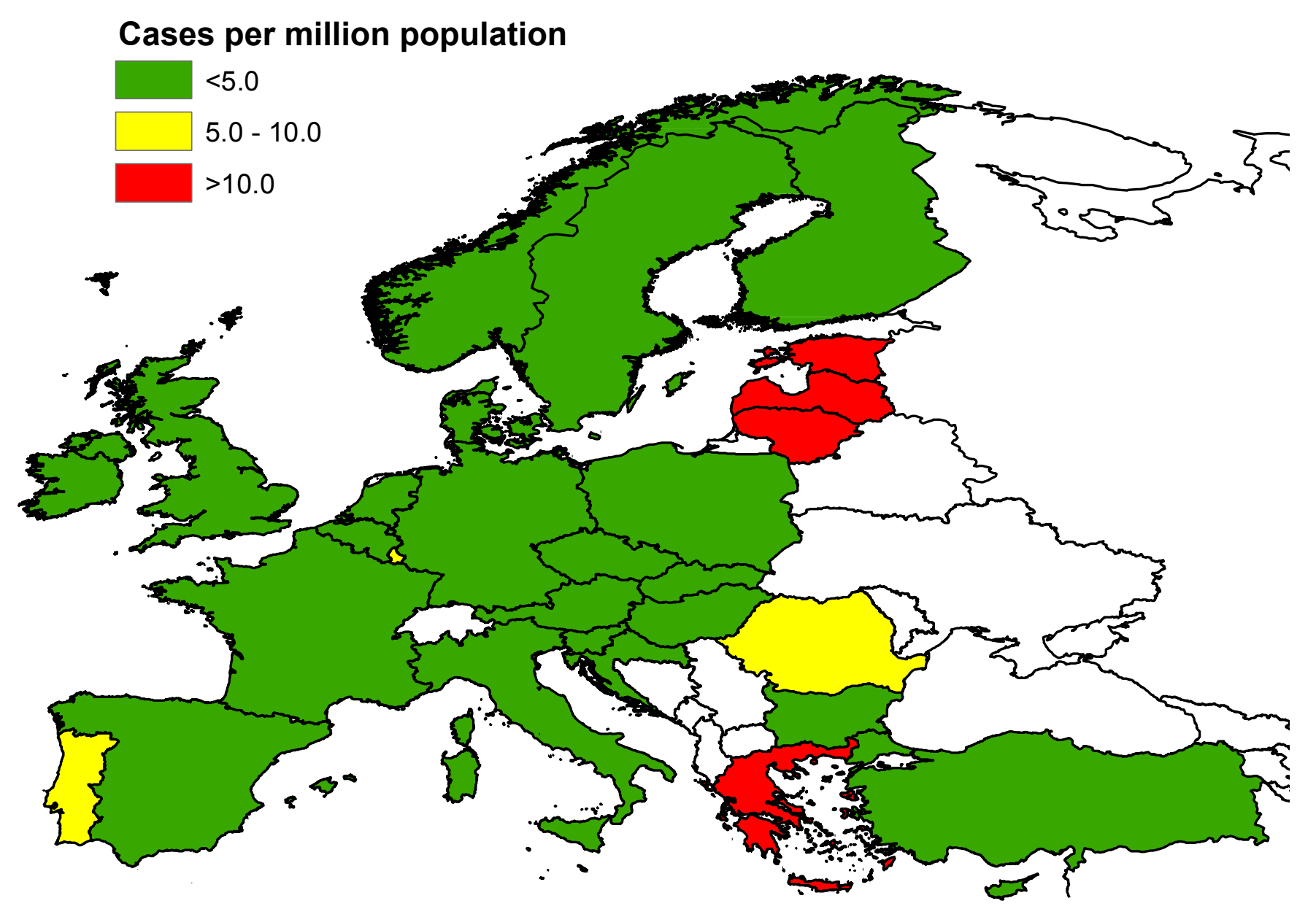

From EMCDDA ${ }^{75}$ 
Table 1: Incarceration for drug offenses as percentage of all incarceration, selected countries

(Note that in the US about $86 \%$ of prisoners for all offenses are in the state system.)

\begin{tabular}{|c|c|c|}
\hline Country & $\begin{array}{l}\text { \% } \\
\text { imprisoned } \\
\text { for drug } \\
\text { offenses (all) }\end{array}$ & $\begin{array}{l}\text { \% } \\
\text { imprisoned } \\
\text { for drug } \\
\text { offenses } \\
\text { (women) }\end{array}$ \\
\hline Argentina & 33 & 68.2 \\
\hline Australia & 12 & 17 \\
\hline Bolivia & 45 & \\
\hline Brazil & 24.8 & 53.9 \\
\hline Canada (fed.) & 26.3 & \\
\hline Canada (provincial) & 15.7 & \\
\hline Colombia & 17 & 45 \\
\hline Ecuador & 33.5 & 77 \\
\hline Ireland & 19.6 & \\
\hline Italy & 38.8 & \\
\hline Latvia & 14.3 & 68 \\
\hline $\begin{array}{l}\text { Mexico (2012 study } \\
\text { of } 8 \text { prisons) }\end{array}$ & 57 & 80 \\
\hline New Zealand & 10 & \\
\hline Peru & 23.8 & 68.4 \\
\hline Russian Federation & 20 & \\
\hline Thailand & 68 & \\
\hline US (federal) & 49 & 59.4 \\
\hline US (states) & 16.8 & 25.1 \\
\hline
\end{tabular}

From Penal Reform International; ${ }^{158}$ Giacomello, 2014; $;^{159}$ OAS-CIM report, 2014; $;^{160}$ US Bureau of Justice Statistics, 2015; ${ }^{161}$ Perez Correa and Azeola, $2012^{48}$ 
Table 2: Impediments of access to and utilisation of controlled medicines due to drug control policy and regulations ${ }^{337,338}$

\begin{tabular}{|l|}
\hline Impediment \\
\hline $\begin{array}{l}\text { Requiring hospitals and pharmacies to get special licenses or permissions to procure and stock } \\
\text { controlled medicines rather than allowing them under the institution's general licenses. }\end{array}$ \\
\hline $\begin{array}{l}\text { Requiring special authorizations, licenses or training for physicians, nurses and pharmacists } \\
\text { seeking to stock and dispense controlled medicines, rather than permitting these through general } \\
\text { licensing requirements. }\end{array}$ \\
\hline $\begin{array}{l}\text { Restriction on movement of controlled medicine consignments from one part of the country } \\
\text { to another }\end{array}$ \\
\hline $\begin{array}{l}\text { Disproportionately harsh criminal sanctions and withdrawal of the license of physicians or } \\
\text { pharmacists (or insurers) for minor and unintentional deviations from mandated procedures. }\end{array}$ \\
\hline $\begin{array}{l}\text { Unconditional denial of controlled medicines to anyone with a history suggestive of drug use or } \\
\text { dependence }\end{array}$ \\
\hline $\begin{array}{l}\text { Limitations on prescriptions that restrict the duration of their validity, the amount of medicine } \\
\text { that may be prescribed, or the possibility for its renewal, or requirements of prescriptions in } \\
\text { duplicates or triplicates or through special forms, as well as unclear definitions of "excessive } \\
\text { prescribing". }\end{array}$ \\
\hline $\begin{array}{l}\text { Requirements of bureaucratic processes for determination by multiple agencies of an individual's } \\
\text { "eligibility" to receive controlled medicines, rather than leaving such decisions to the discretion } \\
\text { of the clinical team. }\end{array}$ \\
\hline $\begin{array}{l}\text { Non-confidentiality of information on registered users of controlled medicines which may be } \\
\text { used to deny services, drivers' licenses, certain categories of employment, insurance, even child } \\
\text { custody to persons receiving controlled medicines. }\end{array}$ \\
\hline Limitations on insurance coverage for opioid medications and home-based palliative care \\
\hline
\end{tabular}


Table 3: Miscarriages amongst persons exposed to aerial herbicide spraying, Colombia

Panel A: Complete sample

\begin{tabular}{|l|ll|ll|}
\hline $\begin{array}{l}\text { Dependent variable: } \\
\text { Miscarriages }\end{array}$ & \multicolumn{2}{l|}{ Complete sample } & \multicolumn{2}{l|}{$\begin{array}{l}\text { Municipalities with positive } \\
\text { levels of aerial spraying }\end{array}$} \\
\hline & $(1)$ & $(2)$ & $(3)$ & $(4)$ \\
\hline Aerial spraying (9 months) & $0.12139^{* * *}$ & $0.11890^{* * *}$ & $0.15007^{* * *}$ & $0.15158^{* * *}$ \\
& $(0.04243)$ & $(0.04163)$ & $(0.04041)$ & $(0.03721)$ \\
Percentage of the municipality & & 0.91870 & & $3.50893^{* *}$ \\
with coca crops & & $(0.82469)$ & & $(1.37864)$ \\
\hline \# of observations & $3,352,570$ & $3,352,570$ & $3,352,570$ & $3,352,570$ \\
R-squared & 0.025 & 0.025 & 0.027 & 0.0311 \\
\# of individuals & 780,558 & 780,558 & 780,558 & 780,558 \\
\hline
\end{tabular}

Panel B: Non-migrant population sample

\begin{tabular}{|c|c|c|c|c|}
\hline \multirow[t]{2}{*}{$\begin{array}{l}\text { Dependent variable: } \\
\text { Miscarriages }\end{array}$} & \multicolumn{2}{|c|}{ Non-migrants sample } & \multicolumn{2}{|c|}{$\begin{array}{l}\text { Non-migrants sample with } \\
\text { positive levels of aerial spraying }\end{array}$} \\
\hline & (1) & (2) & (3) & (4) \\
\hline $\begin{array}{l}\text { Aerial spraying ( } 9 \text { months) } \\
\text { Percentage of the municipality } \\
\text { with coca crops }\end{array}$ & $\begin{array}{l}0.16774^{* * *} \\
(0.5838)\end{array}$ & $\begin{array}{l}0.18433^{* * *} \\
(0.04964) \\
6.83612^{* * *} \\
(2.53821)\end{array}$ & $\begin{array}{l}0.17707^{* * *} \\
(0.05003)\end{array}$ & $\begin{array}{l}0.19434^{* * *} \\
(0.0414) \\
7.18591^{* * *} \\
(2.58495)\end{array}$ \\
\hline $\begin{array}{l}\text { \# of observations } \\
\text { R-squared } \\
\text { \# of individuals }\end{array}$ & $\begin{array}{l}3,163,568 \\
0.027 \\
742,616\end{array}$ & $\begin{array}{l}3,163,568 \\
0.027 \\
742,616\end{array}$ & $\begin{array}{l}3,163,568 \\
0.032 \\
742,616\end{array}$ & $\begin{array}{l}3,163,568 \\
0.032 \\
742,616\end{array}$ \\
\hline
\end{tabular}

Standard errors in parenthesis. ${ }^{* * *} \mathrm{p}<0.01,{ }^{* *} \mathrm{p}<0.05,{ }^{*} \mathrm{p}<0.01$.

All regressions include the following controls: age, age squared, health regime, municipal tax income, population, area in square $\mathrm{km}$, rurality index, municipal spending on education and health, year and month dummy

From Camacho and Mejía, $2015^{373}$ 